\title{
Referentes femeninos en publicidad: recurso docente para la implementación de la docencia con perspectiva de género en los estudios de publicidad ${ }^{1}$
}

Alejandra Hernández-Ruiz, Natalia Papí-Gálvez, Sonia López- Berna, María-Jesús Ortiz Díaz-Guerra, Enric Mira-Pastor, Vicenta Baeza-Devesa

Universidad de Alicante

Curso académico 2020-2021

https://doi.org/10.14198/bua.2021.hernandez-ruiz.ref

${ }^{1}$ El presente trabajo ha contado con una ayuda del Programa de Redes-13CE de investigación en docencia universitaria del Instituto de Ciencias de la Educación de la Universidad de Alicante (convocatoria 2020-21). Ref.:5137. 


\section{Contenidos}

1.Conceptos básicos sobre sexo y género

2. La situación de la mujer en la industria publicitaria

3. Referentes femeninos en publicidad

4. Otros recursos 


\section{Conceptos básicos sobre sexo y género}

Tabla 1. Distinción conceptual del sistema sexo-género

\section{SEXO}

Condición biológica, genética y fisiología de nacimiento

Hombre-mujer

Natural

\section{GÉNERO}

Determinado socialmente, culturalmente y aprendido

Masculino-femenino

Social

Fuente: Rodríguez-Jaume, M. J., y Provencio-Garrigós, H. (Coords.) (2017). Guía de Recomendaciones para la Inclusión de la Perspectiva de Género en la Docencia Universitaria de la Universidad de Alicante: claves conceptuales y teóricas (II). Universidad de Alicante. Vicerrectorado de Responsabilidad Social, Inclusión e Igualdad. http://rua.ua.es/dspace/handle/10045/72076 


\section{Conceptos básicos sobre sexo y género}

Los estereotipos se caracterizan por:
Exagerar los rasgos característicos

Minimizar las diferencias individuales

Contener prejuicios

Establecer arquetipos o modelos muy tipificados

Fuente: Rodríguez-Jaume y Provencio-Garrigós (2017) 


\section{Conceptos básicos sobre sexo y género}

\section{Los estereotipos de}

género... atribuyen características y comportamientos "típicos" a los hombres y a las mujeres (sexo) a partir de la distinción entre lo masculino y lo femenino (género).

Su cumplimiento se gratifica con recompensas sociales mientras que su trasgresión es sancionada socialmente.

Fuente: Rodríguez-Jaume y Provencio-Garrigós (2017) 


\section{La situación de la mujer en la industria publicitaria}

Hay paridad en el número de hombres y mujeres trabajando en publicidad:

$$
\begin{gathered}
\text { El } 52 \% \text { de los profesionales son hombres } \\
\text { y el } 48 \% \text {, mujeres. }
\end{gathered}
$$




\section{La situación de la mujer en la industria publicitaria}

La publicidad española está mayoritariamente dirigida por hombres.

$\mathrm{El} 76 \%$ de quienes ocupan las direcciones generales son hombres.

En el departamento de cuentas predomina la presencia femenina y en el departamento de creatividad, la masculina.

Fuente: APG y Club de Creativos (2019) 


\section{La situación de la mujer en la industria publicitaria}

Es una profesión de jóvenes principalmente y bien formada.

El 69\% de los profesionales tiene entre 25-44 años.

Más del $80 \%$ de los profesionales de los principales departamentos tiene estudios superiores o de postgrado.

El 44\% de los profesionales del sector con menos de 5 años de experiencia ha cursado estudios de Publicidad y RR.PP. 
3. Referentes femeninos en publicidad

\section{Dirección general}


Maite Antón

Dirección General

Gerente

Grupo Antón Comunicación 


\section{Trabajo}

Puestos destacados

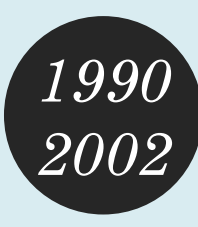

Dirección parte económica de la empresa.

Posteriormente comienza una rotación sobre las distintas áreas de la empresa: comercial, desarrollo tecnológico, organización interna y recursos Humanos

\section{3}

Comienza el cambio generacional y a liderar junto a su hermano la transformación hasta conseguir que la empresa sea hoy un referente en el mundo de la publicidad en todo el arco mediterráneo 


\section{Premio Activa por la igualdad. de género}

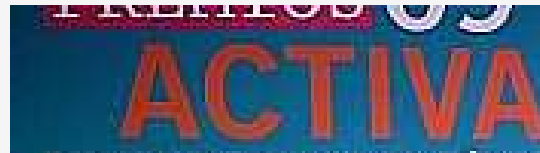

POR IA IGUALDAD DD GDNERO DEUA DIRUDLCORPAOWHLIRL DERUCARIE

DEALICARIF

MNRQ

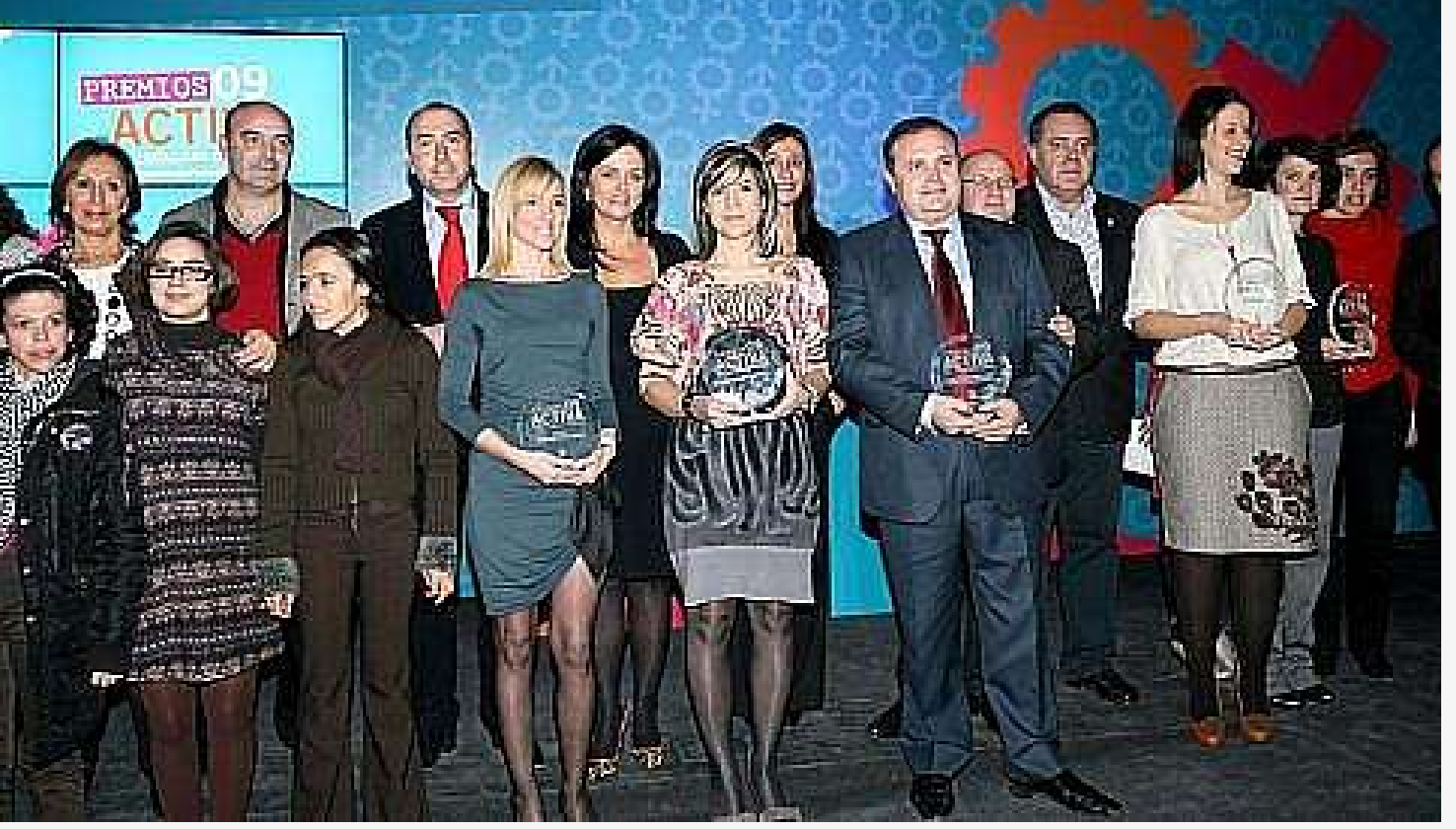

2010. Categoría "Iniciativa Empresarial" por su proyecto "Trabajo en Femenino". La Diputación ha galardonado a la empresa por su fomento a la igualdad de oportunidades entre sus trabajadores, su firme apuesta por la conciliación de la vida familiar y laborar y por las actuaciones dirigidas a mejorar la calidad de vida de sus empleados.

Fuente: https://www.grupoanton.es/ntn/2010/12/16/grupo-anton-recibe-elpremio-activa-por-la-igualdad-de-genero/ 


\section{Reconocimiento}

empresarial por implantación de las medidas de igualdad

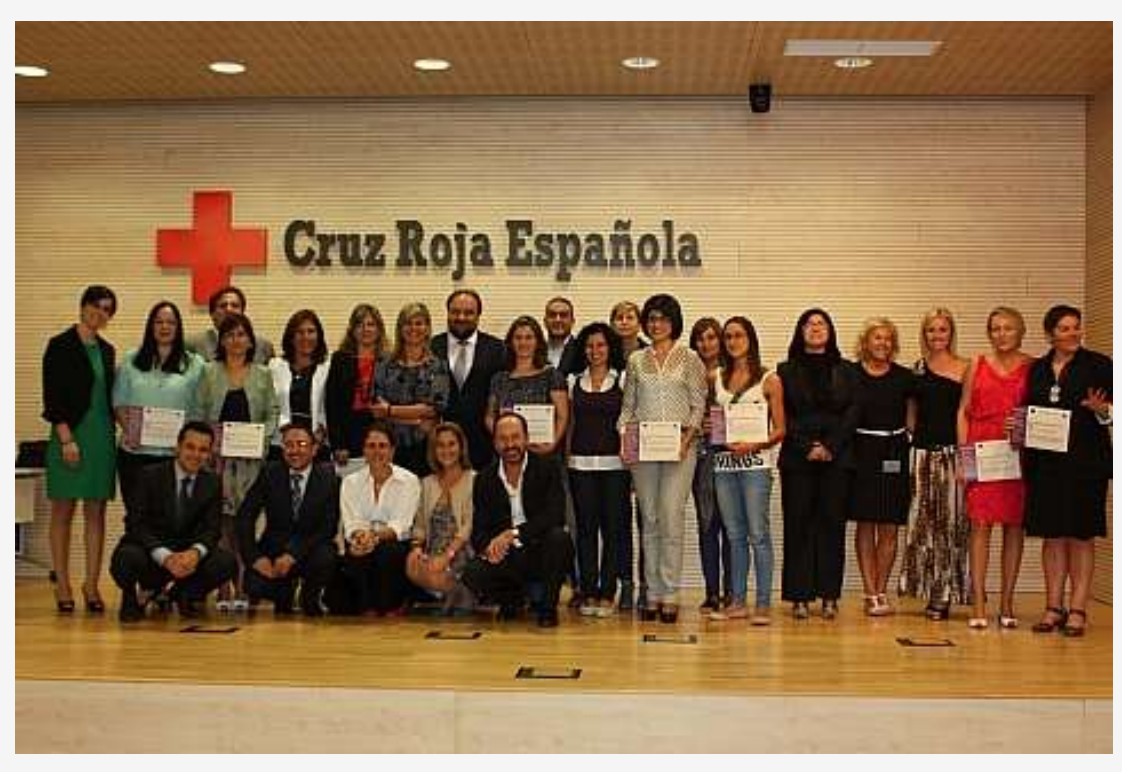

2013. El pasado año Grupo Antón tuvo el honor de ser reconocida por Cruz Roja Española_como empresa que implanta medidas de igualdad de oportunidades entre mujeres y hombres.

Bajo el lema "Sensibilización e implantación de medidas de igualdad entre hombres y mujeres", se daban cita en la sede central de Cruz Roja en Alicante empresas que aplican esta filosofía en sus actividades.

Implantación políticas igualdad

https://www.grupoanton.es/ntn/2012/10/10/la-cruz-roja-reconoce-el-papel-dela-mujer-en-nuestra-empresa/ 


\section{Premio de la Igualdad de $A E P A$}

(Asociación de Empresarias, Profesionales y Directivas de la Provincia de Alicante)

Implantación políticas igualdad

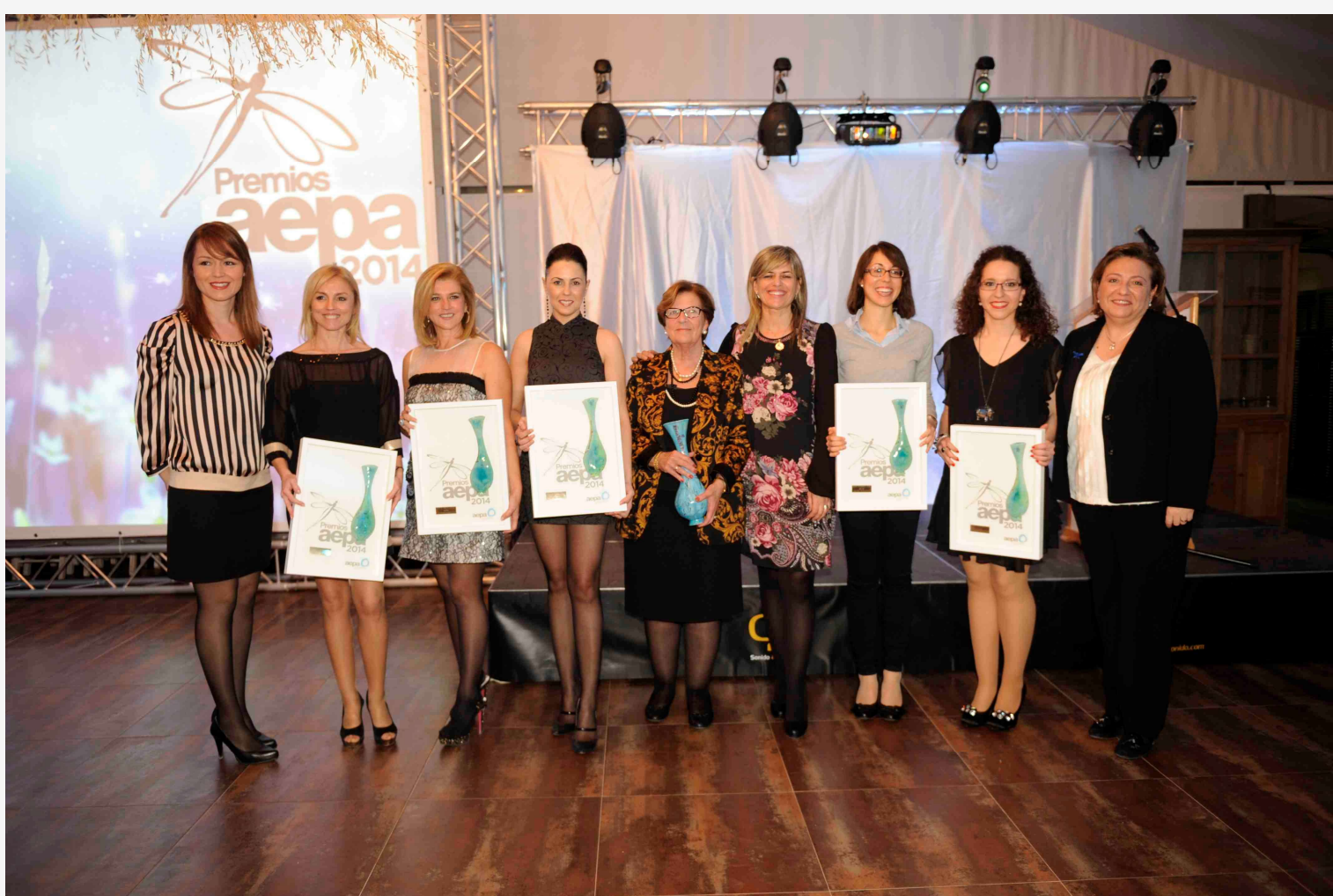

2014. Concedido por la implantación de la política de igualdad en la paridad de equipos de dirección, reducción de la brecha salarial y medidas de conciliación entre la vida profesional y familiar.

Fuente: https://www.grupoanton.es/ntn/2014/03/10/aepapremia-a-grupo-anton-por-su-politica-de-igualdad/ 


\section{Premios y acciones con motivo de la. igualdad}

\author{
Autopromoción
}

Difusión del compromiso con la igualdad

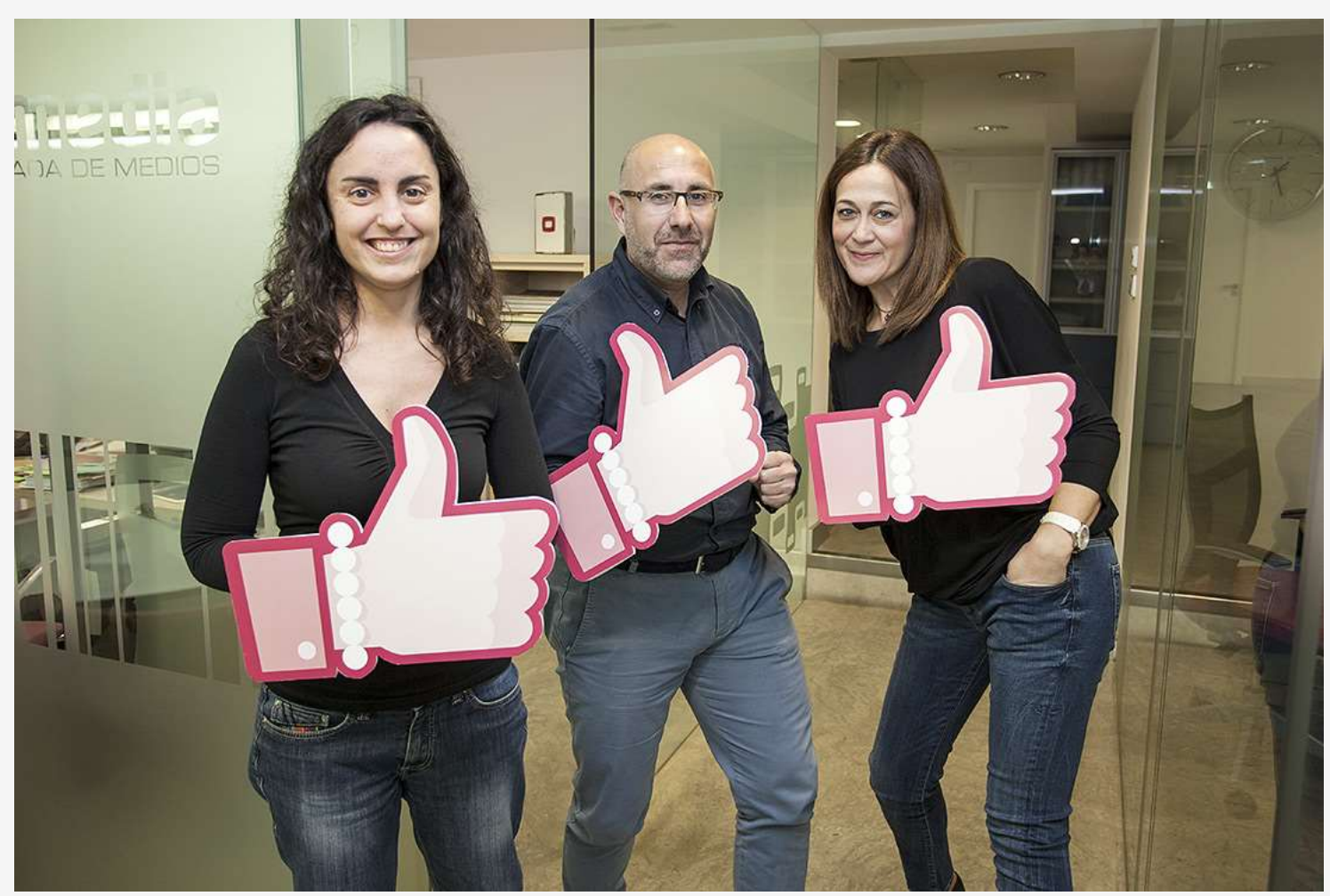

2014. "En la agencia apostamos \#Porlaigualdad" . Sin ningún género de dudas. Día Internacional de la Mujer. Reivindicación en la agencia, autopromoción y difusión de la importancia de la igualdad de oportunidades en el sector de la comunicación.

https://www.grupoanton.es/ntn/2014/03/10/aepapremia-a-grupo-anton-por-su-politica-de-igualdad/ 


\section{Premios y acciones de fomento de la. igualdad}

Original prensa con el hashtag \# por la igualdad

Difusión del compromiso con la igualdad

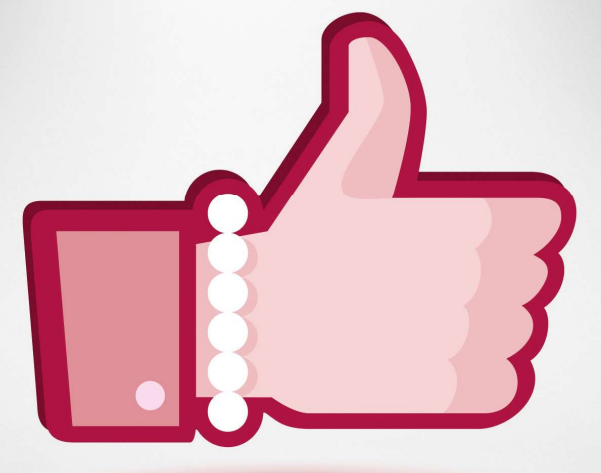

\#Porlaigualdad

Sin ningún género de dudas.

Hoy queremos reivindicar la importancia de la mujer en cualquier faceta de la vida. Porque nadie sabe mejor que nosotros que sin ellas nunca hubiéramos nacido.

Gracias, Ma Teresa Puntes. Cofundadora de Grupo Antón en 1961.

2014. Día Internacional de la Mujer. Reivindicación de la importancia de la mujer en cualquier faceta de la vida. Resaltando a la socia fundadora de la empresa familiar, $\mathrm{M}^{\mathrm{a}}$ Teresa Puntes, como pieza fundamental en la creación y desarrollo de la agencia. 


\section{Encuentro: "Compromiso empresarial por la igualdad"}

Mesa de igualdad de Alicante Diputación de Alicante Cruz Roja

Concienciación al sector empresarial

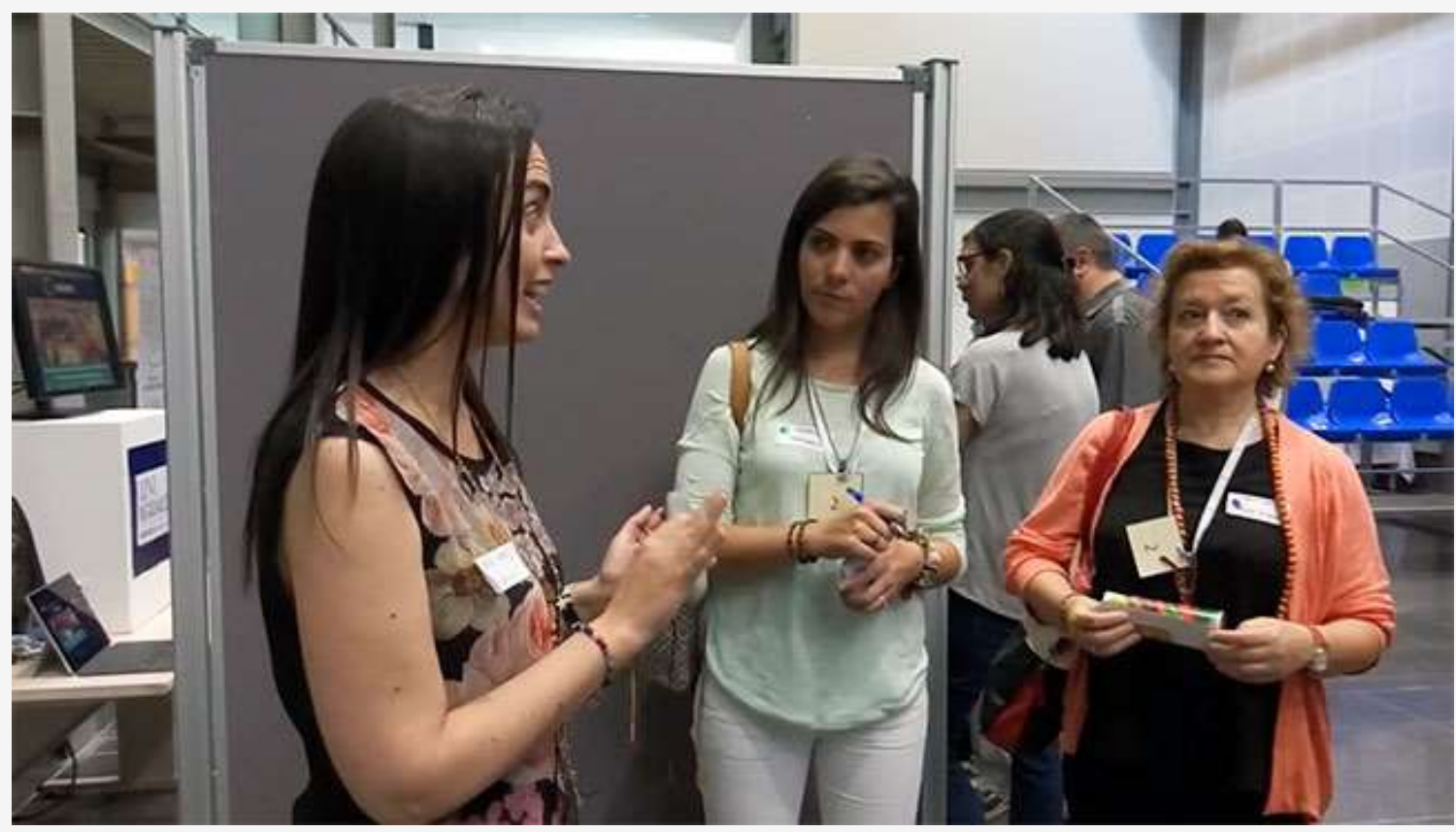

2016. Nueve exposiciones-Nueve grupos de personas-Nueve stands de empresas. Edificio La Nau. UMH Los nueve grupos pasaron por los nueve stands de las empresas participantes donde durante cinco minutos se les dio a conocer las medidas tomadas en materia de igualdad como ejemplo para otras empresas.

https://www.youtube.com/watch?v=DbuoDo4gj-O\&t=53s

https://igualdad.umh.es/2016/05/27/compromiso-empresarial-por-la-igualdad/ 


\section{Actividades,} acciones, encuentros $y$ premios
destacados

Maite Antón forma parte de: "Las 20 de Torre Juana"

Visibilizar talento femenino y liderazgo

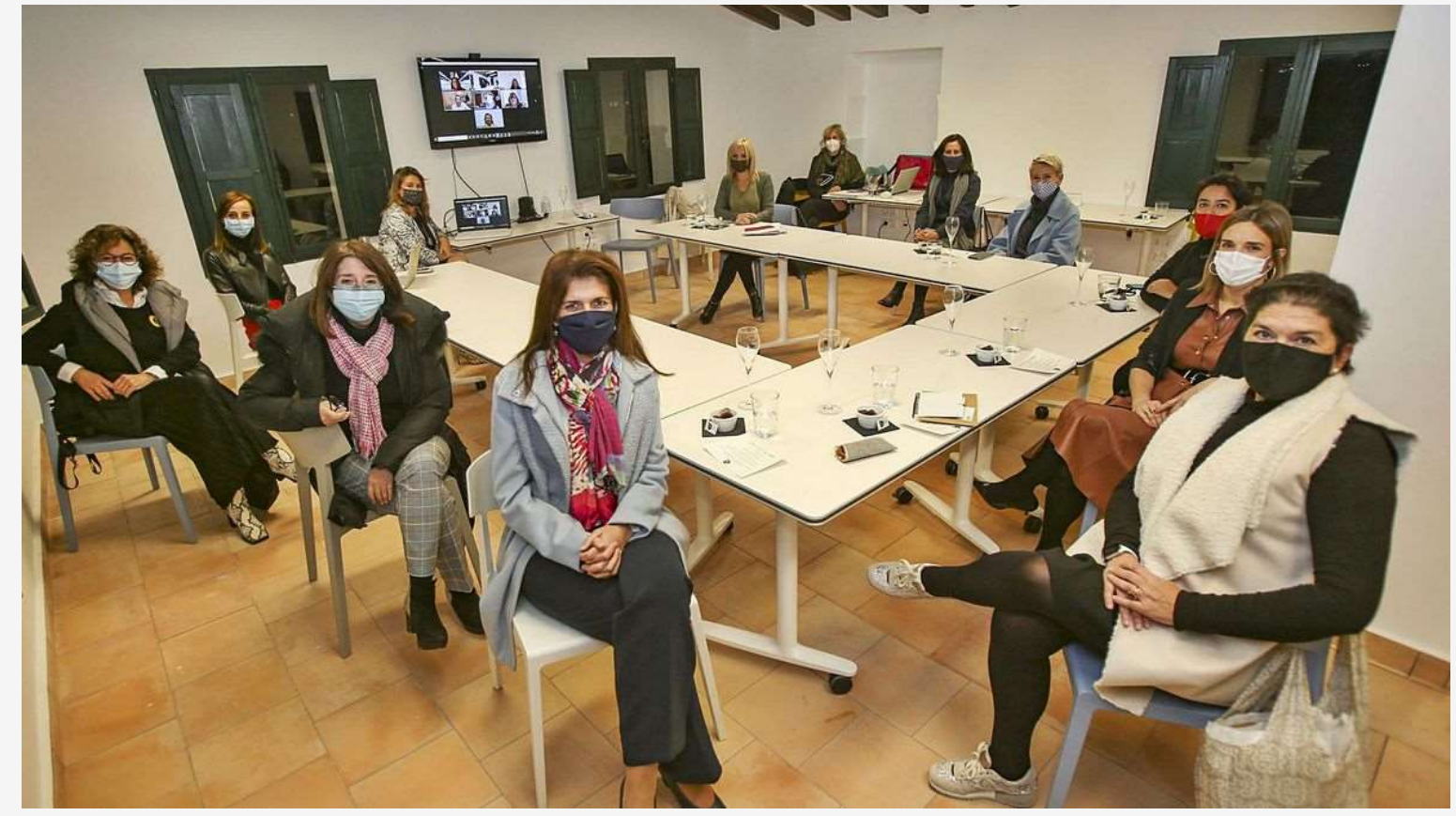

2020.Un «lobby» de mujeres influyentes de la provincia para luchar por la igualdad y para visibilizar el talento y liderazgo femenino. Con este propósito nace el grupo «Las 20 de Torre Juana», del que forman parte políticas, empresarias, científicas, académicas y profesionales liberales destacadas.

https://www.informacion.es/alicante/2020/12/11/20mujeres-influyentes-crean-lobby-26161634.html 


\section{PUESTOS DESTACADOS}

Presidenta de la Asociación de la Empresa Familiar de la provincia de Alicante

Vocal del círculo empresarial de Elche y Comarca

Miembro del Comité Ejecutivo del Plan Estratégico de Elche 2030 (Ayuntamiento de Elche)

Fuente: https://es.linkedin.com/in/maiteanton 
Grupo Antón comunicación

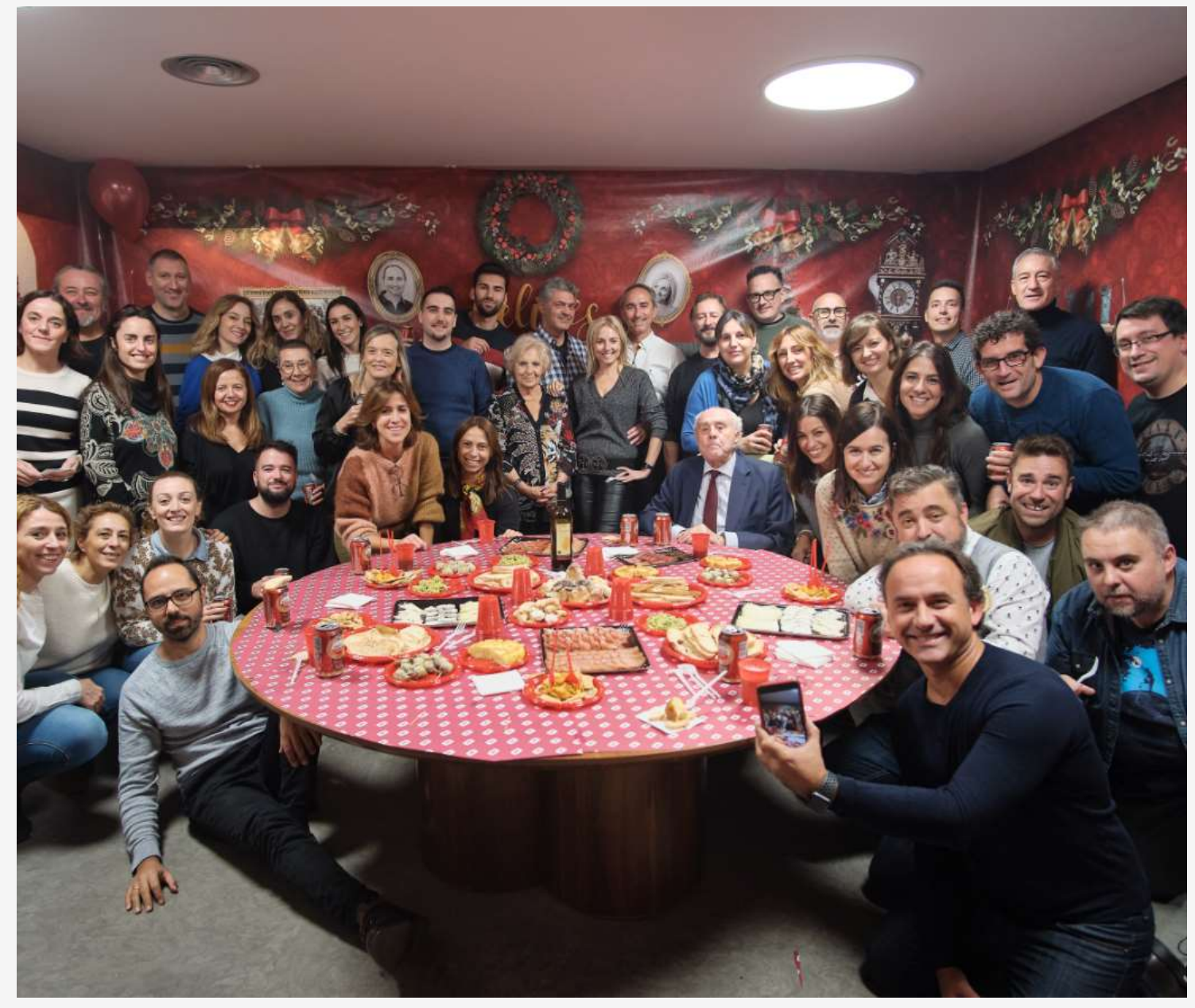


Licenciada en Ciencias Económicas y Empresariales por la Universidad de Murcia, Matrícula de Honor, Premio Fin de Carrera y $\mathrm{n}^{\circ} 1$ de promoción. Finalizados sus estudios se incorpora a la empresa familiar Publicidad Antón, por entonces, dirigida por sus padres y compuesta por 12 trabajadores.

En 2013 asume se produce el cambio generacional empieza a liderar, junto a su hermano Pepe Antón, la transformación de la empresa, con un equipo de más de 50 personas y una trayectoria de 58 años.

Grupo Antón es una empresa con cuatro áreas de negocios que engloban las marcas (Publi Antón exterior, Antonline. Antón Media y Seis Sombreros) y en la que, desde su creación, la mujer ha jugado un papel fundamental. Con el cambio generacional, esta filosofía ha seguido reforzándose, prueba de todo esto, es que más de la mitad de la plantilla está constituida por mujeres.

Trabajadora incansable, defensora de la formación, de la búsqueda constante de la mejora en la calidad y de la importancia de que los valores humanos sean la base de todas sus decisiones en la empresa. Fruto de este sentimiento compartido por toda la empresa, en Grupo Antón destacamos por nuestra amplia colaboración con multitud de asociaciones de carácter cultural, deportivo o social, estando así implicados en la mejora de su entorno como valor esencial de la empresa.

Fuente: https://es.linkedin.com/in/maiteanton 


\section{Dirección creativa}




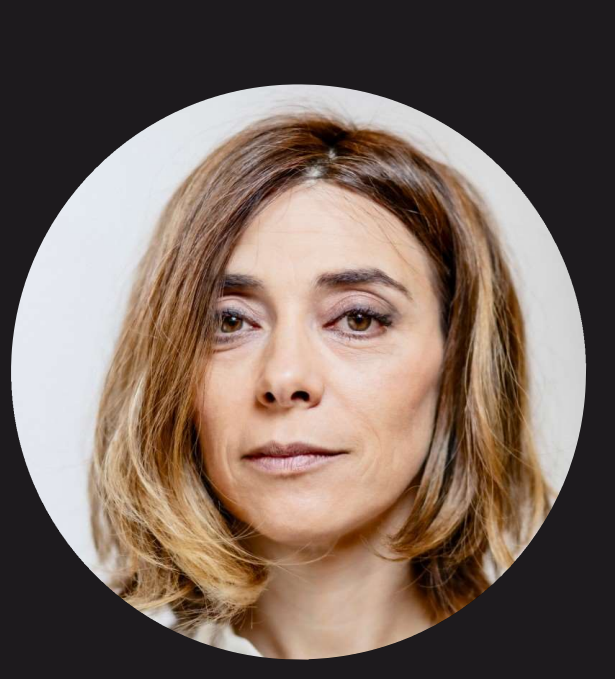

Gema Arias

Directora general de estrategia creativa en Kitchen

Pertenece a la Junta directiva del Club de Creativos y de la APG Y a \#másmujerescreativas 


\section{Trabajo}

Puestos destacados

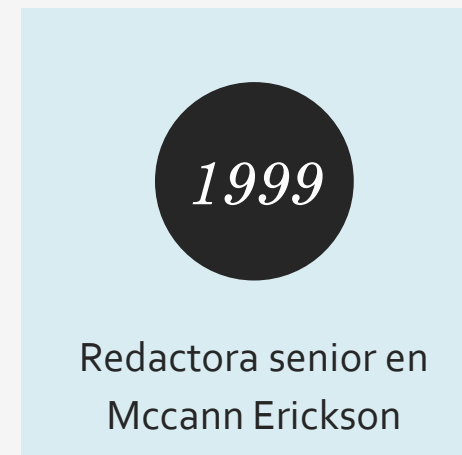

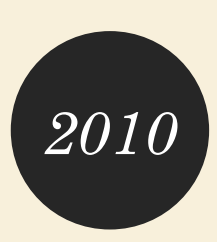

Directora Creativa en El Laboratorio

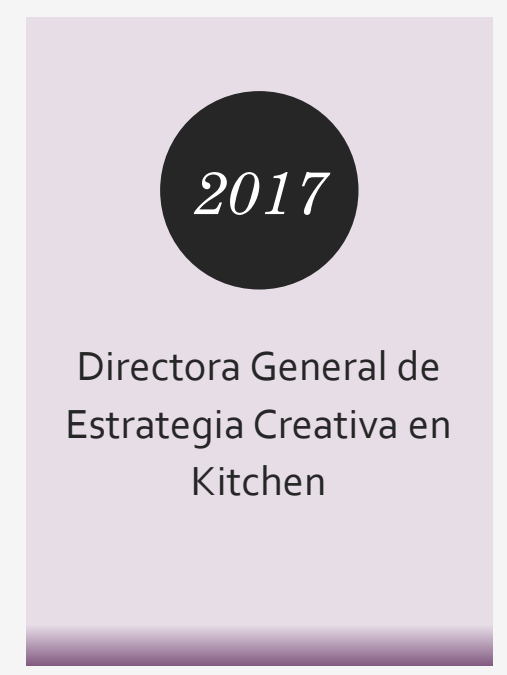




\section{Premios y campañas destacadas}

"El primer café que te ayuda a dormir mejor" Intermón Oxfam

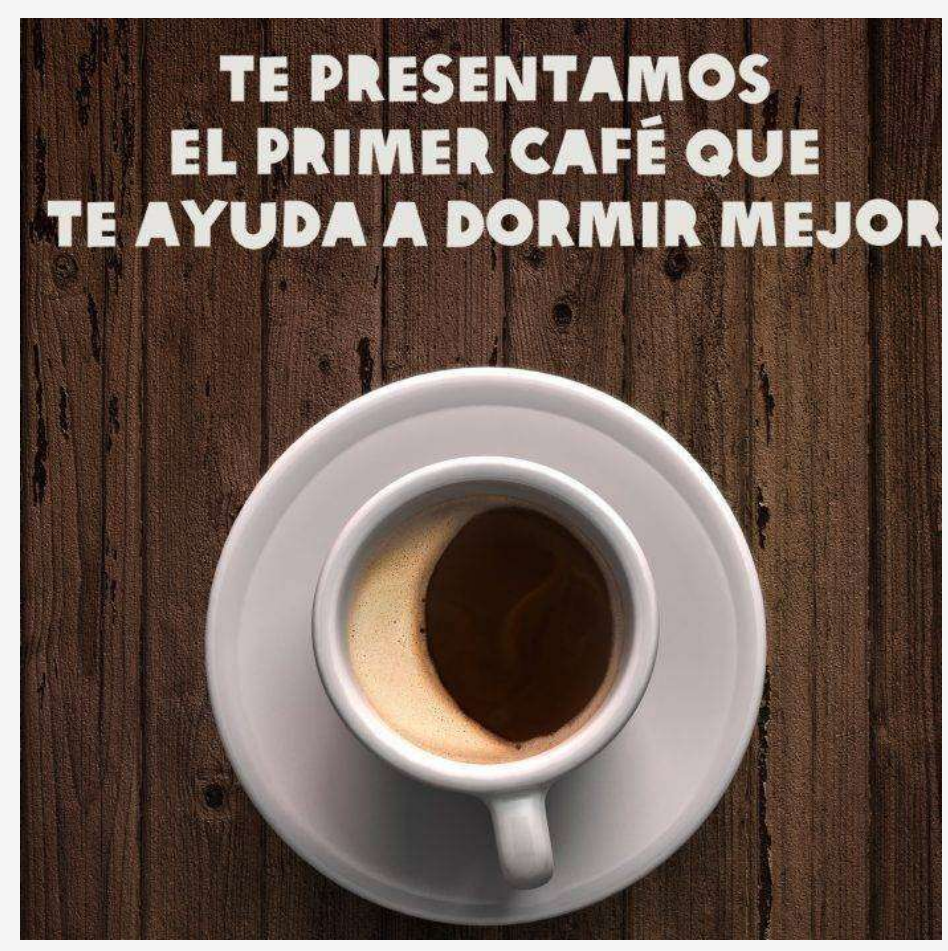




\section{Descripción:}

Dormir plácidamente a pesar de tomar café. A partir de esta paradoja, la agencia de publicidad que tiene por nombre Kitchen desarrolló la última campaña creativa para promocionar el café Intermón Oxfam de comercio justo. Un comercio que permite a 25.000 .000 de pequeños agricultores de más de 50 países recibir un precio justo por su producto y acceder así a unas condiciones de vida dignas.

El bloguero Mikel López Iturriaga -responsable de El Comidista-y los actores Ana Morgade, Melanie Olivares y Álex Gadea fueron los rostros elegidos por la agencia para concienciar a los ciudadanos de la importancia del comercio justo a través de un anuncio que acumuló más de 245.000 reproducciones en el canal de YouTube «Soy Activista» de Intermón Oxfam, convirtiéndose en el spot de una ONG española más visto en 2014.

La campaña tuvo además un alto componente viral al invitar a los usuarios de Facebook a bajarse una aplicación para «poner a dormir su perfil» y mostrar de esta forma su solidaridad con el comercio justo. En esta red social, la base de fans de Intermón Oxfam se incrementó en más de un $80 \%$... mientras que las descargas de la aplicación superaron las 400 en las dos semanas que duró la campaña. La actividad en Twitter también fue destacada, con un aumento de seguidores superior al 30\%.

Todas estas acciones se complementaron con catas en empresas dirigidas por el prestigioso Kim Ossenblock, barista internacional y campeón nacional de cata de café en 2012, así como con otras activaciones en punto de venta que lograron un alza de las ventas superior al $30 \%$ el primer día de campaña.

«El primer café que te ayuda a dormir mejor» logró, en definitiva, el compromiso sólido de buena parte de la sociedad, que gracias a la campaña pudo comprender mejor cómo un gesto tan sencillo y cotidiano como elegir un café puede ayudar a cambiar el mundo.

Fuente:https://www.elpublicista.es/reportajes/case-study-gran-premio-oros-eficacia-2014 


\section{PREMIOS}

Premio ORO en Eficacia en la Categoría Responsabilidad Social 2014

Premio Bronce en FIAP (Festival Iberoamericano de la Publicidad) en la categoría Televisión 2014

Premio Publifest eficacia 2014

Premio Publifest mejor pieza social 2014

Campaña recogida en Lürzers Int'I Archive en sus ediciones gráficas

Fuente: https://www.elpublicista.es/reportajes/case-study-gran-premio-oros-eficacia-2014 


\section{Premios y campañas destacadas}
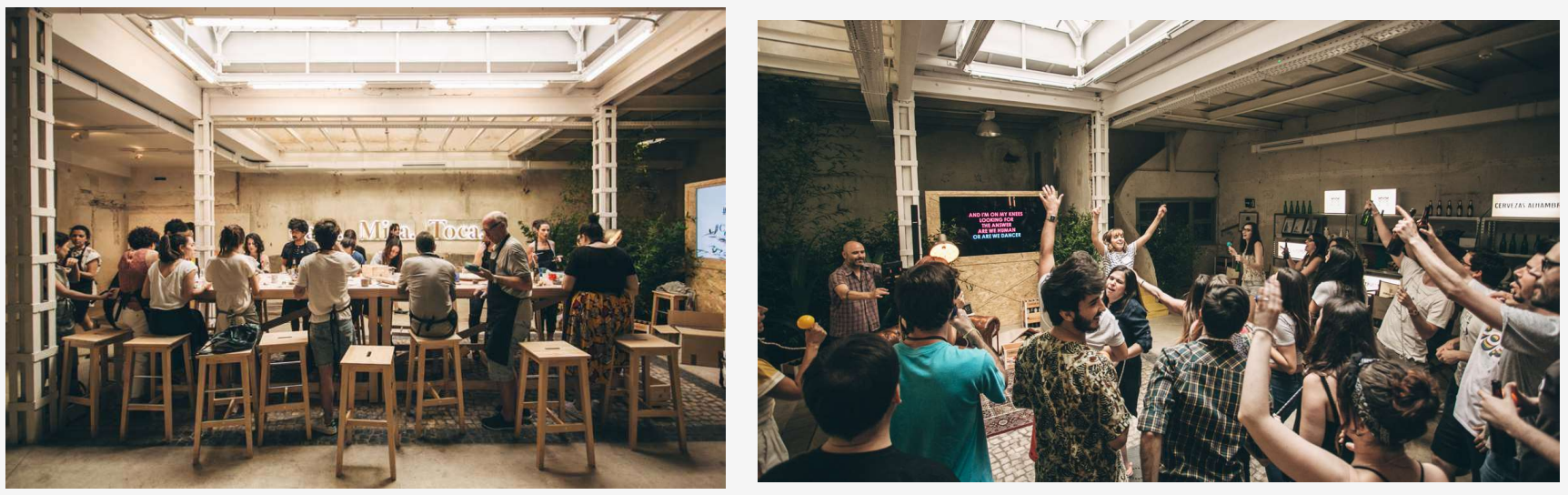

Para, mira, toca.

Cervezas Alhambra

https://www.cervezasalhambra.com/es/crearsinprisa/para-mira-toca https://kitchen.es/work/espacio-para-mira-toca/

https://www.youtube.com/watch?v=YEokiyakaqo\&feature=youtu.be 


\section{Sobre la campaña:}

En 2017 Cervezas Alhambra lanzó en Madrid su campaña nacional de comunicación "Para. Mira. Toca.", basada en la obra de Álvaro Catalán de Ocón y que forma parte de la plataforma de creación artística de la marca. Con la idea de materializar esta idea y acercarla al público, Kitchen creó este espacio donde, junto con artistas muy actuales, y a través de talleres de artesanía y gastronomía, exposiciones de arte, encuentros con diseñadores y músicos, y catas sensoriales, ofrecieron esta singular oferta cultural durante todo el mes de junio.

Más de 5.000 personas visitaron el espacio; 2.230 personas vivieron alguna de las experiencias que se llevaron a cabo (talleres, catas, charlas y encuentros con músicos)... y se consumieron 7.248 cervezas Alhambra

Fuente: https://www.eventoplus.com/casos/espacio-para.mira.toca.-el-oro-a-mejor-evento-cultural-de-kitchen/ 


\section{PREMIOS}

Oro al mejor evento cultural en los premios EVENTOPLUS 2020

Plata en Best Awards con Lapso (https://vimeo.com/477965096)

Fuente: https://www.eventoplus.com/casos/espacio-para.mira.toca.-el-oro-a-mejor-evento-cultural-de-kitchen/ 


\section{Equipo Kitchen para las campañas:}

Iñaki Bendito (Presidente y Director General Creativo)

Gema Arias (Directora General de Estrategia Creativa)

Nacho Tovar (Director General de Estrategia de Marcas)

Rafa Fortis (Director Creativo)

Isabel Gonzalez (Copywritter)

Lucía Calvo (Directora de Arte)

Jaime Outerelo (Director de Servicios al Cliente)

María Casado (Supervisora de Cuentas)

Selene Torres (Digital Manager)

Marina González (Community Manager)

Fuente: https://kitchen.es/equipo/ 


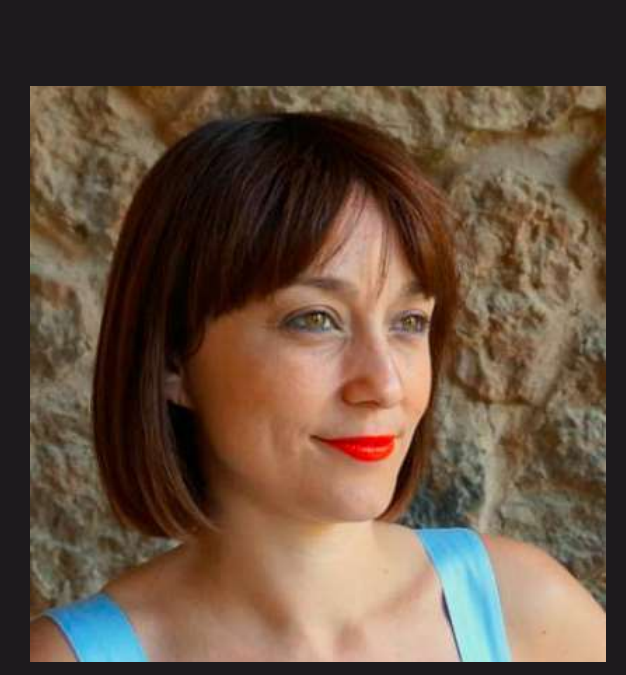

\section{Eva Santos}

Socio fundadora Delirio \& Twain Cofundadora de \#másmujerescreativas 


\section{Trabajo}

Puestos destacados
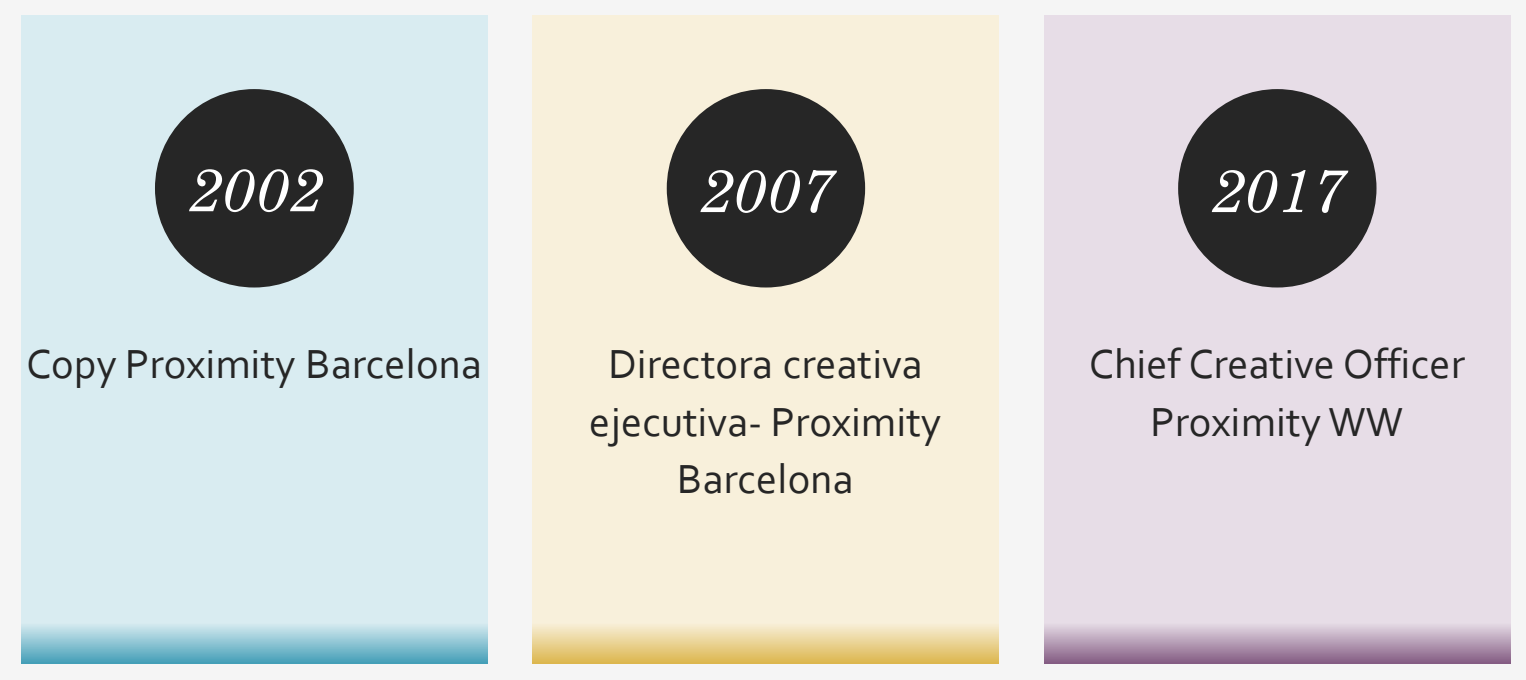


\section{Premios y campañas destacadas}

"La muñeca que eligió conducir"

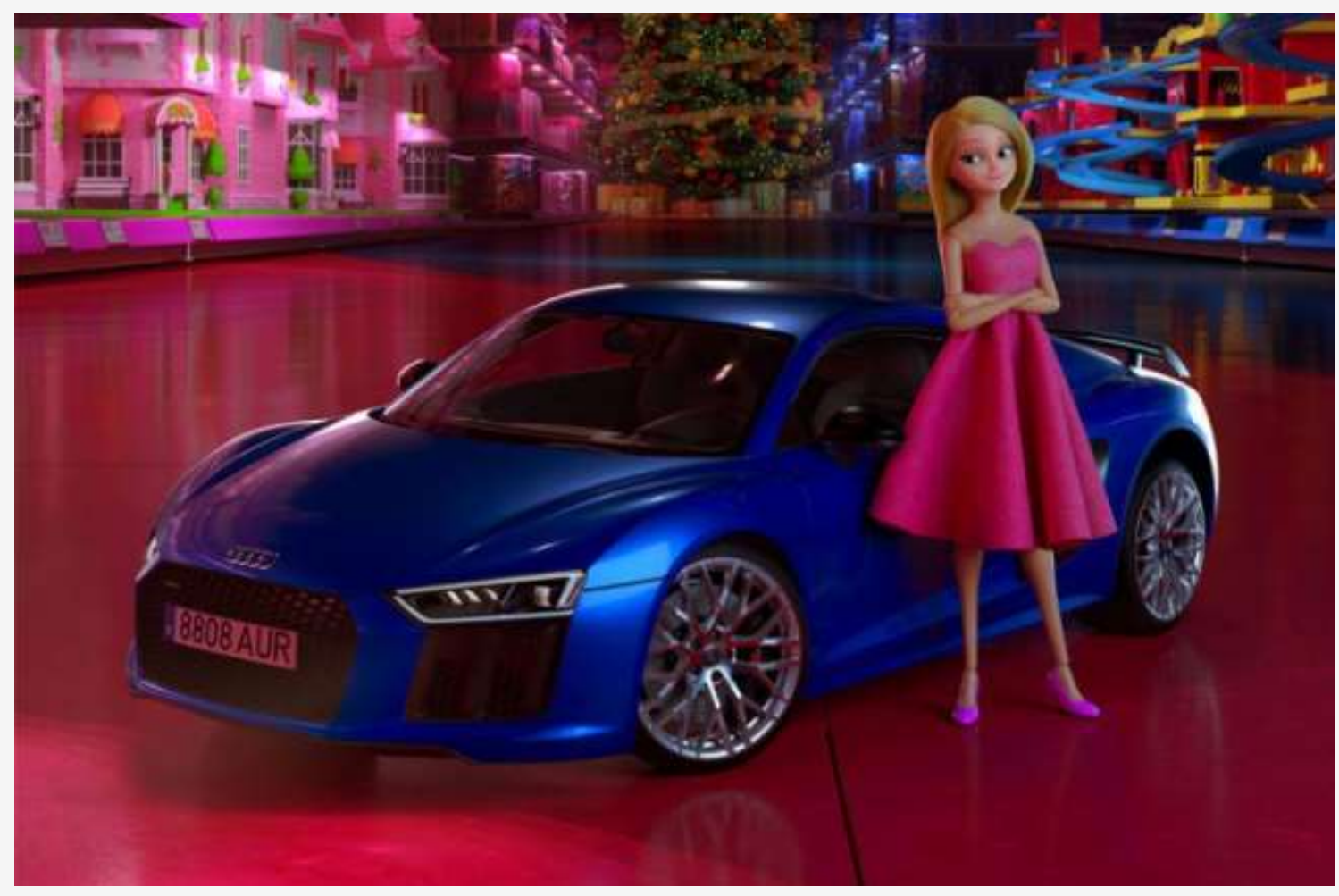

"Aprender a jugar, como conducir, no debería incluir estereotipos de género"

https://www.youtube.com/watch?v=V-siux-rWOM 


\section{Descripción:}

En España hay un 42\% más de conductores hombres que mujeres, un dato evidente de la desigualdad que existe entre géneros. Para combatir los estereotipos de género todavía presentes en la conducción, Audi lanzó un corto de animación sobre una muñeca que se decide a abandonar su estantería rosa de la juguetería y saltar a la azul para conducir un Audi R8. La película contó con una gran producción con texturas muy realistas y movimientos relativamente humanos de los juguetes. Para los personajes humanos se usaron el key frame, técnicas de motion capture y reconocimiento facial. La luz y el color fueron un protagonista más. Con las luces, reforzamos el enfrentamiento entre el rosa y el azul para representar esa división de mundos que es el origen del problema.

\section{Fuente: https://www.clubdecreativos.com/archivodelacreatividad/pieza-11588o.html}


Ficha técnica:

Compania Productora: Post 23

Direccion Arte: Rodrigo Chaparreiro, Iván Aguado, David Casado.

Direccion Creativa: Carles Alcon

Direccion Cuentas: Patricia Miret

Direccion General Creativa: Eva Santos

Equipo Creativo: Directora de Servicios al Cliente: Amanda Muñiz

Otros Creditos: Directora de comunicación: Laura Carrillo

Planning: Strategic Planner: Patricia Urgoiti

Produccion Agencia: Producción digital: Lluis García. Directora de Producción:Mercè Fernández

Productor Audiovisual: Diana Asenjo

Redaccion: Neus Gimenez, Laura Cuni, Edu Escudero.

Supervisor Cuentas: Carla Franco, Laia García

Fuente: http://bit.ly/2NonGjX 


\section{PREMIOS}

\section{Gran Premio a la Eficacia 2017}

ORO Mejor Campaña en Medios Ganados (Premios Eficacia 2017)

ORO Relevancia Social de una Marca (Premios Eficacia 2017)

Club de Creativos (Gran Premio, 2 Oros y 1 Plata),

Laus (2 bronces y 1 plata),

AMPE (Gran Ampe de oro)

Fuente: http://bit.ly/39T1gz4 


\section{PREMIOS}

El sol (2 Grandes Premios, 6 oros, 2 bronces)

\section{Cannes (1 Bronce)}

Fiap (1 oro, 2 platas y 1 bronce)

Echo Awards ( 2 oros, 1 bronce y un Runner up)

El Chupete (3 premios)

4 Merit Awards en el One Show

Fuente: http://bit.ly/39T1gz4 


\section{Premios y campañas destacadas}

A Moustache: mi bigotillo

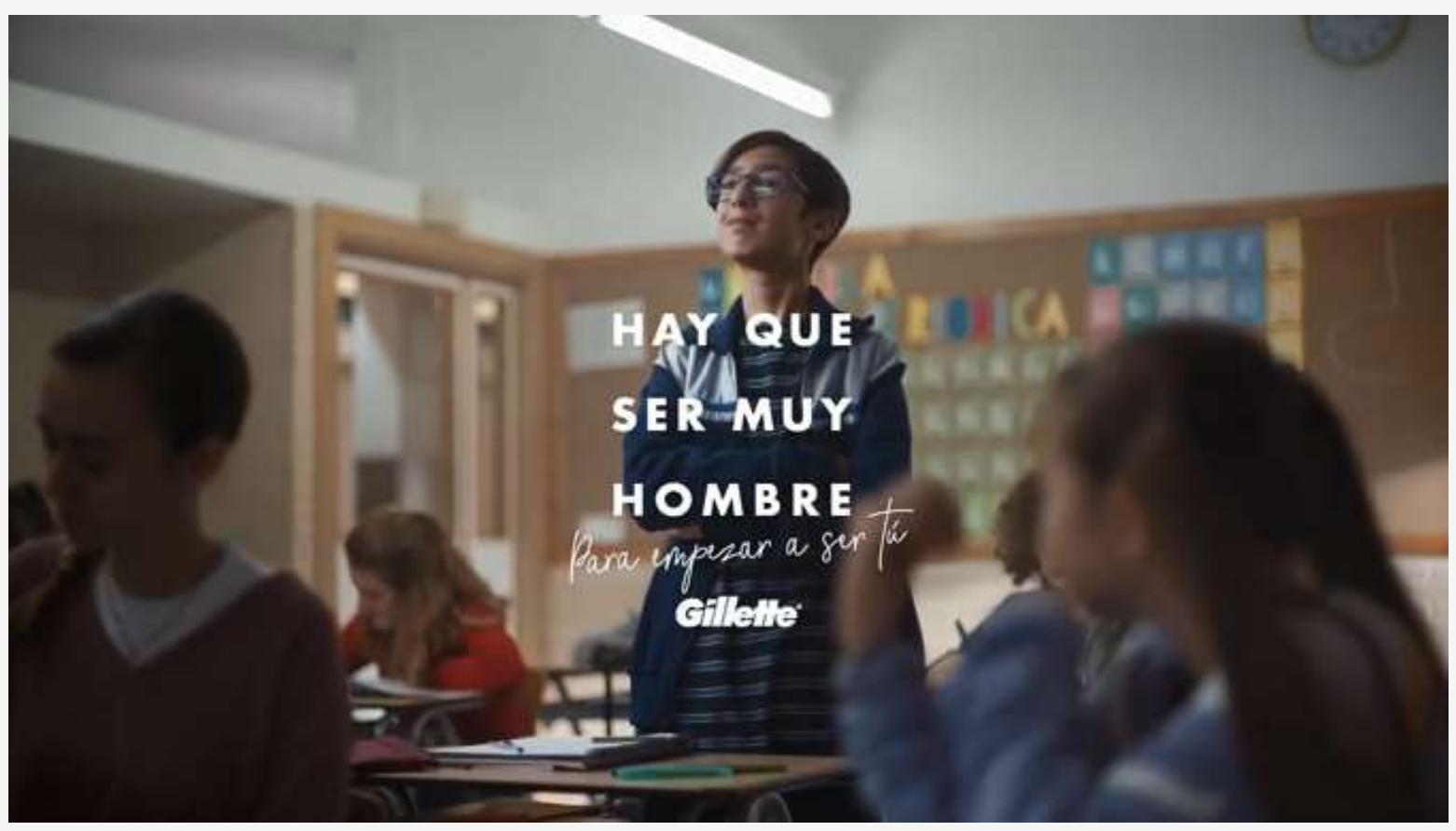

"Hay que ser muy hombre" quiere animar a todos los hombres a ser el tipo de hombre que quieran ser.

https://youtu.be/X6GjovoRvmg 


\section{Sobre la campaña:}

Santiago Antolin, Gillette brand manager Iberia: "Como marca vemos importante transmitir valores positivos y constructivos a la sociedad, empezando por los más jóvenes. "Hay que ser muy hombre" es nuestro esfuerzo para evitar que los hombres se sientan presionados por estereotipos de ningún tipo, y puedan sentirse cómodos en todo momento de tomar sus propias decisiones para llegar a ser la mejor versión de si mismos".

Según Susana Pérez, directora creativa ejecutiva de Proximity: "es en la pubertad donde se empieza a forjar la masculinidad y ahí es donde hemos encontrado un insight nunca tratado en publicidad, el bigotillo adolescente, símbolo visible de toda una serie de cambios que llegan en la pubertad y que pueden llegar a acomplejar a los jóvenes. Una campaña valiente por parte de Gillette que les dice a los jóvenes: "que nadie te diga cuando empezar a afeitarte, ni siquiera nosotros".

Fuente: http://bit.ly/39WYsAN 


\section{Manifiesto Gillette: Hay que ser muy hombre para ser tú}

En Gillette tenemos un propósito, ayudar a los hombres a alcanzar la mejor versión de si mismos.

¿Pero a qué versión de hombre nos referimos? Nos equivocaríamos si pensáramos que hoy en día existe un único tipo de hombre. Solo hay que salir a la calle y comprobarlo.

Desde pequeños estamos expuestos a una imagen mental de lo que se supone que un hombre debe ser, creando estereotipos que a menudo se transmiten entre generaciones.

Un hombre es guapo y fuerte. No llora. No hace cosas 'de chicas'. Debe ser siempre valiente y autoritario...estos son algunos ejemplos de creencias que existen en nuestra sociedad y limitan el comportamiento masculino.

Fuente: http://bit.ly/2KGw6SK 
Anunciante: $P \& G$

Marca: Gillette

Ficha técnica:

Producto: Afeitado

Campaña: A Moustache $\mid$ Mi Bigotillo

Contactos del anunciante: Giulia Bloise, Santiago Antolín y Nuno Constant

Agencia: Proximity Madrid

Global chief creative officer: Eva Santos

Directora creativa ejecutiva: Susana Pérez

Director creativo: David Despau

Copys creativos: José Cope, Albert Alcacer, Fernando Esteban

Director de arte: Gerardo Vaquerizo

Coordinador creativo de video: Elías Maldonado

Director de tecnología: Víctor Madueño

Channel integration manager: Diego Alonso

Content manager: María Martínez

Directora de servicios al cliente: Marta Yllera

Supervisora de cuentas: Inma O'Gallar

Planner: Esla de Murga
Directora de comunicación: Laura Carrillo

Directora de producción: Gemma Selga

Agencia de medios: Carat

Productora: Blur

Realizador: Zipi

Productor ejecutivo: Mario Fornies

Producer: Juan Bascón

Director de fotografia: Nilo Zimmmerman

Editor: Rocio Perez

Coordinador de postproducción: Blur

Composición musical: Fede Pajaro

Estudio de sonido: The Lobby

País: España

Fecha de emisión: 18 de noviembre de 2019

\section{Fuente: http://bit.ly/3cjtlgr}




\section{PREMIOS}

Premio del Jurado Popular en la categoría TV en Los Premios Anuncios.

1 plata en la categoría Ideas en los premios del Club de Creativos (2020)

1 planta en la categoría Producción Audiovisual Digital en los premios Inspirational (2020)

Fuente: http://bit.ly/39T1gz4 


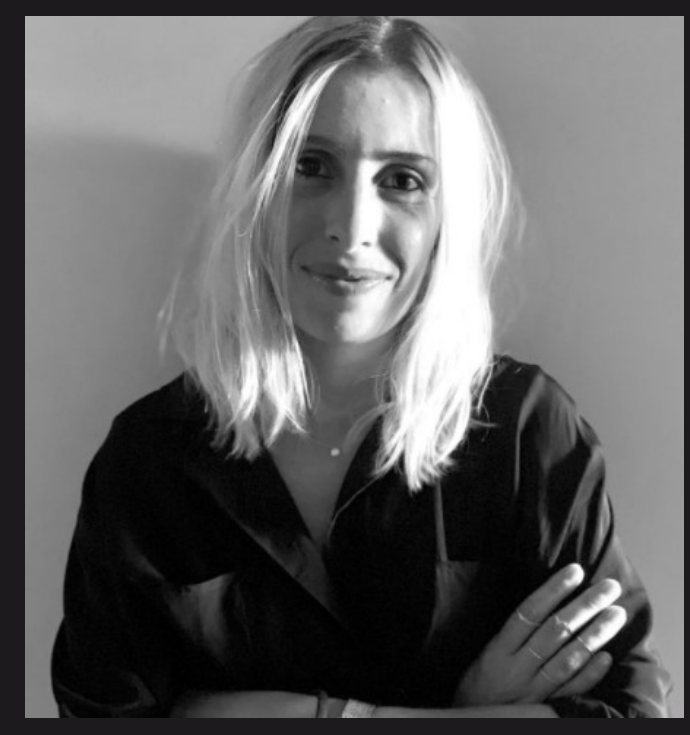

\section{Nerea Cierco}

Directora creativa ejecutiva en $D D B$ Miembro de \#másmujerescreativas https://adhertising.com/idolas/la-directora-creativa-nerea-cierco-y-la-presencia-de-las-mujeres-en-la-publicidad/ 


\section{Trabajo}

Puestos destacados
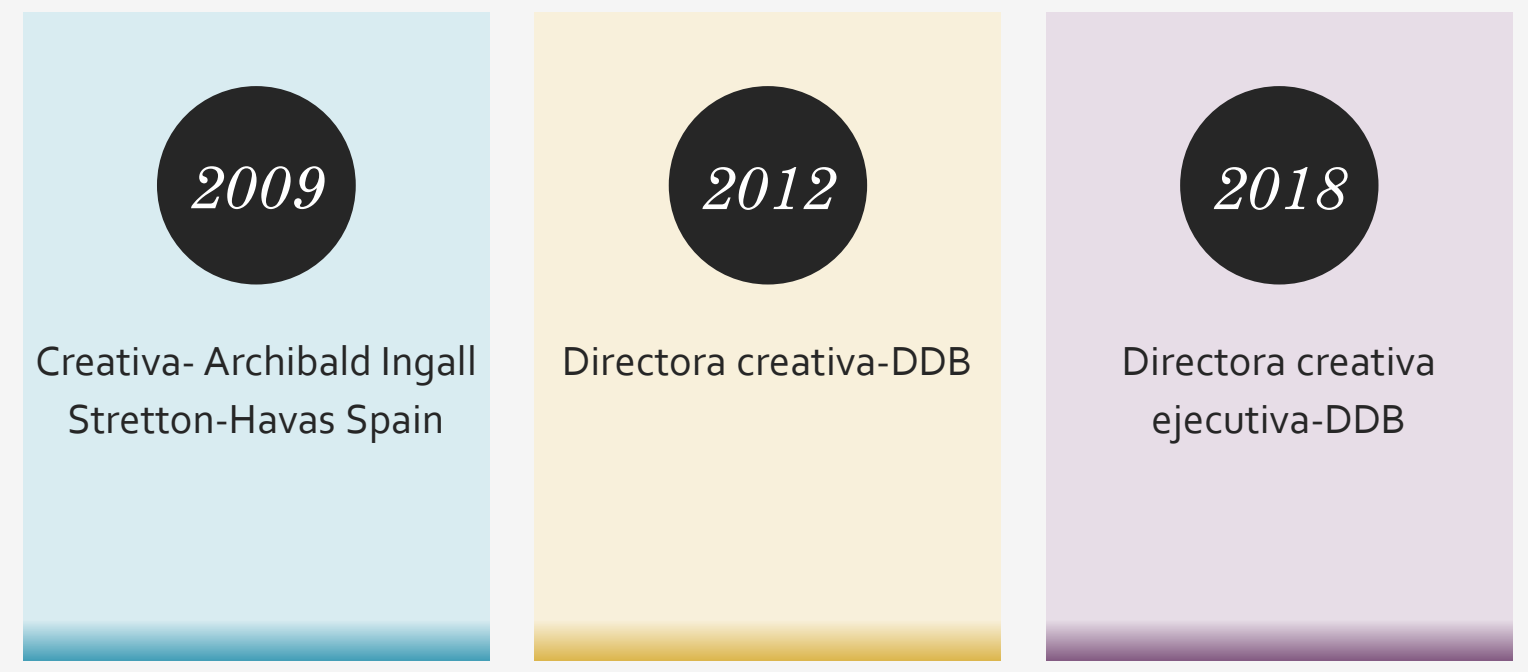


\section{Premios y campañas destacadas}

"Héroes de hoy"

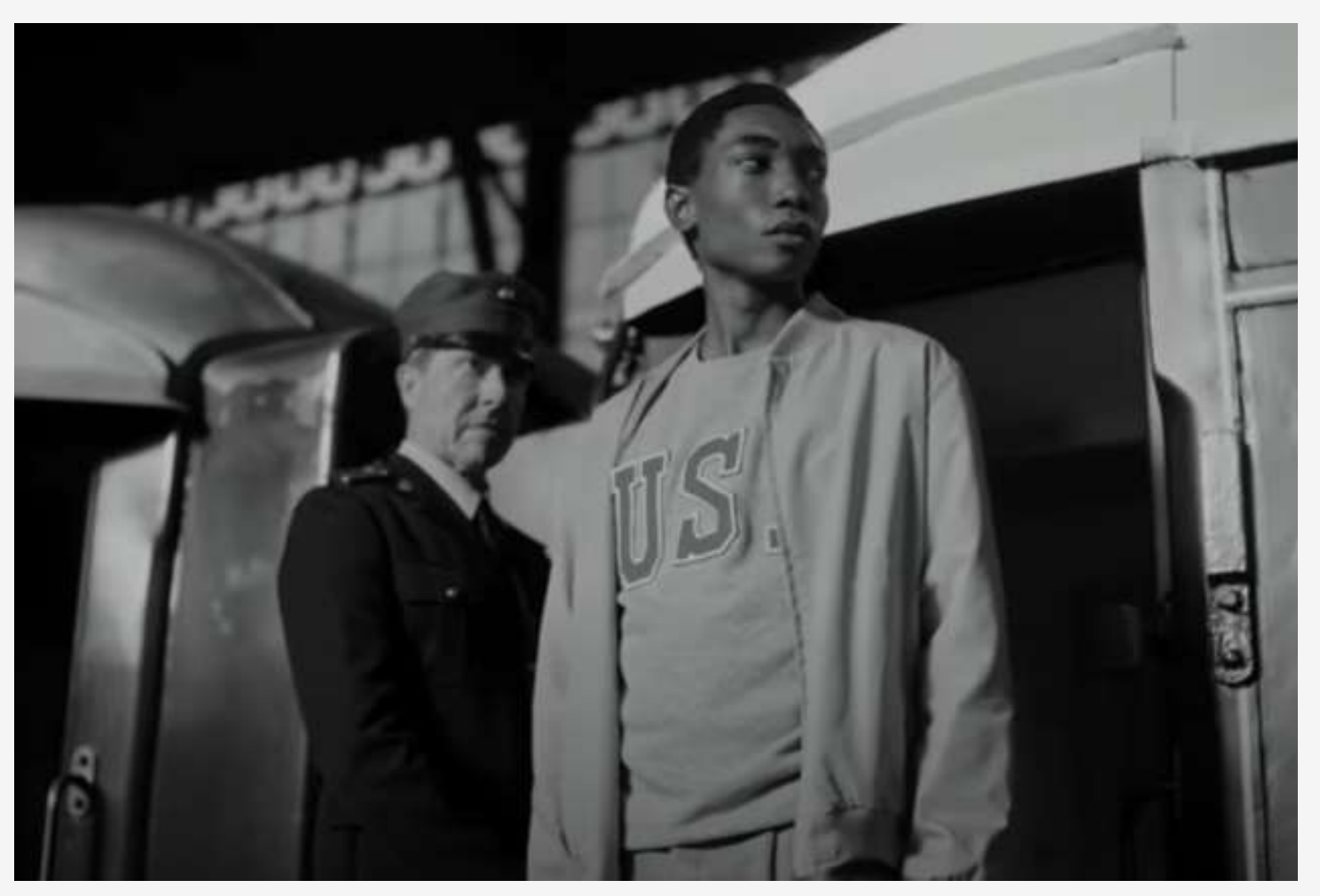

"La intolerancia sigue ahí. Pero los héroes también"

https://www.youtube.com/watch?v=SOXXwoGg7NE 


\section{Descripción:}

'Héroes de hoy' reúne a marcas comprometidas que buscan transformar la sociedad para exponer sus iniciativas sociales y poner cara a sus héroes. Convencidas de que la unión de todas ellas es más eficaz, LaLiga, Iberia, Correos, Telepizza, Clínica Baviera y 11811 impulsan esta iniciativa. El primer cortometraje de la plataforma, ambientado en los JJOO del Berlín 1936, refleja la discriminación racial que actualmente existe en el deporte, es la primera historia:

La plataforma Héroes de Hoy impulsada por la agencia de publicidad DDB, nace para hacer frente a la intolerancia y discriminación social reuniendo a diferentes marcas con el objetivo de unir fuerzas y transformar la sociedad. LaLiga, Iberia, Correos, Telepizza, Clínica Baviera y 11811 han sido las primeras en unirse a la plataforma.

Fuente: https://www.programapublicidad.com/ddb-crea-la-campana-heroes-hoy-la-discriminacion-la-intolerancia/ 
Ficha técnica:

Anunciante: LaLiga, Iberia, Correos, Telepizza, Clínica Baviera y 11811

Agencia: DDB España

Director general creativo: José $\mathrm{M}^{\mathrm{a}}$ Roca de Viñals

Dirección creativa ejecutiva: Daniel Rodríguez, Nerea Cierco y Alfredo Vaz

Director de arte: Fernando Morate

Redactor: Arturo Dorado

Director de servicios al cliente: Alejandro Lavezzolo

Coordinación: Miguel Rodriguez

Supervisor de cuentas: José de la Fe

Dirección de producción: Enrique Feijoo

Producer: Beatriz Mancha

Productora: Garlic

Realizador: BRBR

Productor ejecutivo: Alvaro Gorospe e Irene Nuñez

Producer: Laura Ibáñez
Director de fotografía: Michal Babinec

Postproducción: El Ranchito

Sonido: Miguel Calvo

Montador: Ale García

Project manager Digital: Iván Olavarría

Producción Digital: The OMS

Agencia de PR: QMS Comunicación

Fuente: https://www.elpublicista.es/videos/heroes-ddb-para-laliga-iberia-correos-telepizza-clinica-baviera 


\section{PREMIOS}

1 oro en la categoría "Entertainment Lions for Sport" (Cannes Lions, 2019)

1 plata en la categoría "Entertainment Lions for Sport" (Cannes Lions, 2019)

2 platas en la categoría "Film" (Cannes Lions, 2019)

1 oro, 3 bronces (Festival Iberoamericano de la Comunicación Publicitaria El Sol, 2019)

1 Bronce en la categoría "Branded Entertainment" (London International Awards, 2019)

1 Bronce en la categoría "Film" (London International Awards, 2019) 


\section{Premios y campañas destacadas}

"Start the Dance"

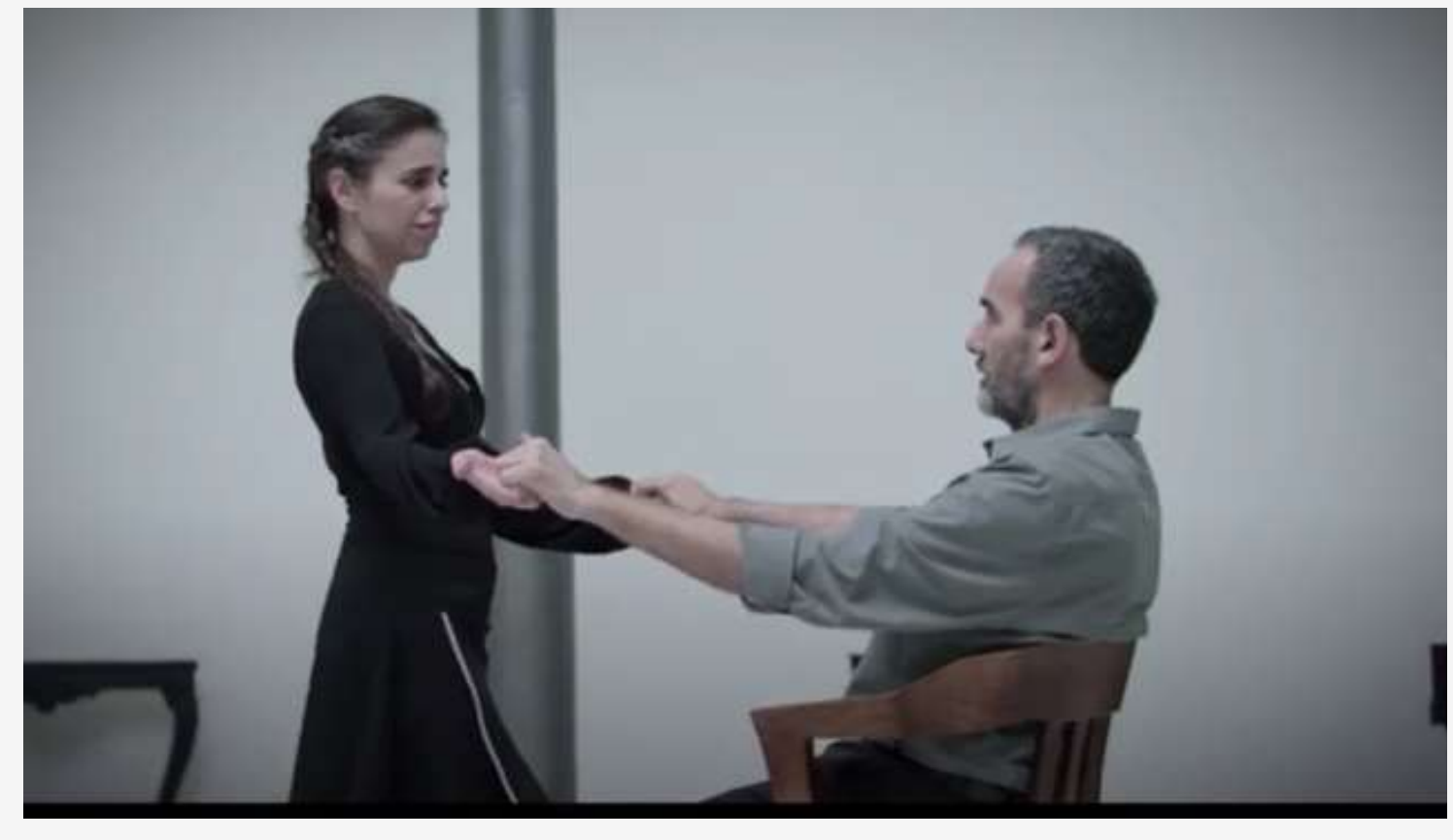

"Dona contra la ELA" 


\section{Descripción:}

La agencia ha realizado un videoclip en el que, foto a foto, mediante la técnica del stop motion logra crear la ilusión de movimiento en el cuerpo de un paciente de ELA. La campaña de DDB España, Start The Dance, es la primera fase de una colaboración a largo plazo en la que Samsung apoyará a la Fundación Luzón en mejorar la calidad de vida de las personas que sufren ELA y sus allegados a través de la tecnología. El objetivo de esta primera acción será recaudar fondos para proporcionar a los enfermos de ELA la asistencia sanitaria que necesitan, así como para la creación de un Banco Nacional de Ayudas Tecnológicas.

En el video se puede ver a Marco, paciente de ELA, bailar el famoso tango "Por una cabeza" del conocido Carlos Gardel, pero se trata solo de una ilusión de movimiento que la agencia ha conseguido gracias a dicha técnica y a la tecnología fotográfica del nuevo Samsung Galaxy S9+

Fuente: https://www.programapublicidad.com/ddb-espana-crea-start-the-dance-la-fundacion-francisco-luzonsamsung-la-ela/ 
Ficha técnica:

Agencia: DDB España

Anunciante: Fundación Luzón + Samsung

Vice President \& Chief Creative Officer, CCO: José María Roca de Viñals

Directores Creativos Ejecutivos: Daniel Rodríguez, Nerea Cierco, Alfredo Vaz

Equipo creativo: Marina Fornet y Óscar Pérez

Supervisora de Cuentas: Gabriela Castro

Dirección de producción audiovisual: Enrique Feijoo

Producer: Beatriz Mancha

Editor: José Sueiro
Productora: Sal Gorda

Realizador: Julián Zuazo

Productor ejecutivo: Juanjo Gómez

Producer: Javier Blázquez/ Enrique Gómez

Director de fotografía: Ramón Grau

Montador: Ángel Ingelmo

Director postproducción: Juanma Gómez

Música: Sound Garden

Estudio de postproducción: Chelsea 22

Producción Microsite:The Crowd

Director Técnico: Israel Ortiz

Equipo PR: QMS Comunicación

\section{Fuente: http://bit.ly/3egxU3e}




\section{PREMIOS}

1 oro en la categoría "Digital y móvil" (Festival Iberoamericano de la Comunicación Publicitaria El Sol, 2018)

1 plata en la categoría "Medios" (Festival Iberoamericano de la Comunicación Publicitaria El Sol, 2018)

1 bronce en la categoría "Campañas integradas" (Festival Iberoamericano de la Comunicación Publicitaria El Sol, 2018)

1 bronce c de c (2019)

\section{Fuentes:}

https://www.adlatina.com/articulo.php?slug=/publicidad/el-sol-2018-lola-mullenlowe-la-agencia-del-festival https://www.clubdecreativos.com/wp-content/uploads/2019/03/PALMARES-2019.pdf https://www. behance.net/gallery/82104003/Samsung-Start-the-dance 


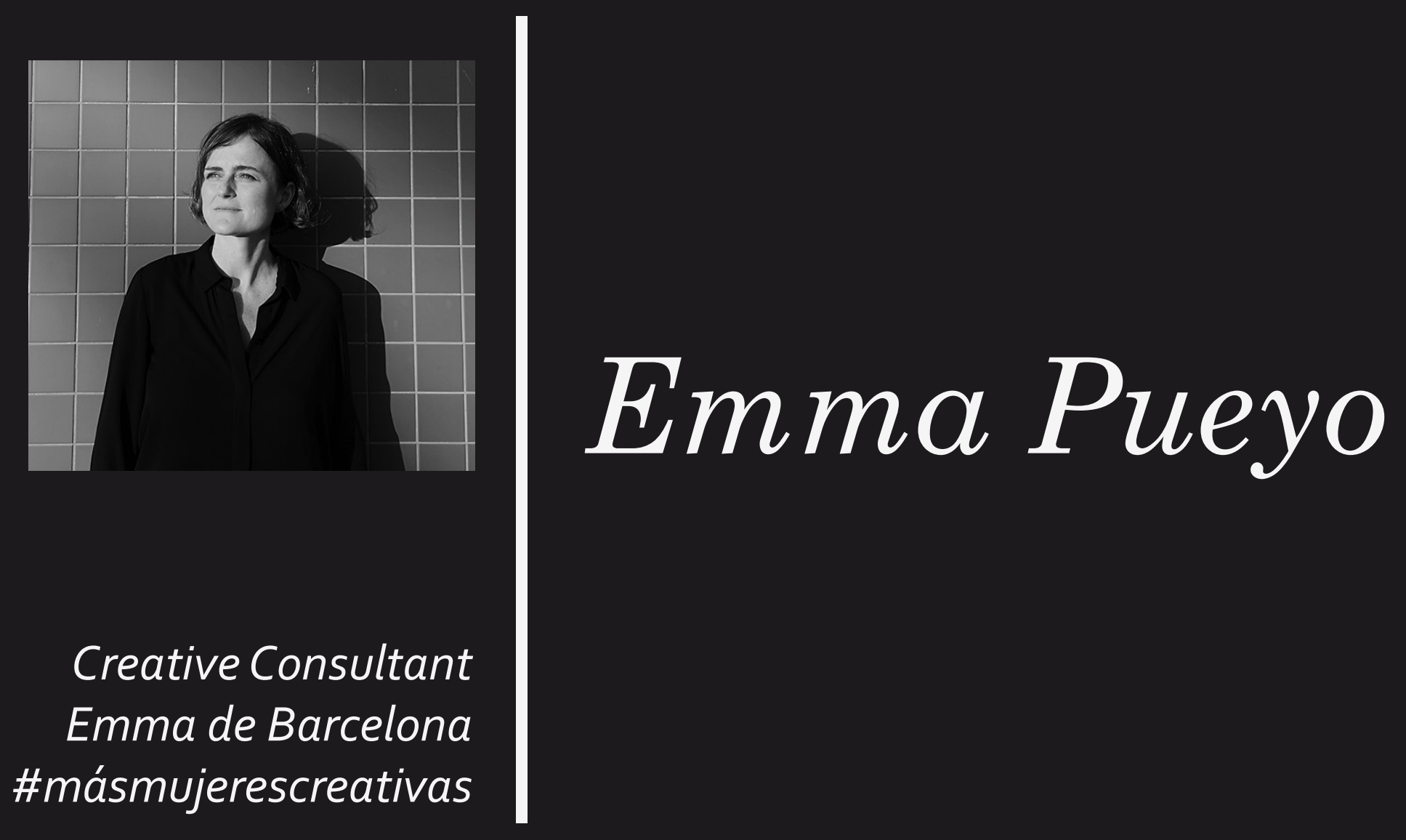

Cofundadora de \#másmujerescreativas 


\section{Trabajo}

Puestos destacados

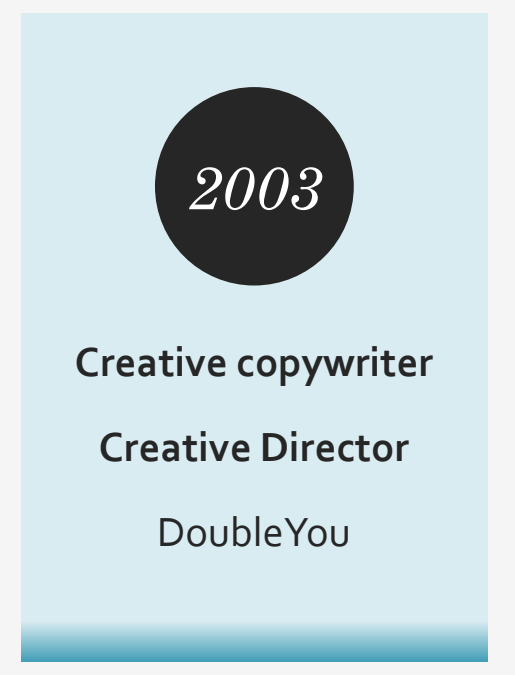

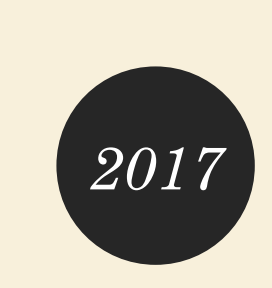

Creative Partner

This Here

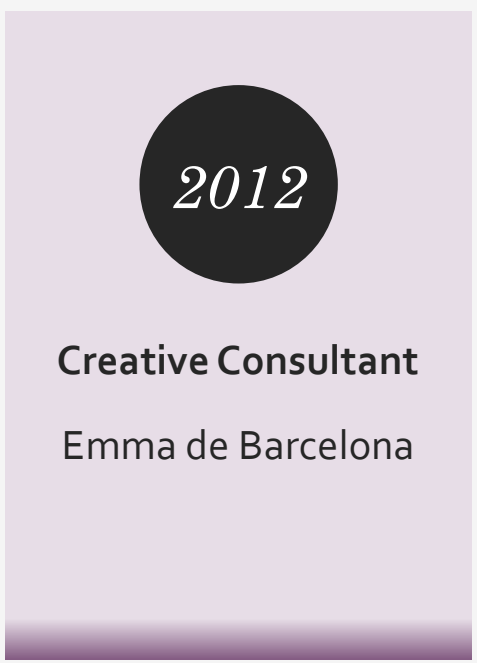




\section{Premios y campañas destacadas}

"Hotel Amour" 


\section{Descripción:}

"Ikea pone a prueba hasta a las parejas más fuertes. Ahora os toca ponernos a prueba a nosotros. Presentamos Hotel Amour, el hotel para que probéis a fondo nuestros colchones, textiles de cama y almohadas en la noche de San Valentín. ¡Sólo para parejas aventureras! En la pieza teaser se da a conocer el mensaje "probar los colchones de IKEA" en tono de humor a través de insights que ocurren en las tiendas de Ikea ("discusiones de pareja") y se da a conocer el Hotel Amour, de esta forma redirige al site de la campaña para captar a participantes".

Fuente: https://www.clubdecreativos.com/archivodelacreatividad/pieza-114491.html 


\section{FICHA TÉCNICA}

-Anunciante: IKEA Iberia

-Marca: IKEA

-Producto: colchones

-Agencia de publicidad: MRM//McCann España

- Director general creativo: Mónica Moro

-Director creativo (ejecutivo): Raquel Martínez y Jon Lavín

-Equipo creativo: Mónica Moro, Raquel Martínez, Rafael Martínez, Borja Diego, Emma Pueyo,

David Bolea y Miriam Martín.

-Productora audiovisual: Primo Madrid.

- Director de cine: Javier Ruiz Caldera

-Postproducción: Free You Mind

-País: España

-Categoría: Tiendas

Fuente: http://www.latinspots.com/sp/noticia/ikea-iberia-y-mrmmccann-ponen-a-prueba-sus-colchones-con-hotel-amour/35337 
PREMIOS campaña

BRONCE ( Ideas ) - CLUB DE CREATIVOS, año 2015

Sol de Bronce ( Exterior ) - EL SOL, año 2015

Fuente: https://www.mccann.es/clientes-de-publicidad/ikea/hotel-amour.html 


\section{Premios y campañas destacadas}

"Nike's first maternity collection"

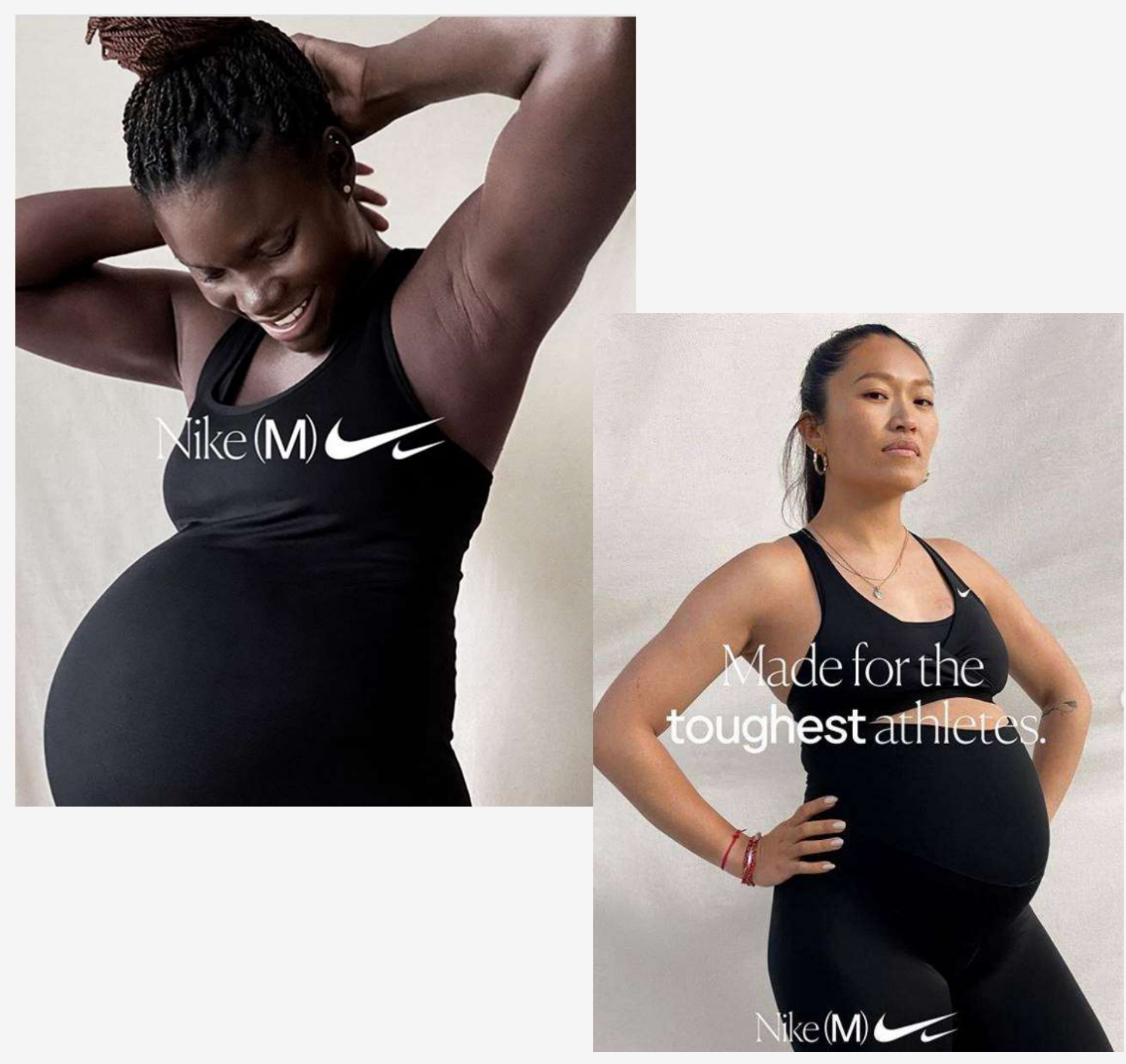

https://www.emmadebarcelona.com/Naming-Nike-s-first-maternitycollection 


\section{Descripción Nike (M):}

"En su misión de hacer que el deporte sea lo más inclusivo posible, Nike pasó tres años creando su primera colección de maternidad, destinada a apoyar a las mujeres durante todas las etapas del embarazo y más allá. El equipo dirigido por mujeres del proyecto en Nike me llamó para que las ayudara a idear un nombre y un concepto."

Fuente: Emma Pueyo, https://www.emmadebarcelona.com/Naming-Nike-s-first-maternity-collection 


\section{Premios y campañas destacadas}

IIIE SIIOW WMUST GO ON AIR

Haz sonar las bandas que han cancelado sus actuaciones en Barcelona por el COVID-19 para que sus pérdidas se compensen con royalties y exposición.

Programa su música en tu emisora de radio, ponla en tu próximo anuncio o simplemente escúchala online. Cada reproducción cuenta.

ABCDEFGHIJKLMNOPRSTUVWYZ

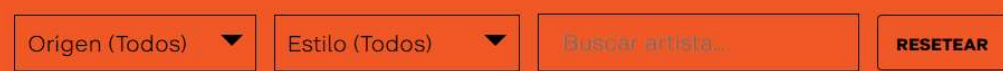




\section{Descripción:}

"Debido a la pandemia, miles de artistas musicales vieron cancelados sus shows en vivo de la noche a la mañana, con importantes pérdidas en finanzas y promoción.

BMAT, una empresa de innovación musical a la que ayudé a construir una marca hace unos años, quería aliviar parte del dolor que estaba experimentando la industria de la música debido al coronavirus. Sugerí construir una plataforma que alentara a las televisiones, radios y agencias de publicidad a utilizar las canciones de artistas cancelados para generar "royalties" y exposición para ellos".

Fuente: Emma Pueyo, https://www.emmadebarcelona.com/Helping-help-the-bands-most-impacted-by-COVID-19

\section{Cliente: BMAT}

Año: 2020

Rol: Consultor creativo y director creativo 


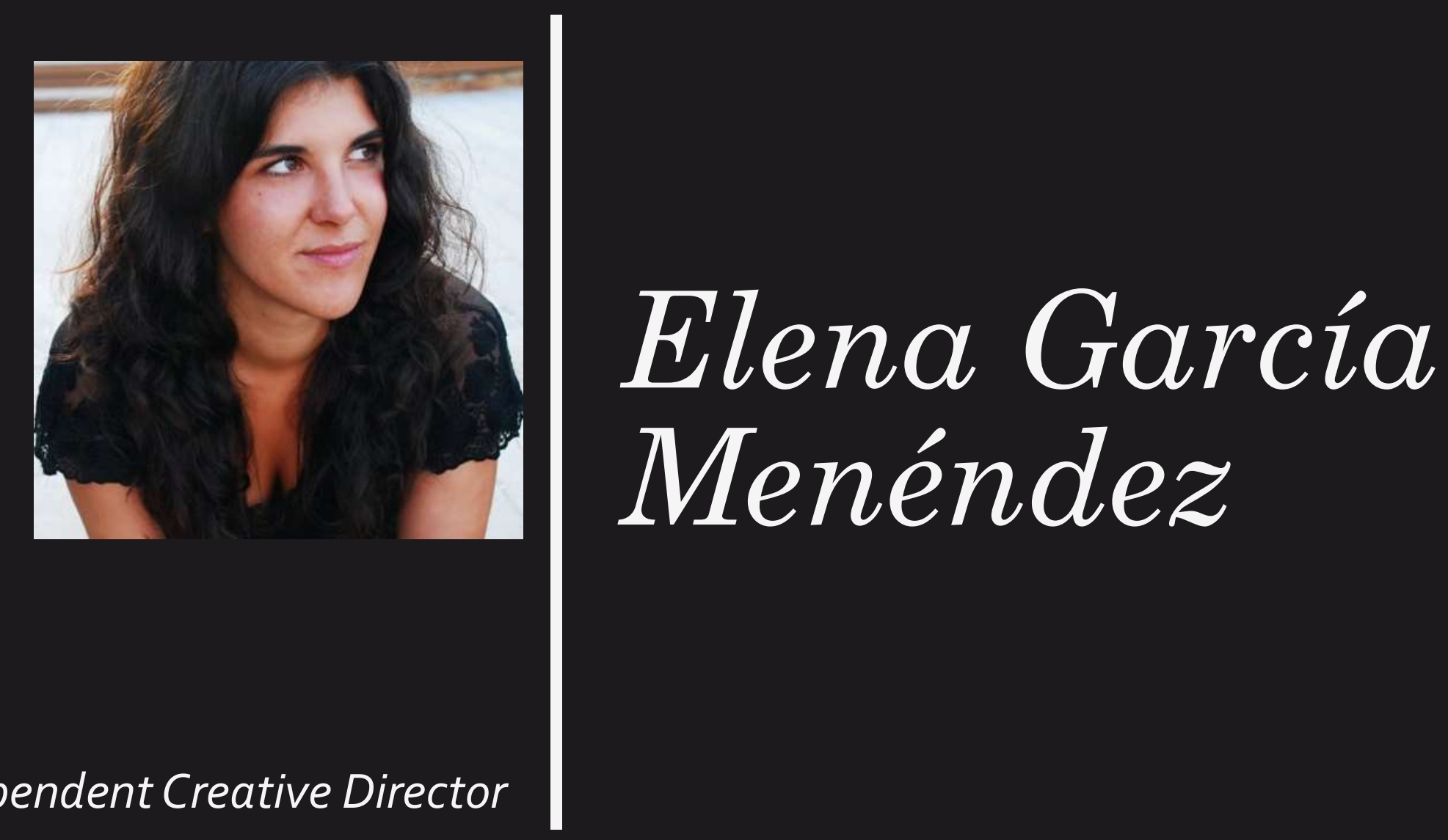

Independent Creative Director 


\section{Trabajo}

Puestos destacados

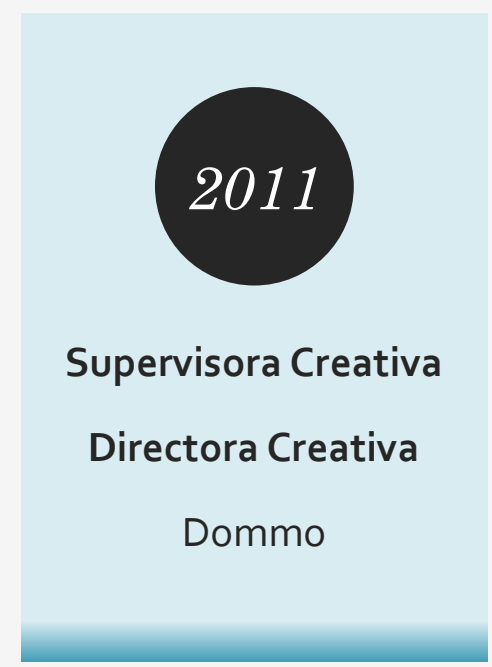

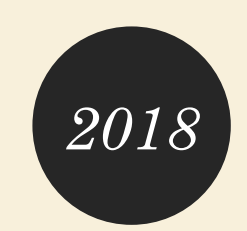

Head of art, Executive

Creative Director,

Creative director

PS21

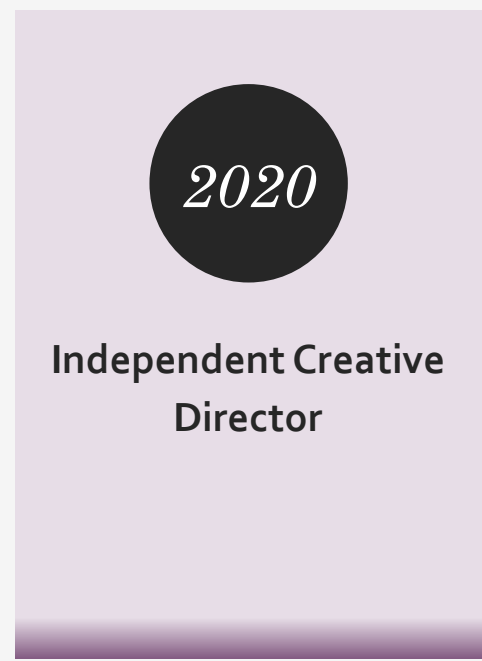




\section{Premios y campañas destacadas}

"Tuenti Móvil"

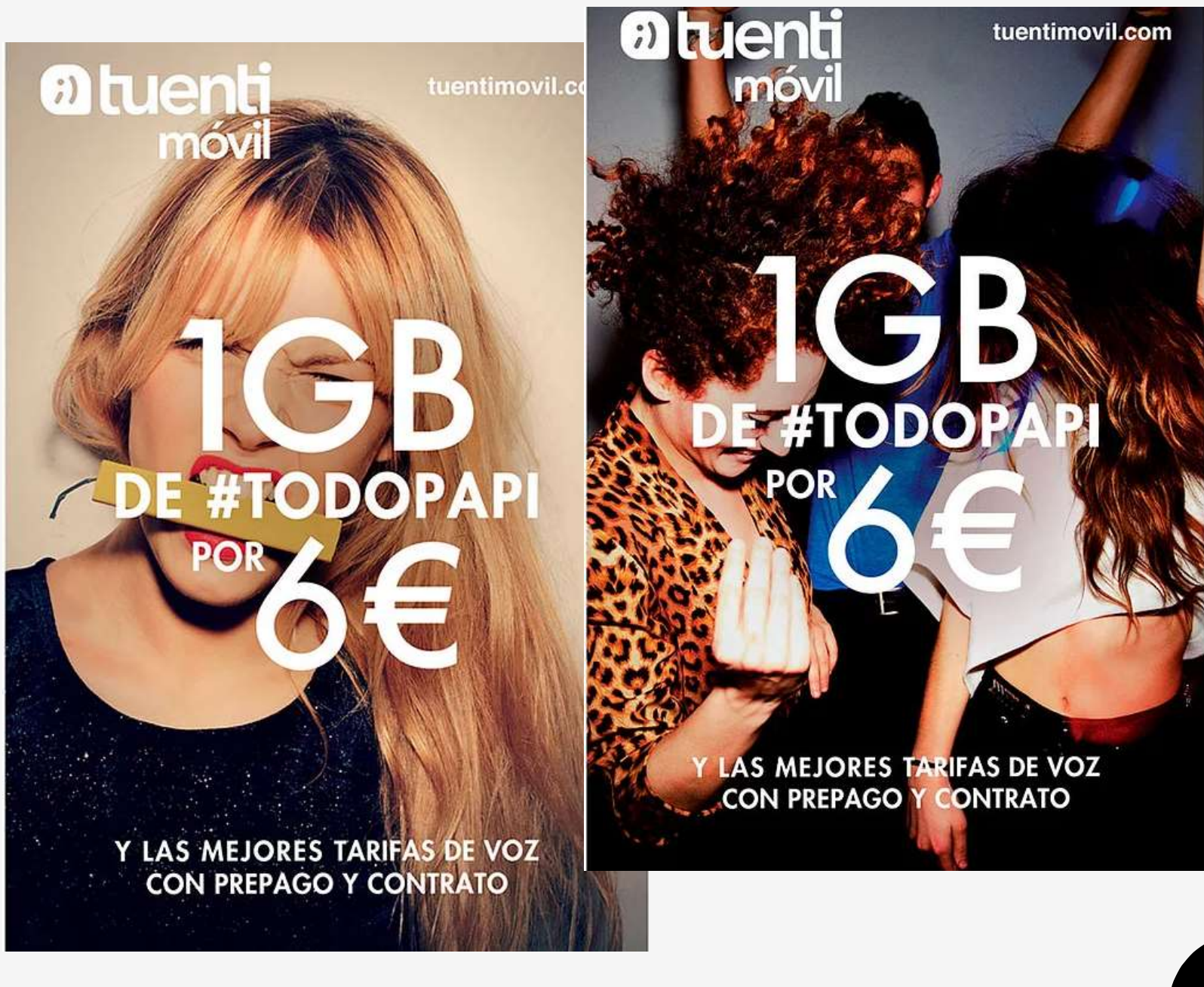

Tu vida se mide en gigas

https://www.elenagarciamenendez.com/tuenti-movil 


\section{Descripción:}

"En 2010 la Red Social Tuenti nos llamó para lanzar una nueva empresa de telefonía móvil: Tuenti Móvil. Su objetivo era crear un gran impacto en los más jóvenes a través de una oferta comercial inmejorable: 1 gb por $6 € \ldots$ pero ¿quién sabe para qué sirve un Gigabite ? Te lo explicamos en una divertida campaña. Usamos ejemplos simples para que la gente entienda cómo pueden usar sus Gigas, como 1gb, 12546 videos o 67898 fotos.".

Fuente: Elena García, https://www.elenagarciamenendez.com/tuenti-movil

"Tuenti, la red social de referencia en España, decide lanzar un operador móvil para conectar a los usuarios de la red social, también por datos y voz. Tras un año en el mercado, una crisis económica, el boom de los smartphones y una revolución social en ciernes, se fija un objetivo: ser la operadora móvil de referencia para los jóvenes, y destacar en un mercado sobresaturado. Para conseguirlo, el foco se puso en lo que le importa a los jóvenes de su Smartphone: los Gigas. Por lo que se decide hacer una campaña donde se traduzcan los gigas a su equivalencia en la vida. Así nace la campaña "Tu vida se mide en Gigas", una campaña de comunicación integrada en la que destaca una creatividad basada en contenidos y una estrategia de comunicación multi-medios".

Fuente: https://www.clubdecreativos.com/archivodelacreatividad/pieza-112915.html 


\section{FICHATÉCNICA}

-Agencia: Miss W.D. by dommo

-Anunciante: Tuenti Móvil

-Sector: Telefonía

- Campaña: Tu vida se mide en gigas

-Dirección creativa ejecutiva/creativos/estrategia: Equipo multidisciplinar Miss W.D.

- Director de proyecto (CEO): Agustín Vivancos

-Directora creativa ejecutiva: Marta Lluciá

-Director creativo: Pablo Barrionuevo

- Supervisores creativos: Elena García y Joan Mikel Orga

-Supervisora de cuentas: Tatiana González

-Ejecutivo de cuentas: Teresa Gómez

-Redactor: Jesús Manuel Flete

-Productora: Wind

-Realizador: Darío Peña

-Director de Fotografía: Nacho López

- Producer: Mario Padilla

-Director de Postproducción: Néstor Costafreda

-Estudio de sonido: La Panadería

-Música original: Maluca El Tigeraso

-Piezas: Spot 60 Tv e internet + spot 20 Tv e internet

-Título: Tu vida se mide en gigas

-Medios: Televisión, radio, exterior, digital, punto de venta y patrocinios

Fuente: https://interactivadigital.com/campanas-de-marketing-digital/tu-vida-se-mide-en-gigas/ 
PREMIOS campaña

SILVER. Festival "Cdec", 2014

Fuente: https://www.clubdecreativos.com/archivodelacreatividad/pieza-112915.html 


\section{Premios y campañas destacadas}

"\#Realinfluencers"

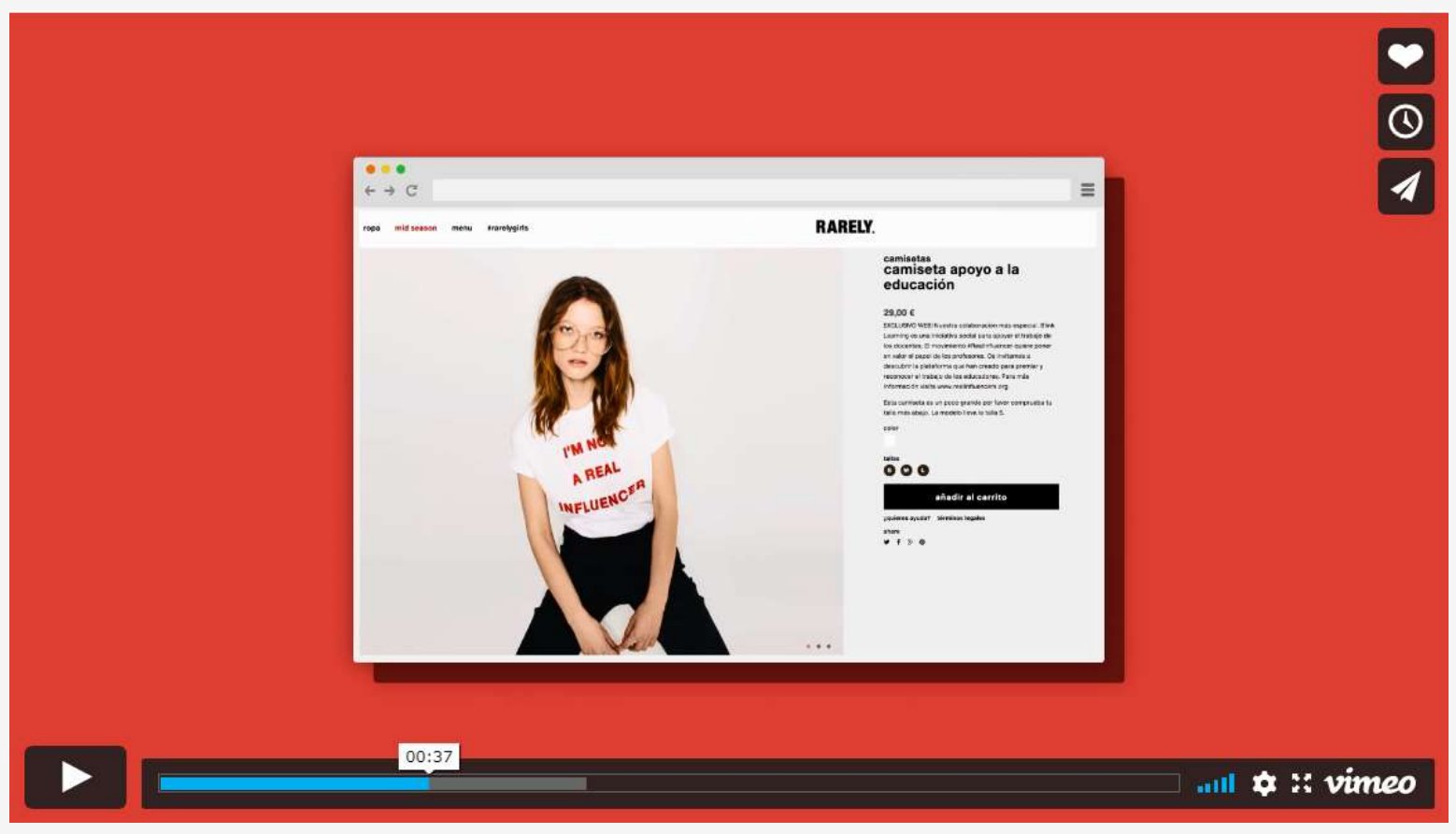




\section{Descripción:}

"Nuestro Reto es concienciar a la gente de la importancia de los profesores en la vida de las personas, sin ningún presupuesto creamos un concepto y un videoconcepto de "verdaderosinfluencers" que se volvió viral.

Millones en medios ganados, apariciones orgánicas en $t v$, periódicos y un polémico debate que sigue en marcha. Nuestra estrategia es generar debate sobre las influencias que reciben los niños y adolescentes a lo largo de su educación.

Solo un simple objeto para conseguir nuestro objetivo:

Nuestra camiseta "no soy un verdadero influencer", diseñada por rarely y disponible en tiendas online."

Fuente: Elena García, https://www.elenagarciamenendez.com/1 


\title{
FICHA TÉCNICA
}

\author{
-Agencia: Dommo \\ -Anunciante: Blink Learning \\ - Campaña: Real influencers \\ - Contacto cliente: Javier González/Gonzalo Baranda \\ - Head of strategy: Agustín Vivancos \\ -Planner estratégico: Sergio García \\ -Equipo creativo: \\ - Directores creativos: Elena García y Pablo Barrionuevo \\ -Directora de arte: Jana Royo \\ -Redactora: Lara Boto \\ -Director de cuentas: Paloma Cencerrado \\ -Productora: Igloo \\ -Medios: Online \\ -Título: Real Influencers
}


PREMIOS campaña

2016 GOLD. EFI FESTIVAL.

StartUps communication category award

"Realinfluencers".

Client: Blink Learning

Fuente: https://www.elenagarciamenendez.com/ 


\section{Planificación estratégica}




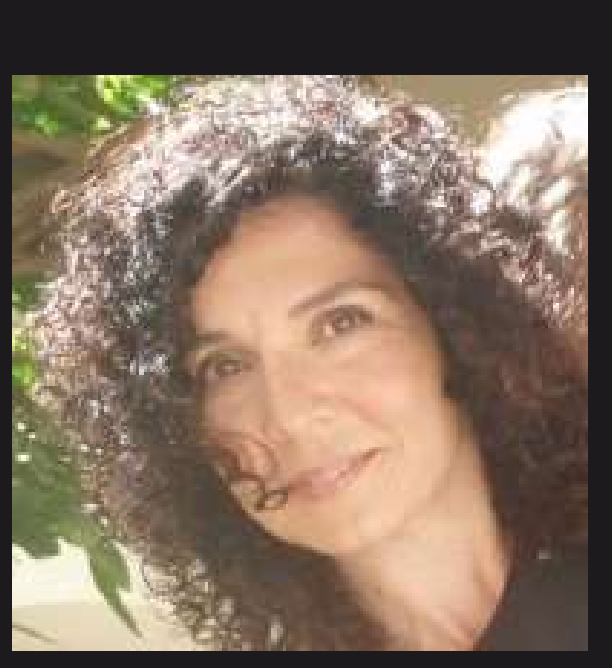

Lucía de la Vega

Directora Ejecutiva y Planner Gettingbetter 


\section{Trabajo}

Puestos destacados

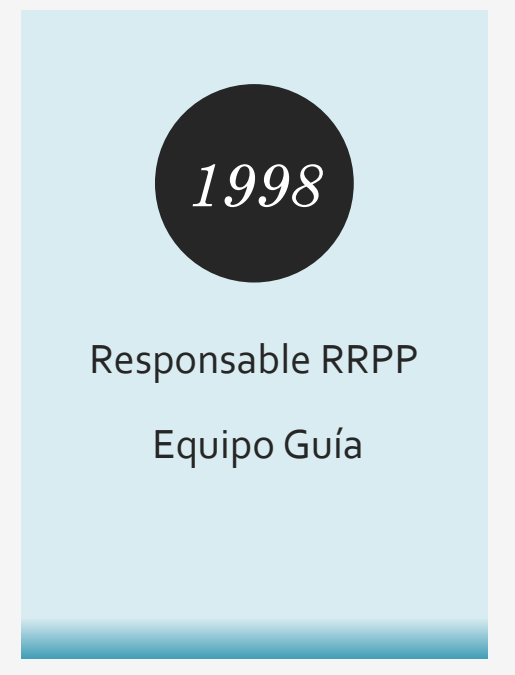

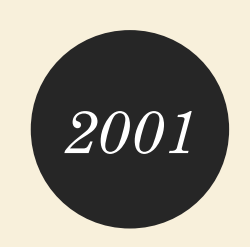

Directora Estratégica y

Planner

Imaginarte

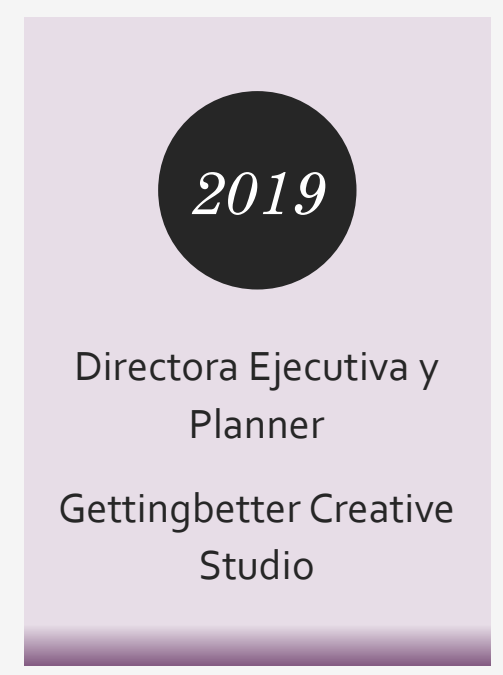




\section{Campañas destacadas}

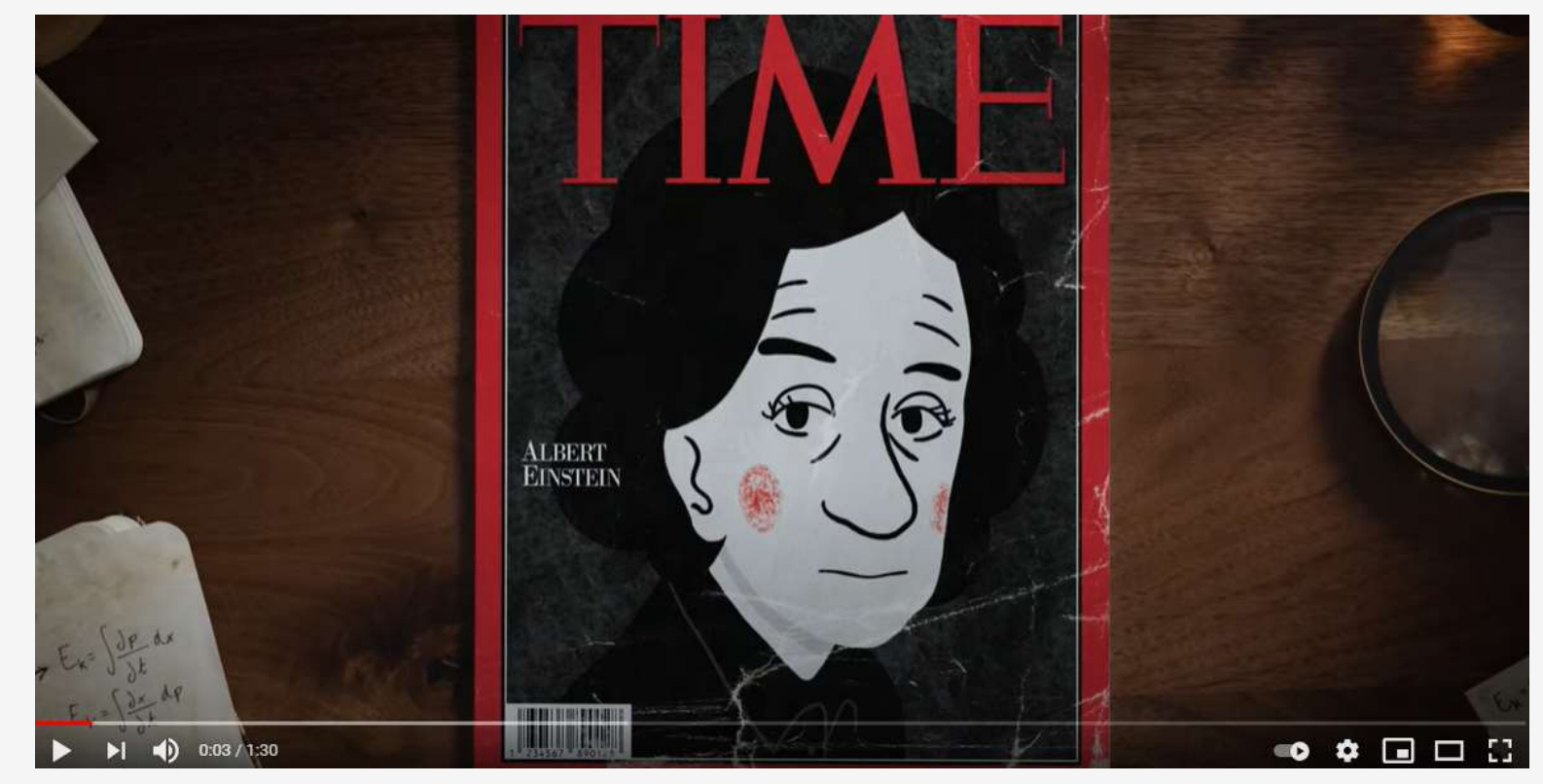

"\#NO MORE MATILDAS"

"¿ Sabes lo que es el Efecto Matilda?"
"¿Qué habría pasado si Einstein, Schrödinger o Fleming hubieran nacido mujer?"

https://www.youtube.com/watch?v=bpVtHBFepDs 


\section{Descripción:}

En la actualidad las mujeres representan el $28 \%$ del alumnado en carreras científicas según la Unesco. AMIT La Asociación de Mujeres Investigadoras y Tecnólogas quería alertar sobre esta importante cifra. Para explicar la baja presencia femenina, Gettingbetter ha lanzado la campaña \#No More Matildas: movimiento para recuperar referentes e inspirar a las científicas del futuro. En la campaña para devolver a las científicas el lugar que les corresponde se empezó por los libros de texto y se creó una colección de cuentos ilustrados de libre descarga para el aula, que narraba las complicadas biografías de Einstein, Fleming o Schrödinger en caso de haber nacido mujeres y se diseñó un anexo con el que se podía hackear los libros de texto de quinto de primaria para reivindicar a las Matildas ausentes.

\section{Fuente:http://www.gettingbetter.es/portfolio/no-more-matildas/}




\section{Ficha técnica:}

Contacto con el cliente: Lucía de la Vega

Planificación Estratégica: Juan Morales, Lucía de la Vega

Dirección General Creativa: Noël Lang

Dirección creativa: Juan Morales, Pablo Mayoral

Dirección de Arte: Rodrigo García, Fernando Beresaluze

Ilustraciones: Rodrigo García

Redacción y guion: Noël Lang

Equipo diseño: Nico Wölfl, Laura Vasallo

Equipo creativo: Rubén Gandía, José Guerrero

Directora de cuentas: Lucía de la Vega

Ejecutiva de cuentas: Ángeles Gómez

PR: Palmira Márquez, Miguel Ayanz

Realizador: Miguel Esteve

Animación: Pablo Morales

Locución: Susana García

Sonido: Rubén Climent

Desarrollo Web: Gilbert Olcina

Agencia: Gettingbetter 


\section{Sobre la campaña:}

Carmen Fenoll, presidenta de Asociación de Mujeres Investigadoras y Tecnólogas:"Si los mejores empleos y las mayores contribuciones al desarrollo tecnológico, humano y social van a estar ligados a la ciencia, tendremos que hacer algo más para que las científicas no sigan infrarrepresentadas y para que el efecto Matilda pase a ser algo del pasado".

Fuente: https://www.eldiario.es/sociedad/efecto-matilda-espana_1_7203019.html

Según Carmen Calvo, vicepresidenta del Gobierno durante la presentación de la campaña en el Parlamento Europeo en España: "La invisibilidad de las mujeres investigadoras hace que las niñas no tengan referentes. Las mujeres estamos cansadas de ser pioneras constantemente, ser pioneras nos debilita, formar parte de una genealogía nos ayuda a ser más fuerte a cada paso que damos".

Fuente:https://www.eleconomista.es/ecoaula/noticias/11038430/02/21/Calvo-reivindica-el-papel-de-la-mujer-en-la-cienciaEstamos-cansadas-de-serpioneras-Ser-pioneras-nos-debilita.html 


\section{Manifiesto \# No More Matildas:}

"...que las niñas y las adolescentes sepan que antes que ellas hubo mujeres que hicieron avanzar la ciencia" concluyendo que "el talento no tiene género y prescindir del que podrán desarrollar las niñas y adolescentes que no eligen una carrera científica por falta de espejos en los que verse reflejadas es una herencia cultural que no podemos seguir permitiéndonos".. https://aquimediosdecomunicacion.com/2021/02/12/exposicion-no-more-matildas/

\section{MANIFIESTO \#NOMOREMATILDAS}

CREEMOS QUE LA BAJA PRESENCIA DE MUJERES EN LAS

AULAS DE CARRERAS STEM SE DEBE EN PARTE A LA FALTA

DE REFERENTES QUE FOMENTEN LA VOCACIÓN

CIENTÍFICA EN LAS NIÑAS Y EN LAS ADOLESCENTES.

\section{MANIFIESTO \#NOMOREMATILDAS}

NOS PARECE POCO INTELIGENTE UTILIZAR ÚNICAMENTE LA MITAD DE LOS CEREBROS QUE TENEMOS A NUESTRA DISPOSICIÓN PARA HACER FRENTE A LOS RETOS QUE PLANTEA EL FUTURO.

\section{MANIFIESTO \#NOMOREMATILDAS}

EL TALENTO NO TIENE GÉNERO Y PRESCINDIR DEL OUE PODRÍAN DESARROLLAR LAS NIÑAS Y ADOLESCENTES QUE NO ELIGEN UNA CARRERA CIENTIFICA POR FALTA DE ESPEJOS EN LOS QUE VERSE REFLEJADAS ES UNA HERENCIA CULTURAL OUE NO PODEMOS SEGUIR PERMITIÉNDONOS.

\section{MANIFIESTO \#NOMOREMATILDAS}

BUSCAMOS QUE LAS NINAS Y LAS ADOLESCENTES SEPAN QUE ANTES QUE ELLAS HUBO MUJERES (Y MUCHAS) QUE HICIERON AVANZAR LA CIENCIA. 


\section{REPERCURSIÓN MEDIÁTICA 2021 (FENÓMENO SOCIAL)}

https://www.eldiario.es/castilla-la-mancha/nomorematildas-campana-visibilizar-cientificas-convertido-fenomeno-social_1_7216098.html https://www.lasexta.com/noticias/ciencia-tecnologia/einstein-hubiera-sido-mujer-sabrias-quien-fue-more-matildas-campana-que-reivindica-papelmujer-ciencia_202102086021410ac7101fooo1538g6a.html

https://www.rtve.es/noticias/20210113/no-more-matildas-campana-acabar-discriminacion-mujeres-ciencia/2065786.shtml

https://elpais.com/sociedad/2021-02-08/no-mas-matildas-la-campana-que-reivindica-el-trabajo-de-las-mujeres-cientificas.html

https://www.lamoncloa.gob.es/serviciosdeprensa/notasprensa/mpresidencia14/Paginas/2021/080221-matildas.aspx

https://www.eldiario.es/sociedad/efecto-matilda-espana_1_7203019.html

https://www.ecoavant.com/ciencia/nomorematildas-campana-senala-machismo-mundo-cientifico 6094_102.html

https://www.elperiodico.com/es/sociedad/20210208/carmen-calvo-apoya-campana-nomorematildas-11506437

https://www.larazon.es/sociedad/20210113/6tcvxy5lu5dthe7v6bgkb2hh6m.html

https://www.cmmedia.es/noticias/castilla-la-mancha/no-more-matildas-la-campana-para-visibilizar-las-desigualdades-de-la-mujer-en-la-ciencia/

https://www.ibecbarcelona.eu/wp-content/uploads/2021/01/AliciaCasals.pdf 


\section{Campañas destacadas}

"Mujeres \#comoninguna"

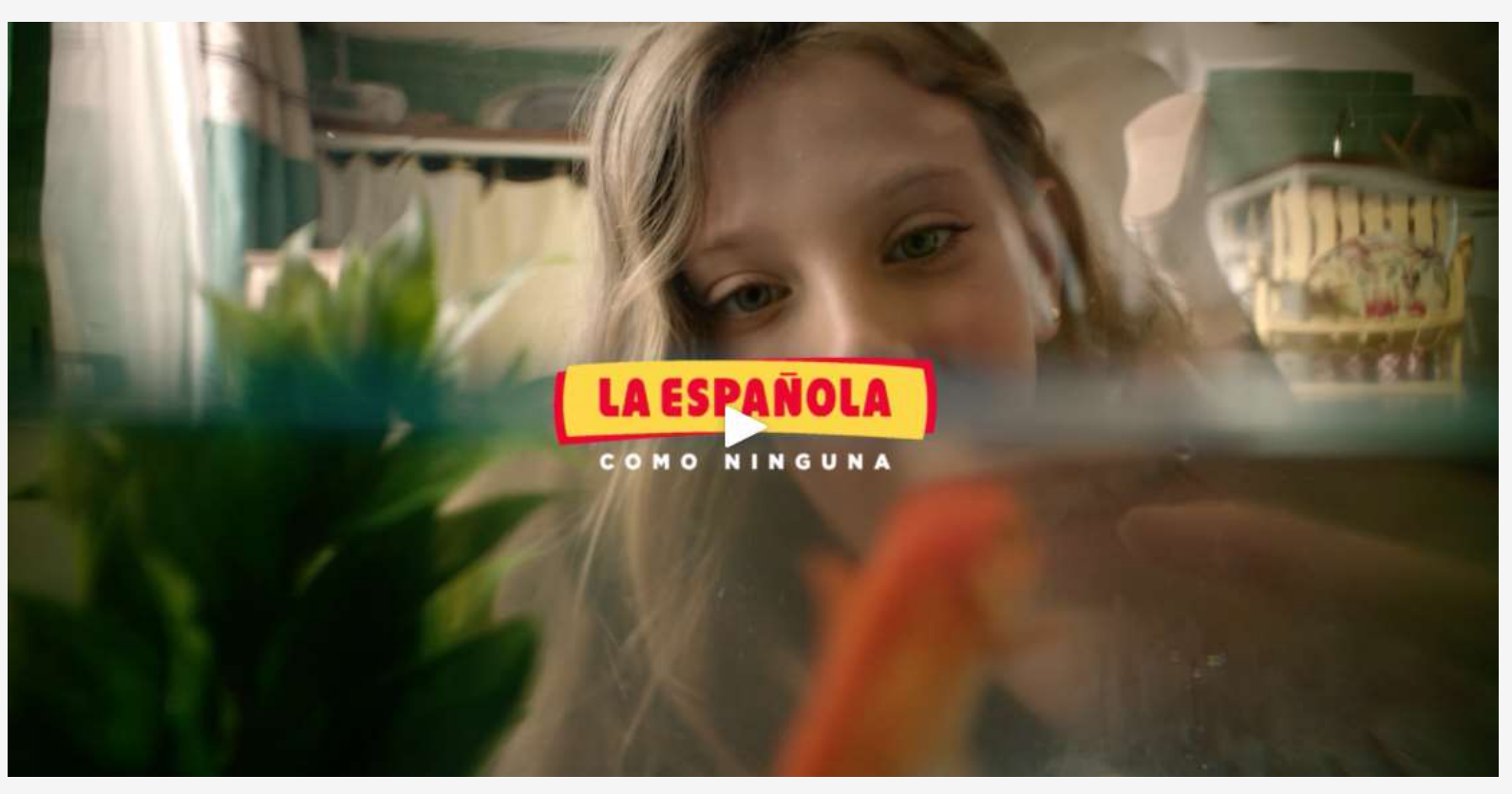

"Es la Española una aceituna como ninguna" 


\section{Situación de partida}

La Española siempre ha sido una marca pionera en el campo de la comunicación. Fue una de las primeras en hacerse un hueco en el imaginario colectivo de la gente: su característico jingle lleva décadas formando parte de la vida de diferentes generaciones. Nuestra labor pasaba por recoger ese testigo, renovando y reforzando el recuerdo de quienes valoran La Española como toda una lovemark.

\section{La Idea}

Reinterpretar el claim asociado a la marca "Es la Española una aceituna como ninguna" para desarrollar un homenaje colectivo a las mujeres "Como Ninguna". Plantear la aportación de La Española al "Female Empowerment" desde una perspectiva cercana, popular y participativa, centrada en esas mujeres únicas que jamás llaman la atención de los medios, pero que todos tenemos en nuestra vida.

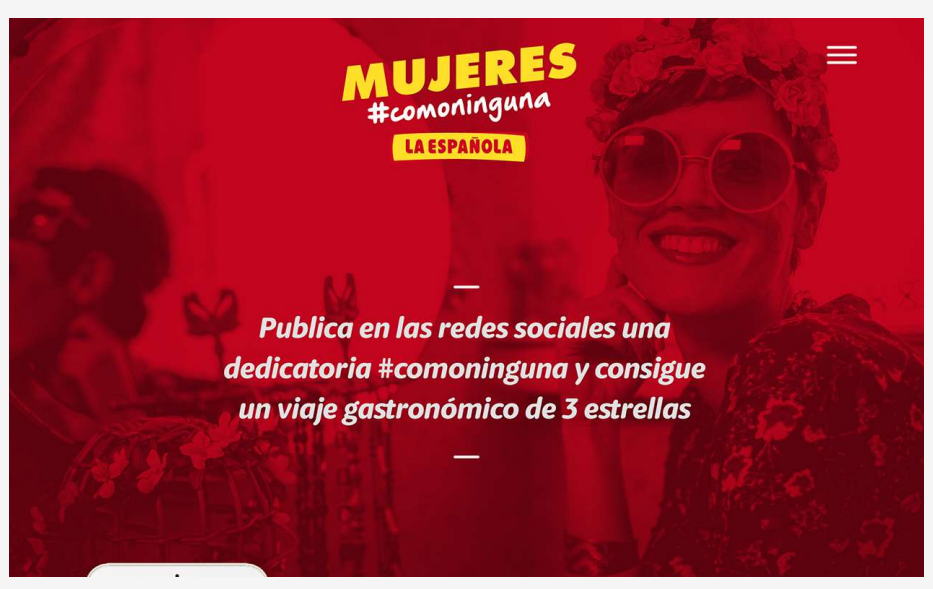

Sigue a @EsComoninguna y comparte una foto dedicada a esa mujer única a la que admiras. No olvides incluir el \#comoninguna. Los más originales y emotivos tendrán un premio con Estrella Michelin y además todas las publicaciones entran en un sorteo semanal.

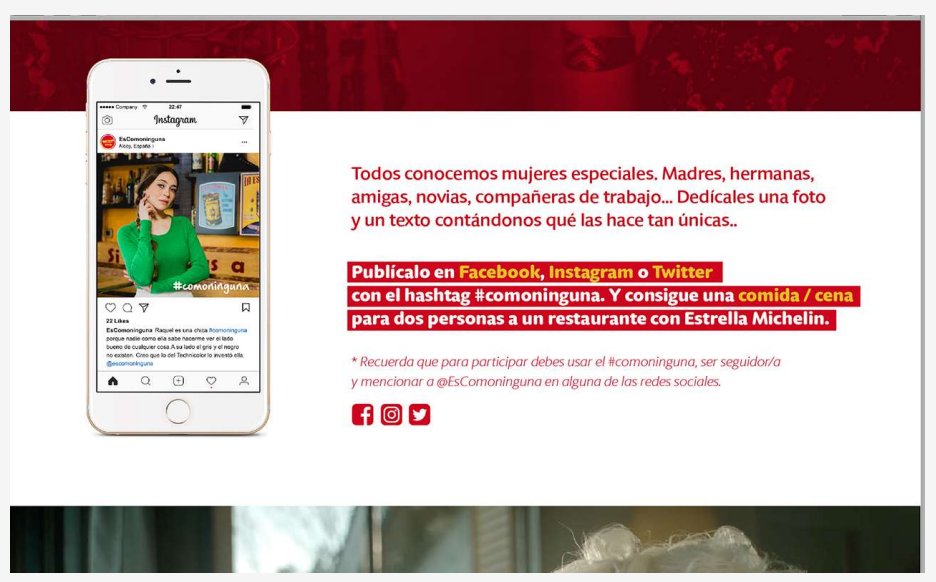




\title{
Ficha técnica:
}

\author{
Anunciante: La Española \\ Marca: La Española \\ Producto: Alimentación \\ Contacto del cliente: Óscar Pérez \\ Agencia: Imaginarte \\ Director creativo: Antonio Piñero \\ Planner y coordinación: Lucía de la Vega \\ Redactor: Nacho Macho \\ Director de arte: Carlos Bretones \\ Producer: Verónica Romero \\ Supervisor: Miki Tono \\ Fotógrafo: Alejandro Loen \\ Productora: MR. Factory \\ Realizador: Miguel Martí \\ Director de Fotografía: Pablo Bürmann \\ Productor: Juan Luis Bravo \\ Postproducción: El Colorado \\ Música: Fran Soto \\ Pieza (difusión): online \\ Título: '\#comoninguna \\ País: España \\ Año: 2018
}




\section{Sobre la campaña:}

Según Sergio Alberola, Director General de la marca: "Desarrollar este homenaje ha sido, en si mismo, un proceso didáctico y enormemente enriquecedor. Hemos aprendido algo en cada etapa: desde el rodaje de la pieza audiovisual a la elección de los propios premios o la misma colaboración con las mujeres que han acabado componiendo el Jurado. Hoy, sabemos más que nunca lo que significa ser \#ComoNinguna".

Según palabras de Rosa Escandell, empresaria social y jurado, "se trata de una campaña que transmitirá emociones a través de las redes sociales y convertirá en ejemplares a mujeres que aún no conocemos, en lugar de dar protagonismo al consumo".

En opinión de Antonio Piñero, director de la agencia, "Hemos tenido la suerte de desarrollar esta campaña junto a una marca sensible a ese verdadero clamor popular que es el apoyo a la causa femenina. No debemos olvidar que los fenómenos como el Female Empowerment y otros similares son, además de tendencias de futuro evidentes recogidas en diversos informes, una fuente de inspiración y una oportunidad para que todos, marcas y consumidores, reflexionemos sobre el papel que la mujer tiene en la sociedad y en la propia comunicación publicitaria."

Fuente: https://www.extradigital.es/la-espanola-nos-invita-a-homenajear-a-mujeres-como-ninguna/

Fuente: https://www.marketingdirecto.com/creacion/campanas-de-marketing/imaginarte-y-la-espanola-convocan-un-homenaje-a-la-mujer-como-ninguna 


\section{Jurado}

Formaban parte de este jurado la chef con dos estrellas Michelín María Marte; la creativa y directora del Club de las Malas Madres, Laura Baena; la escritora, pintora y dibujante Paula Bonet; la vicerrectora de responsabilidad social, inclusión e igualdad de la Universidad de Alicante, María José Rodríguez; la empresaria social y directora de A Puntadas, Rosa Escandell y la artista visual Yolanda Domínguez.

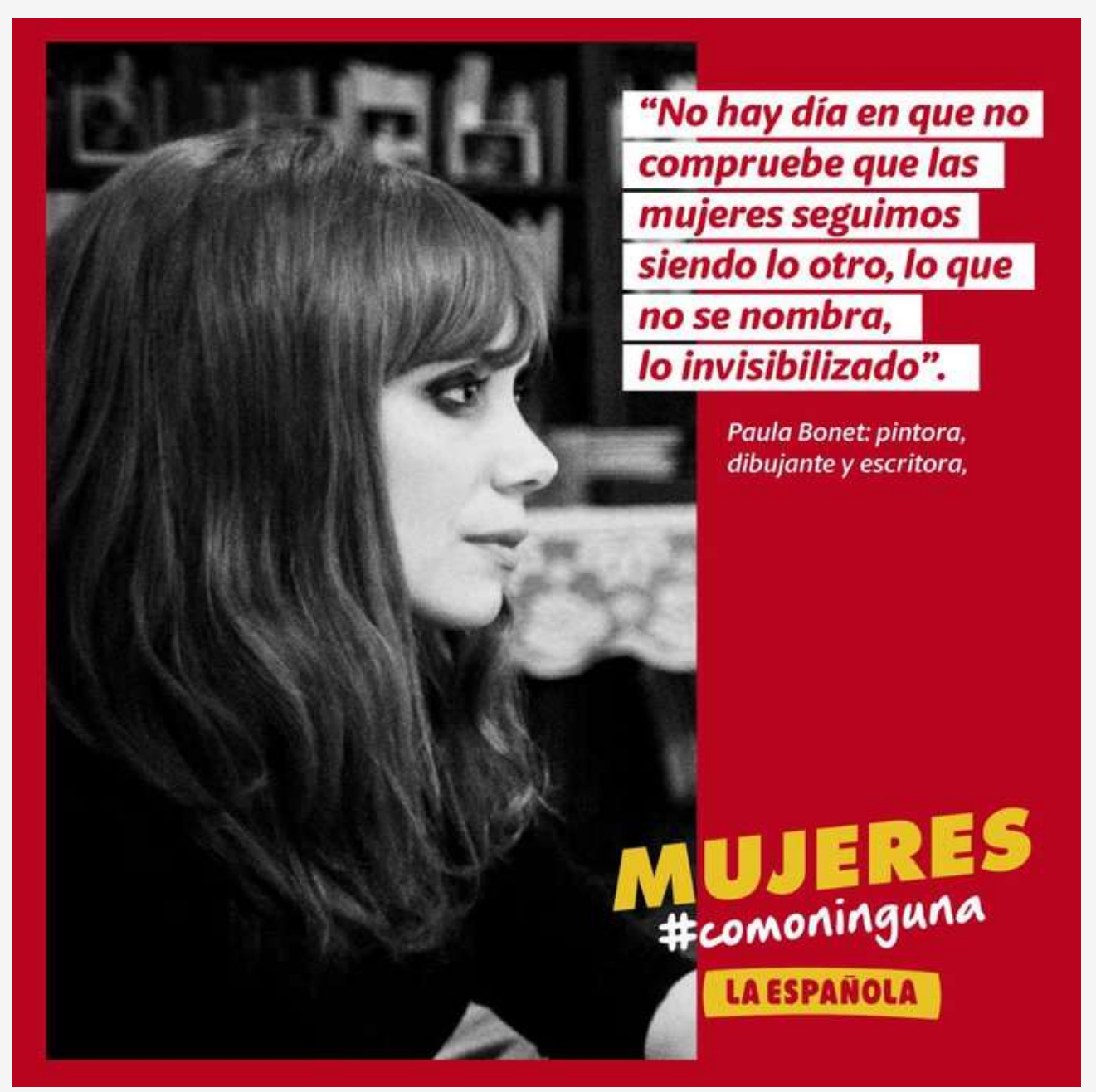




\section{REPERCURSIÓN MEDIÁTICA 2018}

https://www.programapublicidad.com/imaginarte-la-espanola-convocan-homenaje-la-mujer-ninguna/

https://www.elpublicista.es/videosı/comoninguna-imaginarte-para-espanola/print/

https://www.marketingdirecto.com/creacion/campanas-de-marketing/imaginarte-y-la-espanola-convocan-un-homenaje-a-la-mujer-como-ninguna https://economia3.com/2018/05/31/146068-la-espanola-como-ninguna/

https://www.aramultimedia.com/comoninguna-la-espaanola-e-imaginarte-llancen-una-campanya-per-a-visibilitzar-a-les-dones

https://www.programapublicidad.com/imaginarte-la-espanola-convocan-homenaje-la-mujer-ninguna/

https://www.reasonwhy.es/actualidad/campanas/la-espanola-rinde-homenaje-la-mujer-como-ninguna-2018-05-04

https://www.extradigital.es/la-espanola-nos-invita-a-homenajear-a-mujeres-como-ninguna/ 


\section{Realizadoras}




\section{Isabel Coixet}

\section{Realizadora publicitaria}

Académica de honor de la Academia de Publicidad 


\section{Premios}

Trayectoria
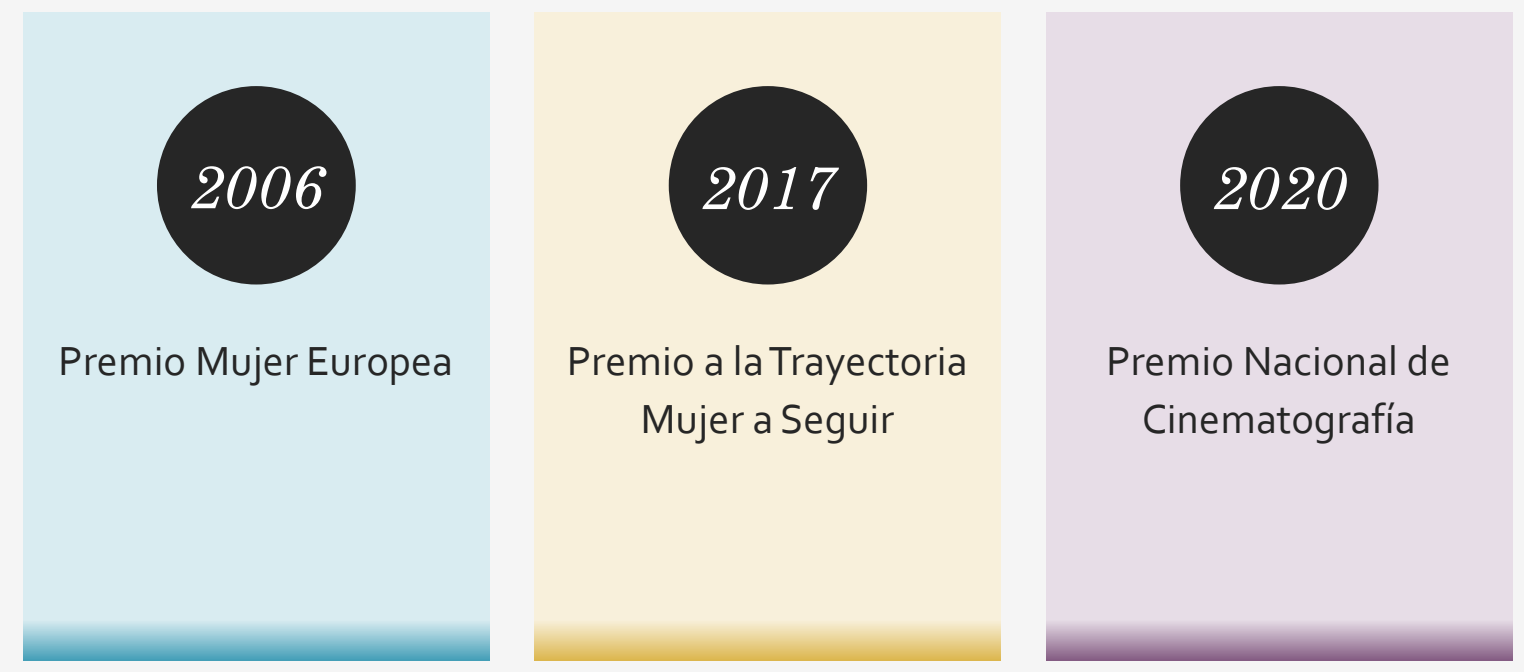

91 


\section{Trabajos destacados}

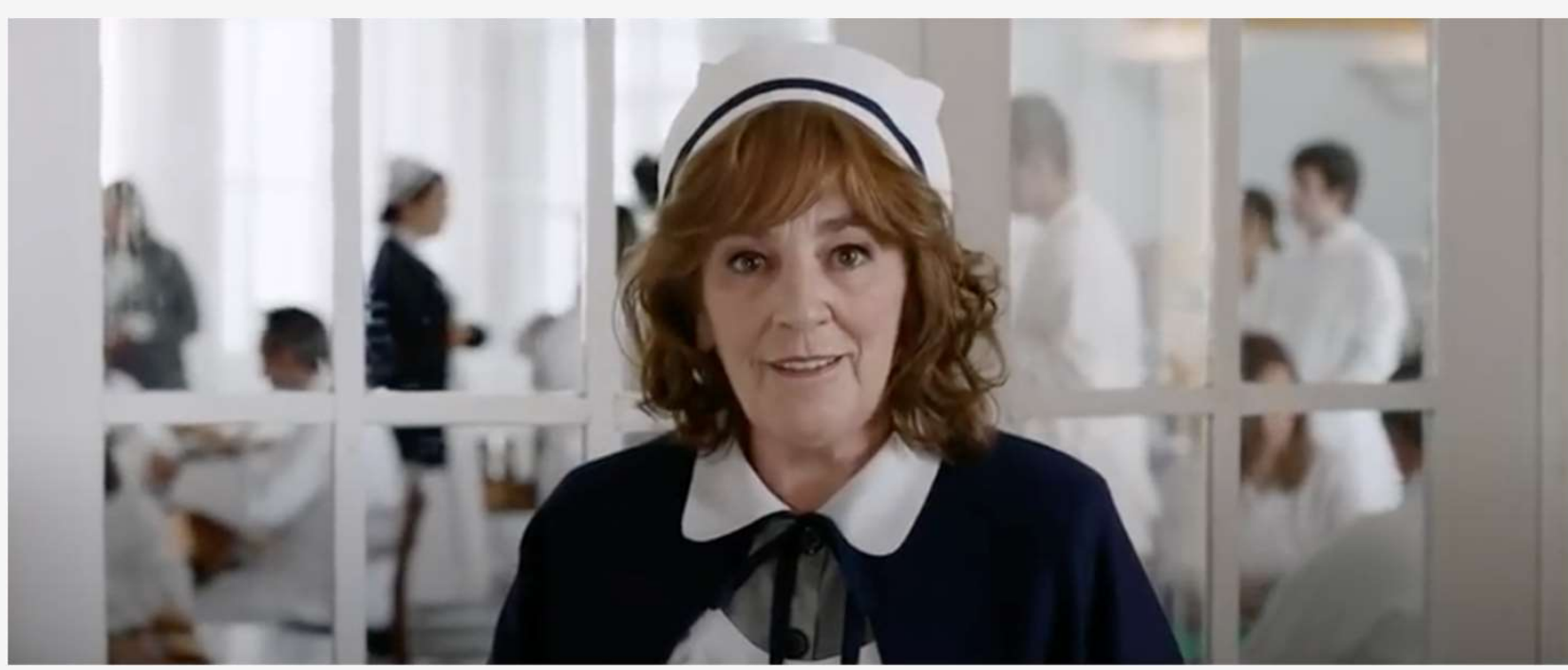

Amodio de Campofrío

Anuncio de Campofrío para Navidades de 2017 de la agencia McCann realizado por Isabel Coixet

https://youtu.be/N73oCoOFsfl 


\section{Descripción:}

Un trabajo de McCann Worldgroup cuya ejecución principal es un anuncio para televisión que se titula Amodio y que se engloba dentro del concepto de marca Que nada ni nadie nos quite nuestra manera de disfrutar de la vida.

Con un tono positivo, la campaña invita a la convivencia del respeto y a ver el futuro y el presente con optimismo, destacando valores como la tolerancia, la alegría, el respeto o la solidaridad. La cineasta Isabel Coixet ha sido la encargada de dirigir el anuncio. Numerosas caras populares aparecen en el anuncio, como la actriz Carmen Maura, el presentador y publicista Risto Mejide, el cantautor Joan Manuel Serrat, el juez Baltasar Garzón, la actriz Candela Peña, la escritora Irene Villa, la deportista Ona Carbonell, el humorista David Broncano, la youtuber Estíbaliz Quesada o el presentador Dani Mateo. 
Agencia: McCann Worldgroup

Anunciante: Campofrío

Producto: Charcutería

Marca: Campofrío

Ficha técnica:

Sector: Alimentación

Contacto del cliente: Jaime Lobera, Aurélie

Morin, Paulo Serra, Pilar Larrea, Javier Portillo,

Laura Álvarez, Daniel Gómez, José María Arias-

Camisón y Silvia Álvarez

Equipo creativo: Mónica Moro, Raquel Martínez y

Jon Lavin

Equipo de cuentas: Jesús Martínez Soria, Javier

Gonzalo Gorostiza y Maria Vázquez

Planificación estratégica: Nicolás Horovitz (BMC)

y Juanma Ramírez (McCann)

Producción audiovisual: Guzmán Molín-Pradel

(Los Producers) y Mercedes García-Parreño

Agencia de medios: OMD

Productora: La Joya

Realizadora: Isabel Coixet

Director de fotografía: Jean-Claude Larrieu

Equipo La Joya: Maripaz Lara, Federico Sánchez-

Seco, Sara Hernández, Guillermo Arce, Sara

Muñoz, Esther Cardenal, Miguel Sanz-Esteso

Estudio de postproducción y sonido: Wework

Música: OEO

Música ambiental: La Nevera

Supervisión musical: Como Yo Te Amo (M.A.

Álvarez-Beigbeder / P. Casas), Universal Music

Publishing / Master, Rocio Jurado, Sony Music

Spain

Comunicación y RRPP: Llorente y Cuenca

Pieza: Spot TV 3'45"

Título: 'Amodio' 


\section{PREMIOS}

Bronce en la Categoría Construcción de una Marca en Eficacia (2018)

Sol de Plata en la categoría Film (2018)

Plata en Campañas Integradas FIAP (2018)

\section{Bronce en Ideas CDEC (2018)}

\section{Gran Tocado (2018)}

Oro en Categoría Best Spot en el festival BestAwards (2018) 


\section{Trabajos destacados}

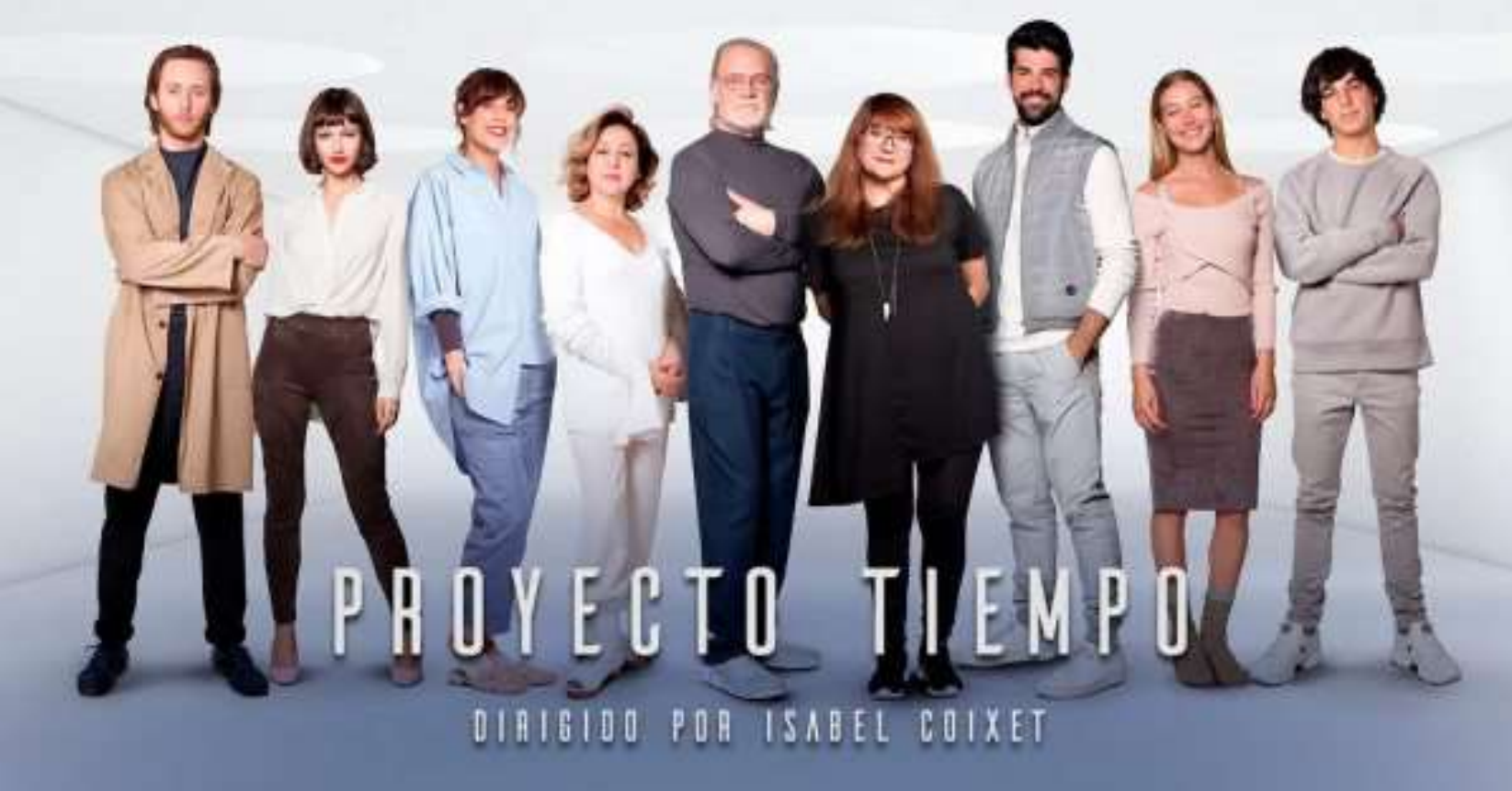

Proyecto Tiempo de Gas Natural Fenosa

Contenido de marca para divulgar el ahorro y la eficiencia energética al gran público a través del séptimo arte.

https://youtu.be/flsfozjqvoo 


\section{Sobre la campaña:}

Es la historia de Pablo Andrade, un prometedor científico sin trabajo, obsesionado en hallar una cura para el cerebro de su madre, Alma, que acaba de sufrir un ictus. La película es una historia futurista de ciencia ficción que comienza en 2019 y acaba en 2069 . Se trata de una producción dividida en cuatro partes entrelazadas y conclusivas en sí mismas, en la que el público pudo personalizar algunos detalles clave de los rodajes.
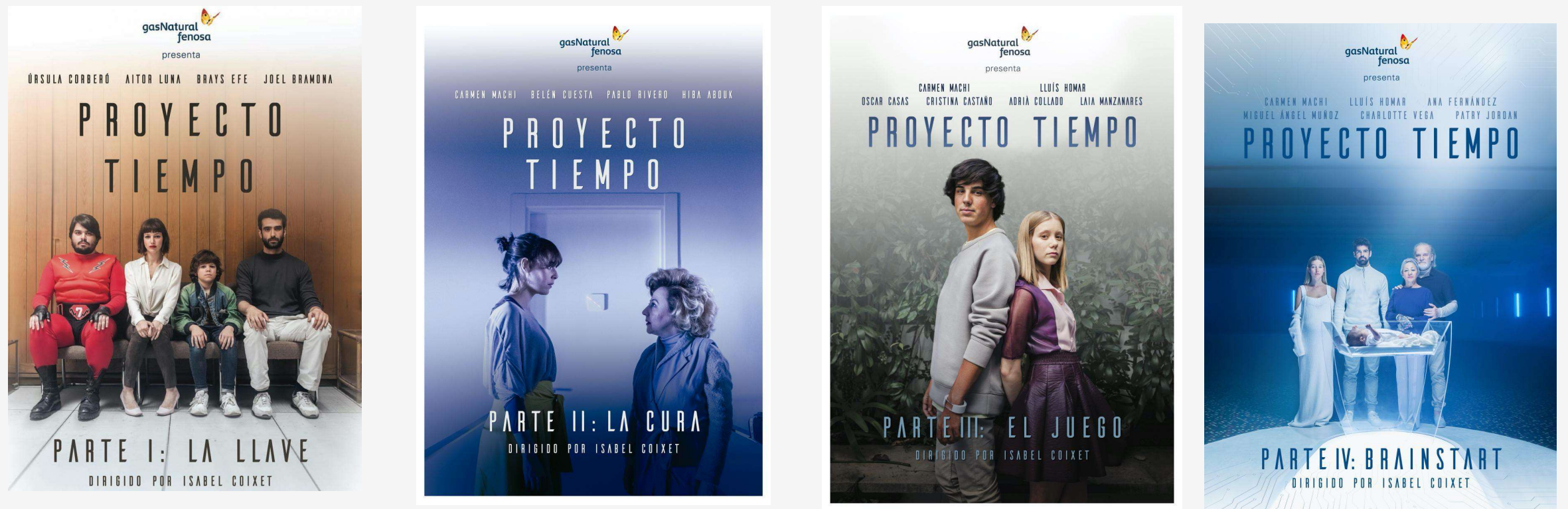

https://www.marketingnews.es/marcas/noticia/1113967054305/gas-natural-fenosa-presento-pelicula-dirigida-isabel-coixet-festival-de-malaga.1.html 


\title{
Proyecto Tiempo
}

Ficha Críticas [4] Tráilers [1] Imágenes [2]

Ficha técnica:

\author{
Título original Proyecto Tiempo \\ Año 2018 \\ Duración $63 \mathrm{~min}$ \\ Pais EEspaña \\ Dirección Isabel Coixet \\ Guion Pep Bras \\ Música Nico Casa \\ Fotografía Gonzaga Manso \\ Reparto Carmen Machi, Lluís Homar, Úrsula Corberó, Pablo Rivero, Óscar Casas, \\ Miguel Ángel Muñoz, Charlotte Vega, Ana Fernández, Laia Manzanares, \\ Belén Cuesta, Cristina Castaño, Adriá Collado, Hiba Abouk, Aitor Luna, \\ Joel Bramona, Brays Efe, Pol Hermoso \\ Productora Gas Natural Fenosa \\ Género Ciencia ficción. Drama | Película de episodios \\ Grupos Proyecto Tiempo \\ Sinopsis El largometraje Proyecto Tiempo se ubica en el futuro, para reflejar qué es una \\ sociedad evolucionada y concienciada en términos de eficiencia energética, as \\ como las dos caras del progreso tecnológico a medio plazo. En esta sociedad \\ evolucionada, existe un biochip que se implanta en el cerebro de todos los recién \\ nacidos del mundo y que representa la tecnología más innovadora del año 2069. Su \\ protagonista, el científico Pablo Andrade, tiene un sueño obsesivo contaminado por \\ una serie de oscuros secretos familiares que se irán revelando a lo largo de medio
} siglo de existencia. (FILMAFFINITY) 


\section{RECEPCIÓN}

En 2017, el proyecto Cinergía obtuvo más de 39 millones de visualizaciones en televisión e internet, siendo el contenido de marca más visto en Youtube en 2017. Además, se incrementaron el número de conversaciones sobre eficiencia energética rozando el 34\%. 


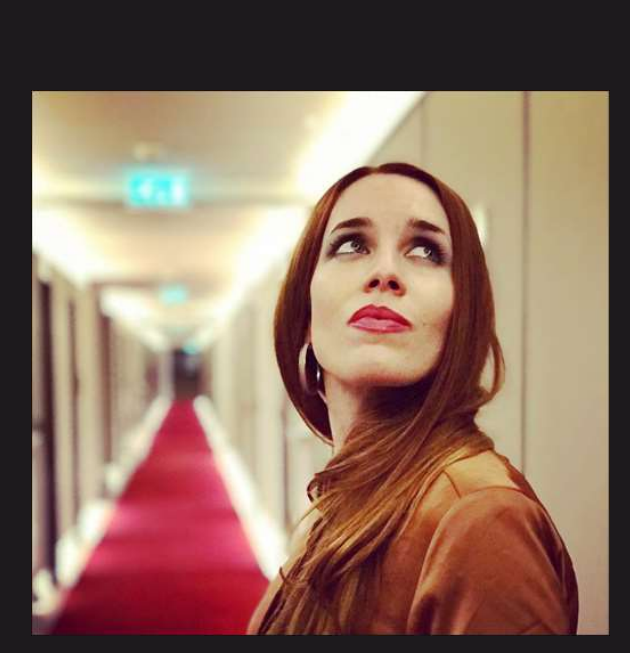

Yolanda Centeno

Realizadora 


\section{Trayectoria}

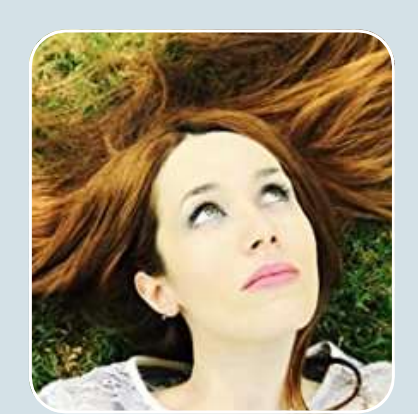

Licenciada en

Publicidad y

Comunicación

Audiovisual.

Master of Fine Arts in

Filmmaking de

la New York

Film Academy.

https://www.yolandacenteno.com/work.html
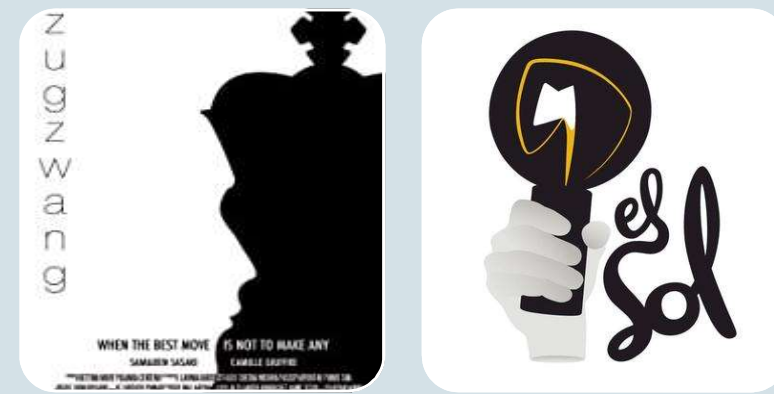

Obtiene un

premio en el

Festival el Sol

con su primer

trabajo como

realizadora

publicitaria.

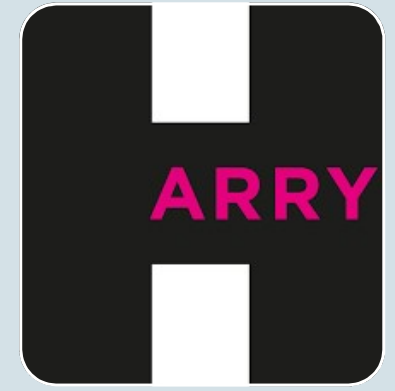

Actualmente

trabaja para la

productora

Harry Rules. 
Todos los anuncios realizados porYolanda Centeno pueden verse en Vimeo o en su web https://www.yolandacenteno.com/

\section{Trabajos}
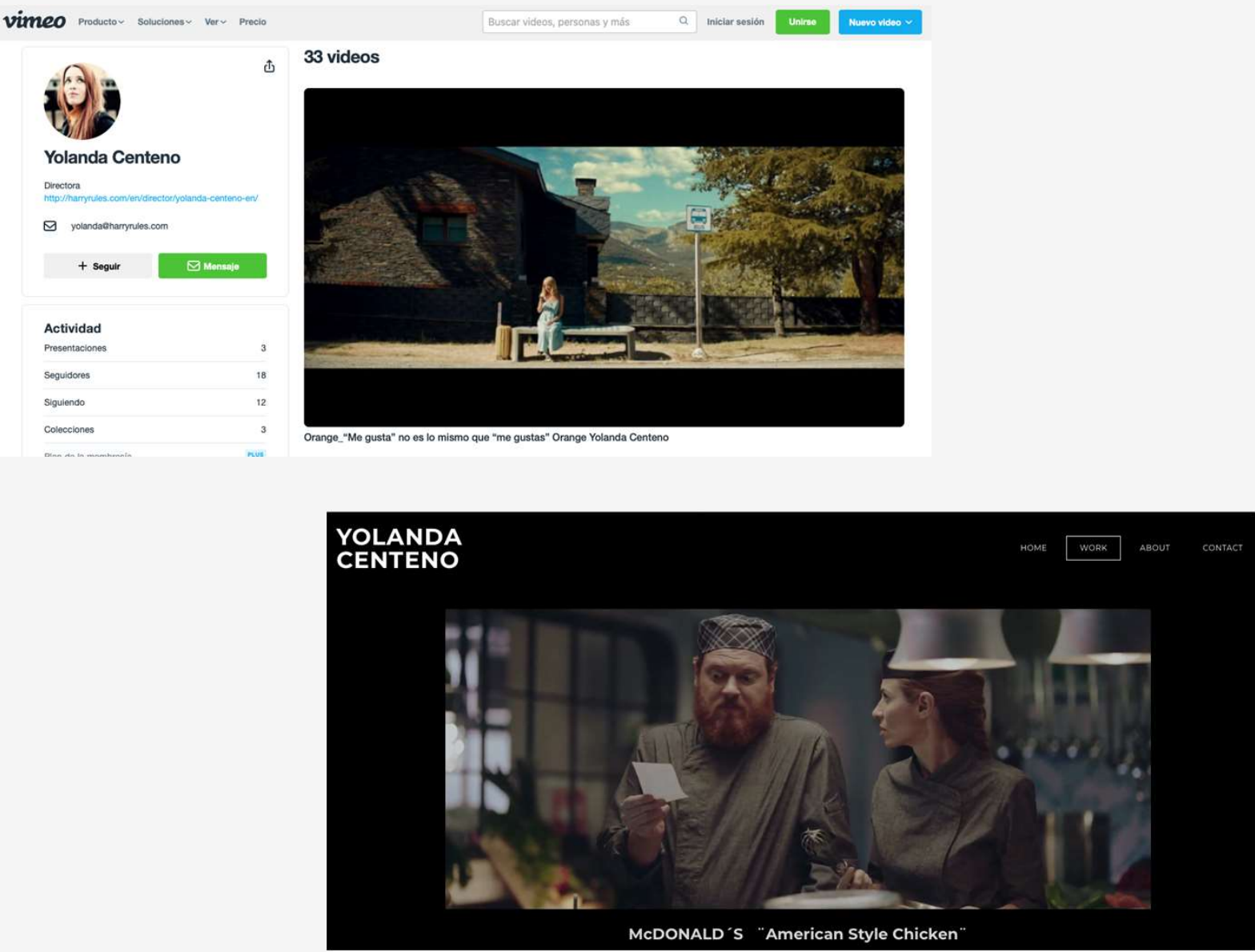
También podemos encontrarlos en la web Harry Rules https://harryrules.com/director/yolanda-centeno

\section{Trabajos}

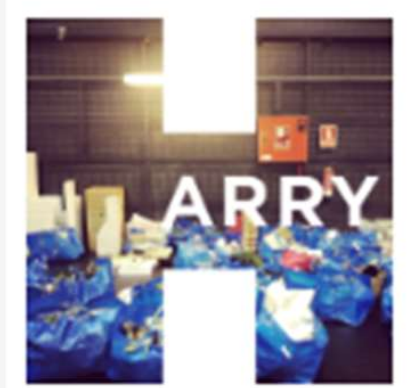

\section{Directores}

Dionisio

Naranjo

victor

Carrey

Yolanda

Centeno

Ayala 
Algunos ejemplos

\section{Trabajos}

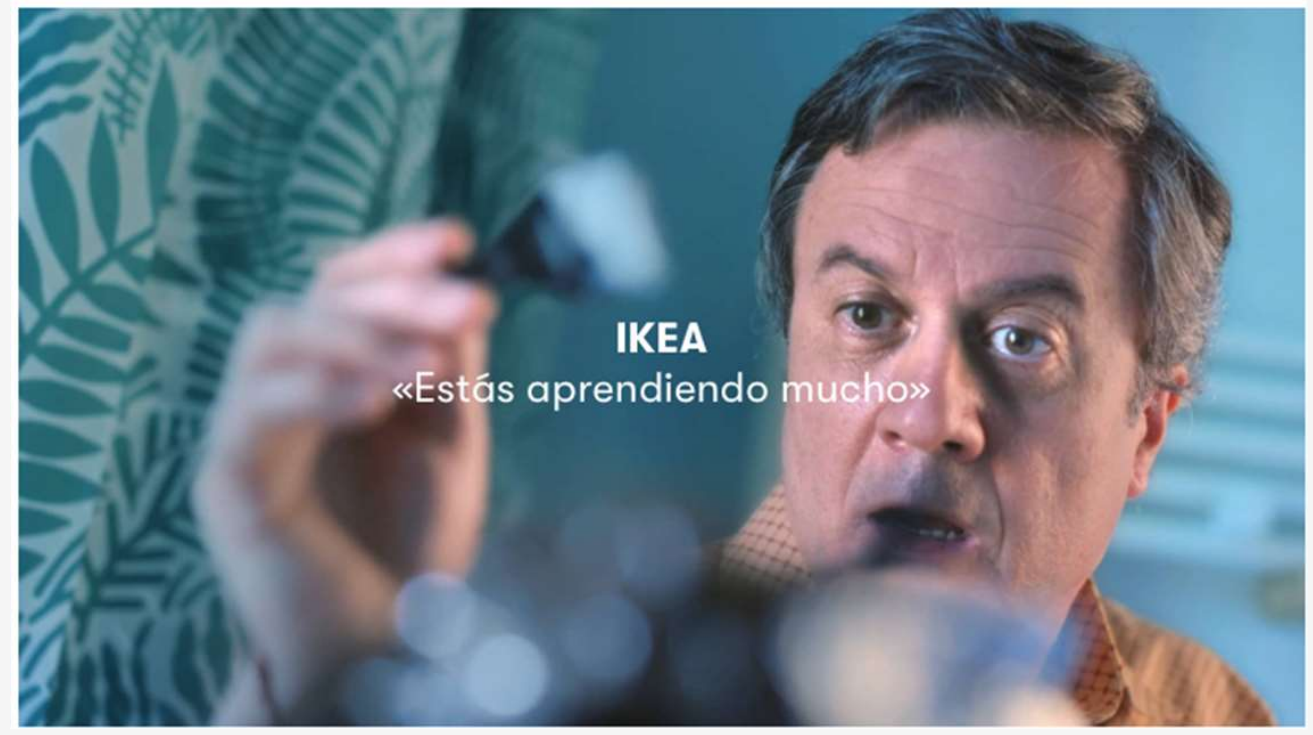

IKEA: «Estás aprendiendo mucho»

$$
\text { McCann }
$$

Contacto Cliente: Laura Durán, Rafael Jiménez, Mar Amador y Manuel Delgado Equipo Creativo: Mónica Moro, Raquel Martinez,

$$
\text { Antonio de Federico, Enrique Moreno, Natalia Campos y }
$$

Gema Cardeña Equipo de cuentas: Javier Pascual, Elena Rodriguez,

Alejandra Sierra y Sonsoles San José Planificación estratégica:

Juan Manuel Ramirez Producción Audiovisual: Paloma Adrien,

Guzmán Molin-Pradel, Vanessa Pizarro y Eduardo Uriarte Directora:

Yolanda Centeno CEO \& Productora Ejecutiva/MD: Tay Sánchez

Productor Ejecutivo: Mario Padilla Producer Junior: Flor Veidez DOP:

Paco Femenia Jefe de Producción: Nick Igea Director de Arte:

Fede Cambero Director de Postproducción y Editor: Néstor Costafredo

Postproducción: Luis Morais 
Algunos ejemplos

\section{Trabajos}

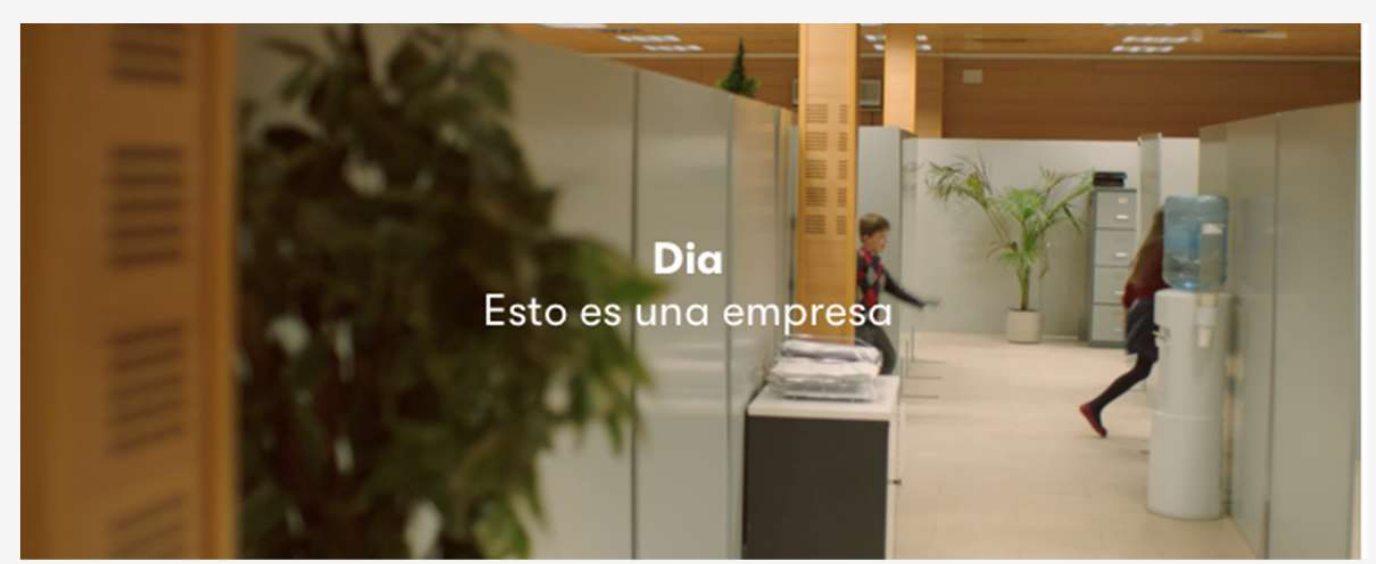

\section{Dia: Esto es una empresa

\author{
Leo Burnett
}

\section{Director Creativo General: Juan Garcia Escudero}

Director Creativo Ejecutivo: Jesús Lada Ejecutivo de Cuentas:

Maria Fernández Producer Agencia: Juanjo Ocio Director: Yolanda Centeno Productora Ejecutiva: Tay Sánchez Productor Ejecutivo: Mario Padilla Jefe de Producción: Nico Mintegui DOP: Paco Femenía Estilista: Ilduara Vandall Director de Arte: Diego Sánchez Postproducción: Serena Locutora: Pilar Pintre Director de Postproducción y Editor:

Néstor Costafreda Música: Audionetwork 
Algunos ejemplos

\section{Trabajos}
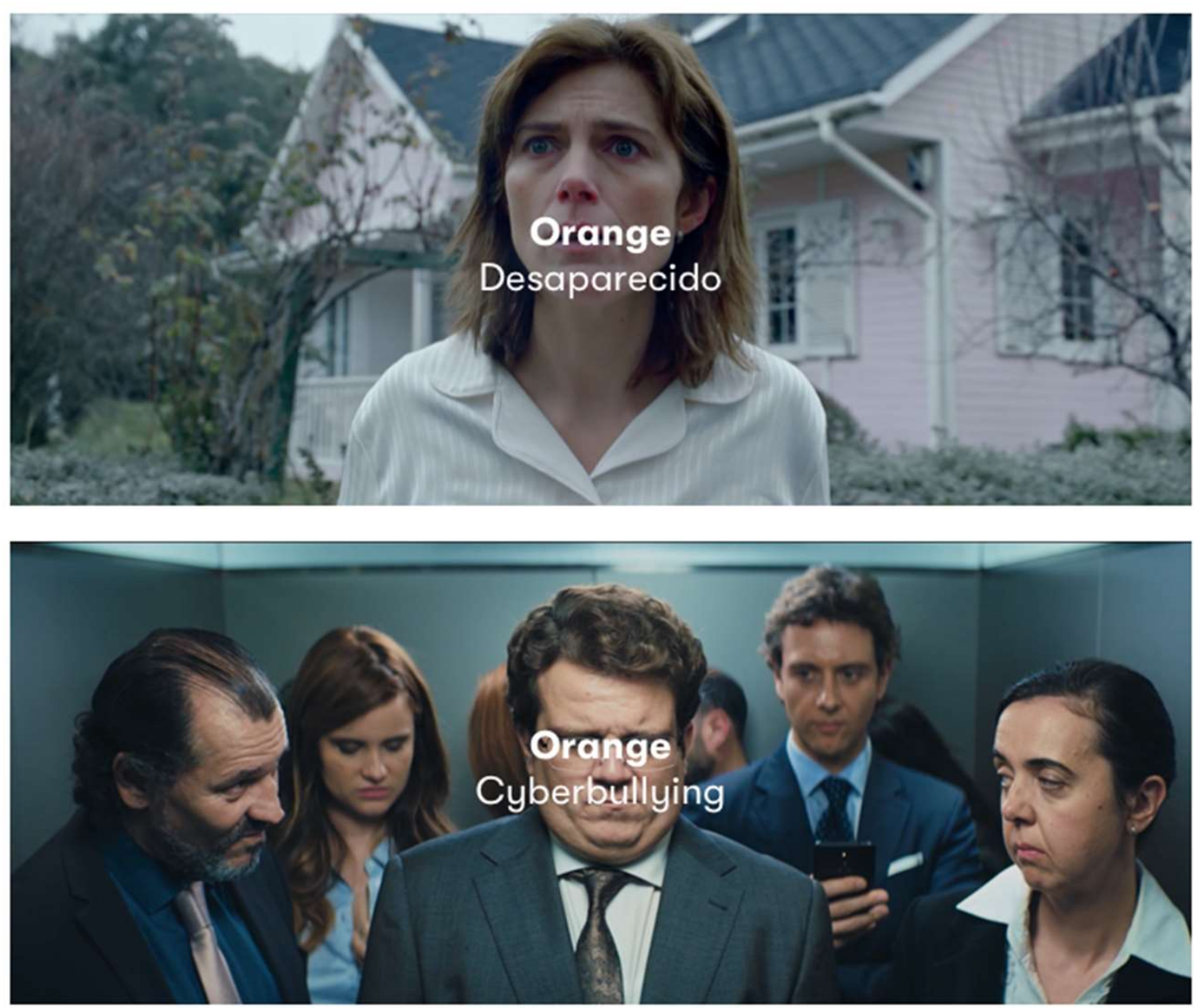
Algunos ejemplos

\section{Trabajos}
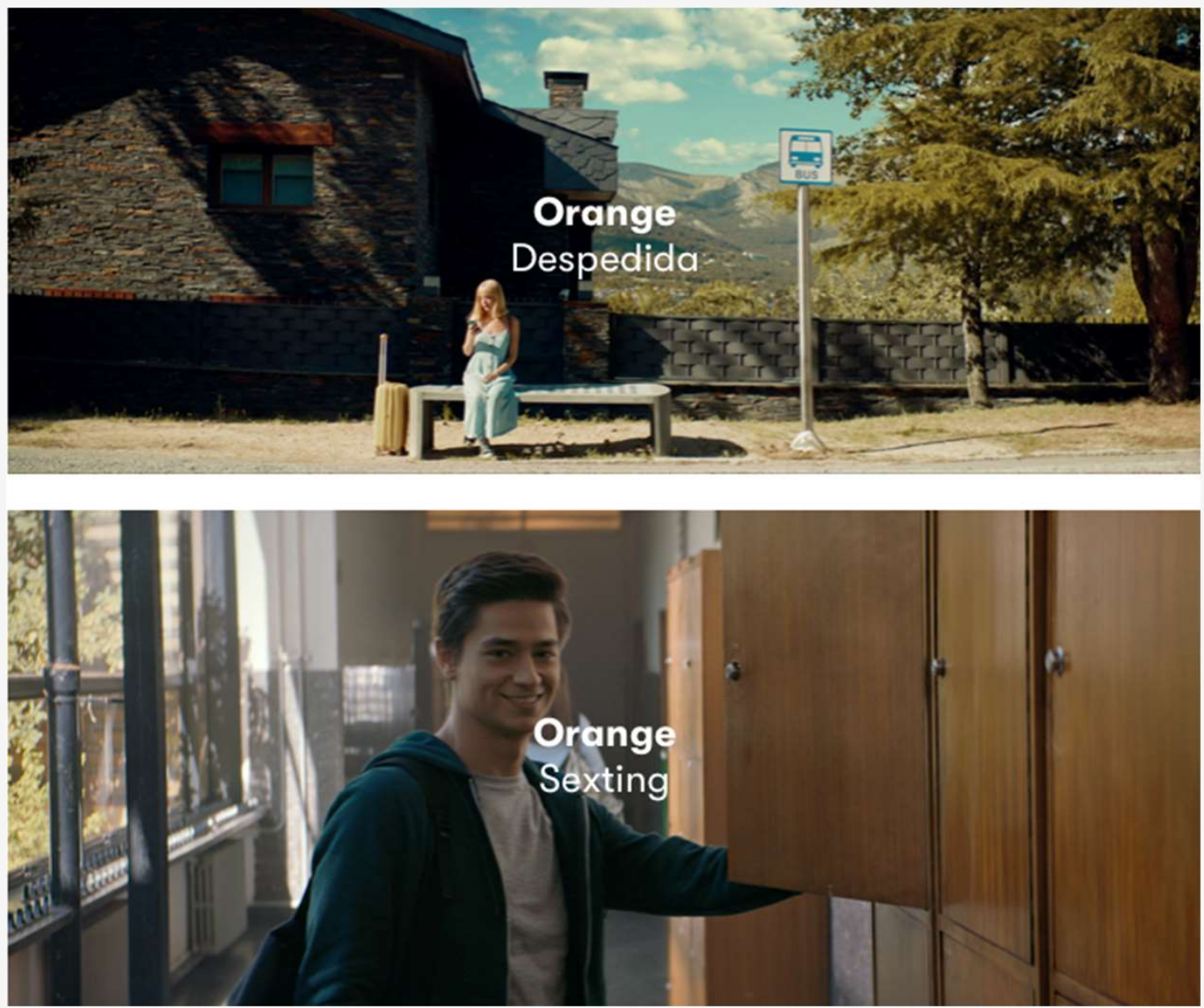
Algunos ejemplos

\section{Trabajos}
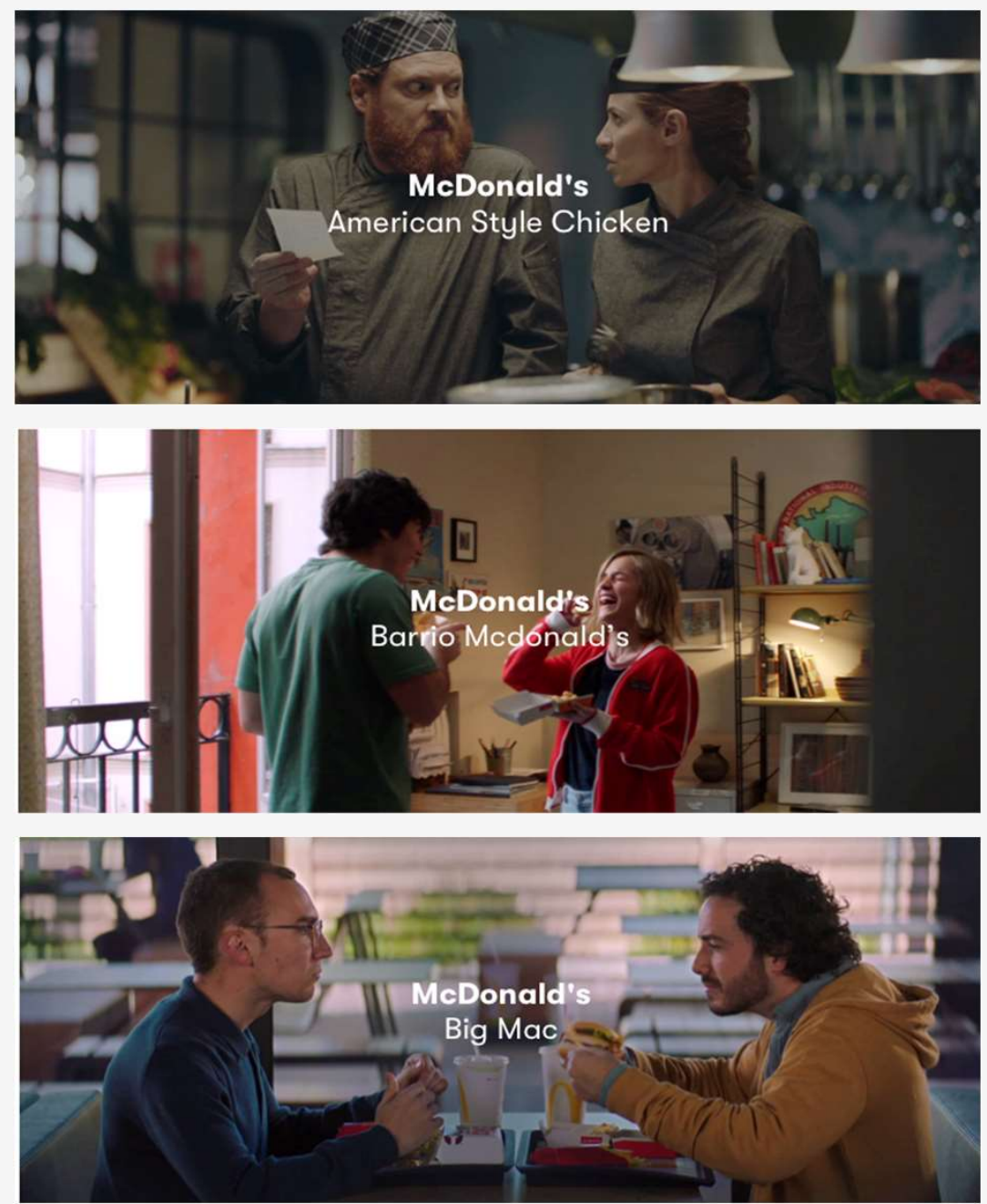


\section{En IMDd figuran algunos de sus premios}

https://www.imdb.com/name/nm5382763/awards?ref =nm awd

\section{Premios}

Accolade Competition 2014

Winner

Short Film
Yolanda Centeno (director)

Action on Film International Film Festival, USA 2 Bilbao Fantasy Film Festival 2014

\begin{tabular}{l|l|}
$\begin{array}{l}\text { Nominee } \\
\text { Action on Film Award }\end{array}$ & $\begin{array}{l}\text { Best Actor - Short } \\
\text { Yolanda Centeno (producer/writer/di }\end{array}$ \\
$\begin{array}{l}\text { Best Actress - Short } \\
\text { Yolanda Centeno }\end{array}$ \\
\hline
\end{tabular}

Almería International Short Film Festival 2014

Winner

Best Andalusian Film
Yolanda Centeno (director)

American Psychological Association (APA) Film Nominee

$$
\begin{aligned}
& \text { Short Film } \\
& \text { Yolanda Centeno }
\end{aligned}
$$

Asians On Film Festival 2014

\begin{tabular}{l|l|}
$\begin{array}{l}\text { Winner } \\
\text { Best Editing }\end{array}$ & $\begin{array}{l}\text { Short } \\
\text { Yolanda Centeno (editor) } \\
\text { David Bertran (editor) }\end{array}$ \\
\hline $\begin{array}{l}\text { Winner } \\
\text { Best Original Score }\end{array}$ & $\begin{array}{l}\text { Best Original Score: Short Film } \\
\text { Mika Selander (composer) }\end{array}$ \\
\hline $\begin{array}{l}\text { Winner } \\
\text { Winter Award }\end{array}$ & $\begin{array}{l}\text { Best Original Score } \\
\text { Juan Carlos Enriquez (composer) }\end{array}$ \\
\hline
\end{tabular}

CineRockom International Film Festival 2015 \begin{tabular}{lll} 
Nominee & $\begin{array}{l}\text { Best Short Film } \\
\text { Yolanda Centeno }\end{array}$ \\
\hline
\end{tabular}
Nominee Best Young Artist

Festival Internazionale del Cinema Povero 2014 Winner

$$
\begin{aligned}
& \text { Best Film } \\
& \text { Yolanda Ce }
\end{aligned}
$$

Gwinnett Center International Film Festival 2014

Winner

$$
\begin{aligned}
& \text { Best Fiction Short Film } \\
& \text { Yolanda Centeno (director) }
\end{aligned}
$$

Hang Onto Your Shorts Film Festival, NJ 2015

Nominee

Best Short Short

Long Beach Indie, California 2015

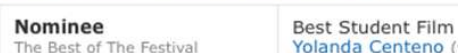

Los Angeles Film and Script Festival, US 2014

Nominee

Best Short Film
Yolanda Centeno 


\section{Fotógrafas}




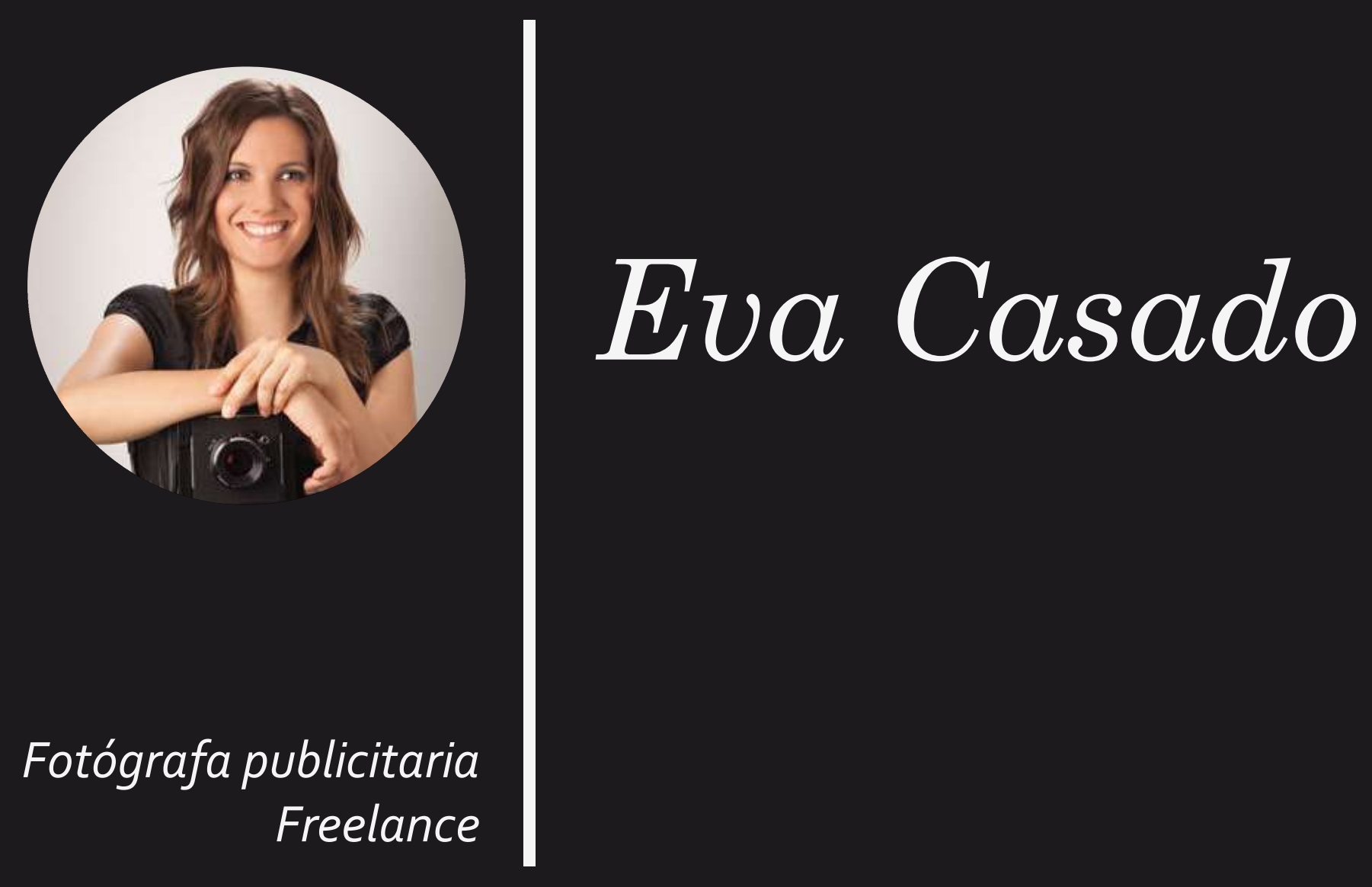




\section{Trabajo}

Especializada en alimentos, bebidas, packaging, producto $y$

animales
Packaging

Producto

Diesel, Kenzo, Hugo Boss, Issey Miyake, Guerlain, Hannibal Laguna, Tous, Actiu, Essilor, Casa de Hualdo, Carrefour, Bouti...

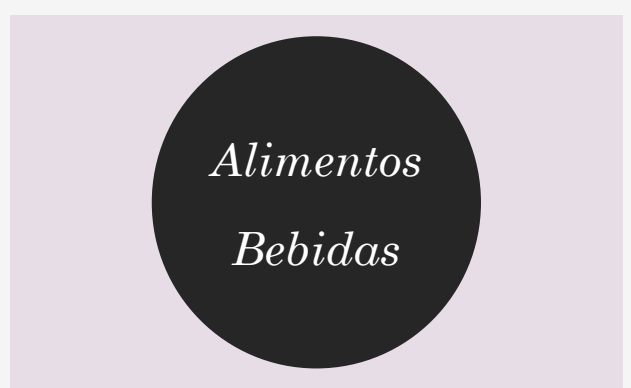

Bacardí, Mayor de Castilla, La

Tagliatella, Aceite Joé Andrés, Don Simón, Macedonia Fruit Café, Rest. TGB, Aquarius, Café Costa, Sal y Pimienta Magazine..

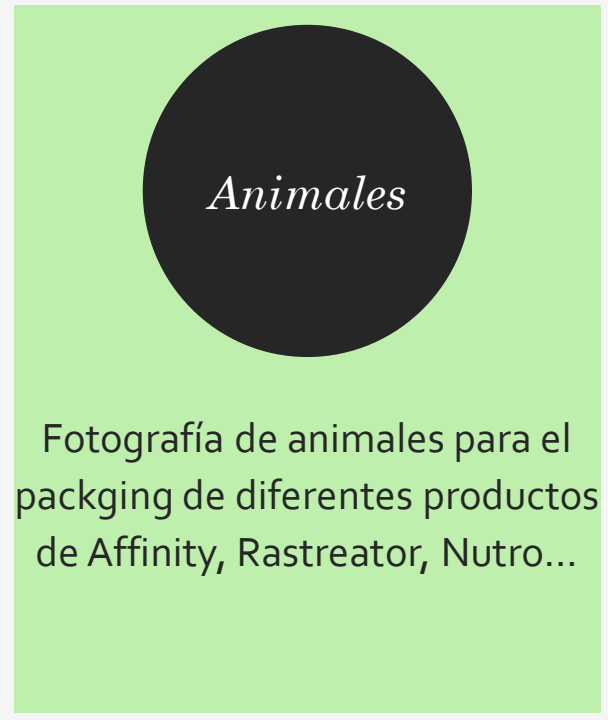




\section{Statement:}

"Mi nombre es Eva Casado, soy fotógrafa profesional orientada sobre todo al mundo de la publicidad, especializada en animales, alimento, bebidas, producto e interiorismo. Desde mi niñez me siento atraída por la fotografía, transformé cada recuerdo de mi vida en imágenes, tras cursar el grado superior de imagen y verme influenciada por fotógrafos de renombre internacional con los que tuve la suerte de trabajar, en 2005 fundé Eva Casado . Fotografía Profesional y empecé mi carrera como fotógrafa profesional de publicidad. Una empresa formada por grandes profesionales del sector como Sandra Pomares y Cris Méndez, ayudantes de fotografía y retocadoras digitales"

Presidenta de la AFPE (Asociación de Fotógrafos Profesionales de España).

\section{Fuentes: https://evacasado.com/fotografo-profesional/}




\section{Producto}

Hannibal Laguna Óptica. 2019

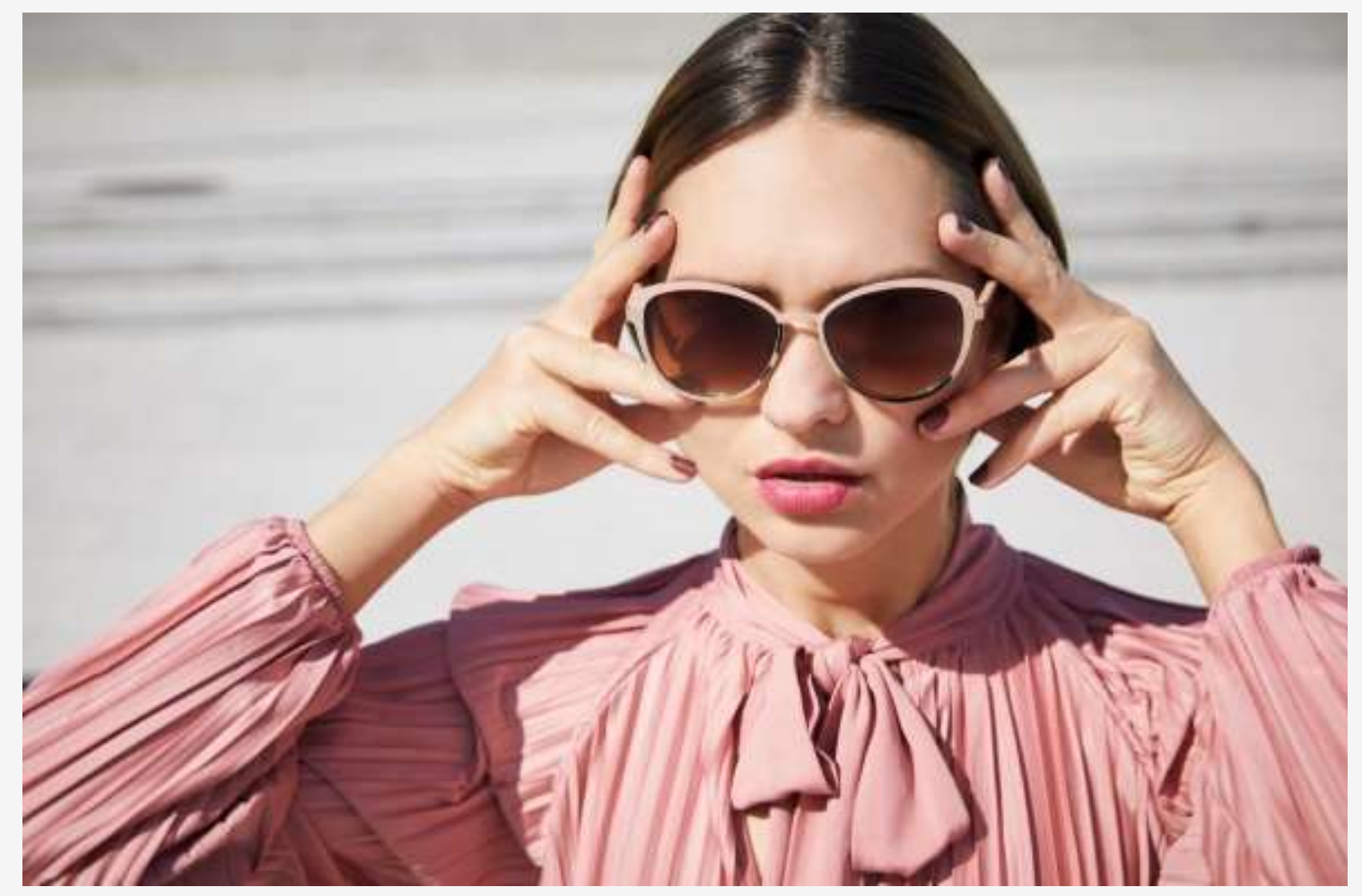


Ficha técnica:

Making Of del shooting para Hannibal Laguna Óptica en el estudio de Eva Casado

https://www.youtube.com/watch?v=nOMElOXRpsU 


\section{Producto}

HogarTextil. 2013 
Ficha técnica:

Making Of del shooting para HogarTextil en el estudio de Eva Casado

https://www.youtube.com/watch?v=JcBcBFIGvZO 
Alimentos Bebidas

Costa Café. 2016

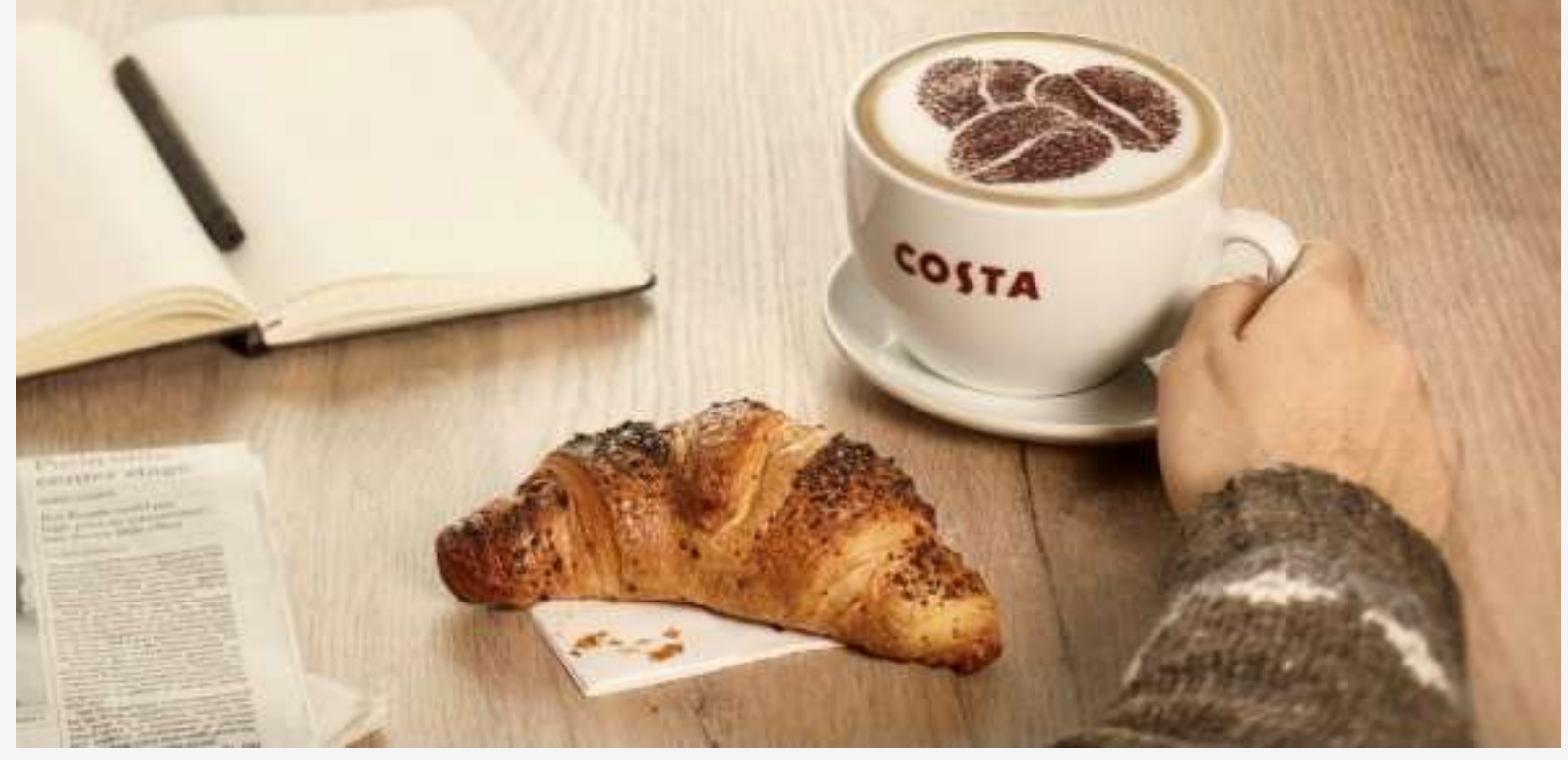


Ficha técnica:

Making Of del shooting para Costa Café en Madrid

https://www.youtube.com/watch?v=Yi5Yshvkxq4 
Alimentos Bebidas

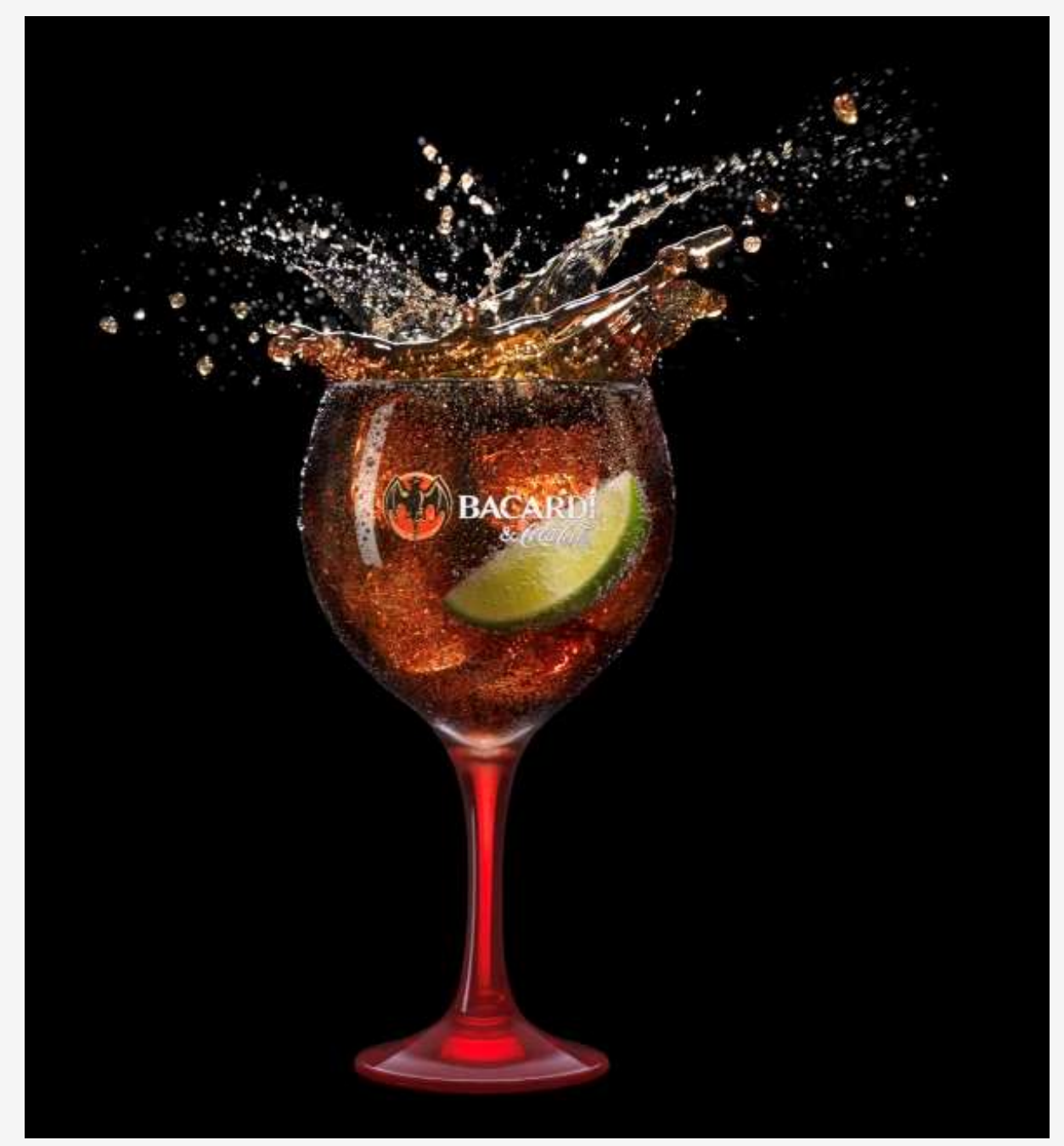




\section{Animales}

Rastreator.

Imagen para web site

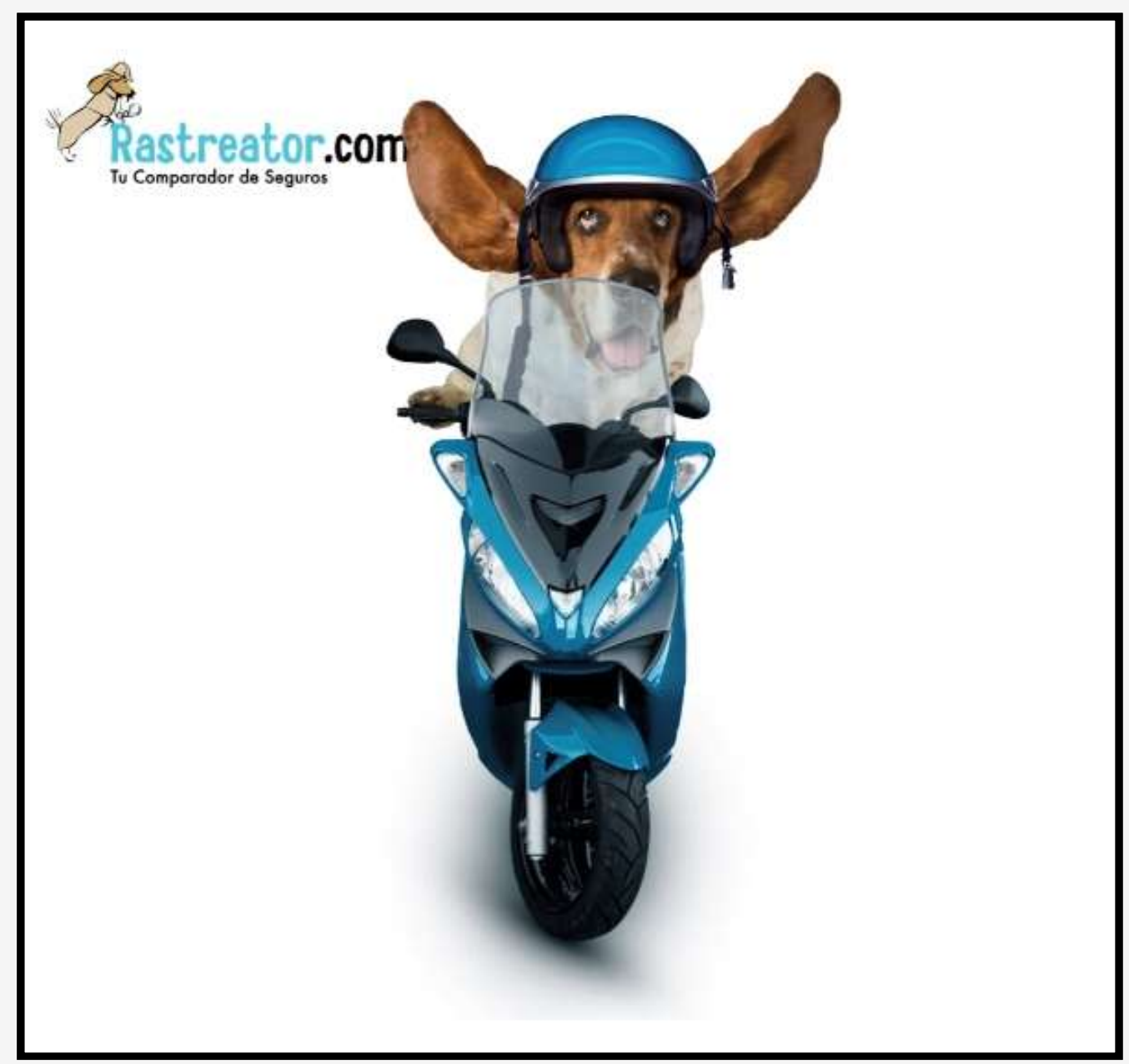




\section{Animales}

Ultima. Affinity Imagen para pacakaging

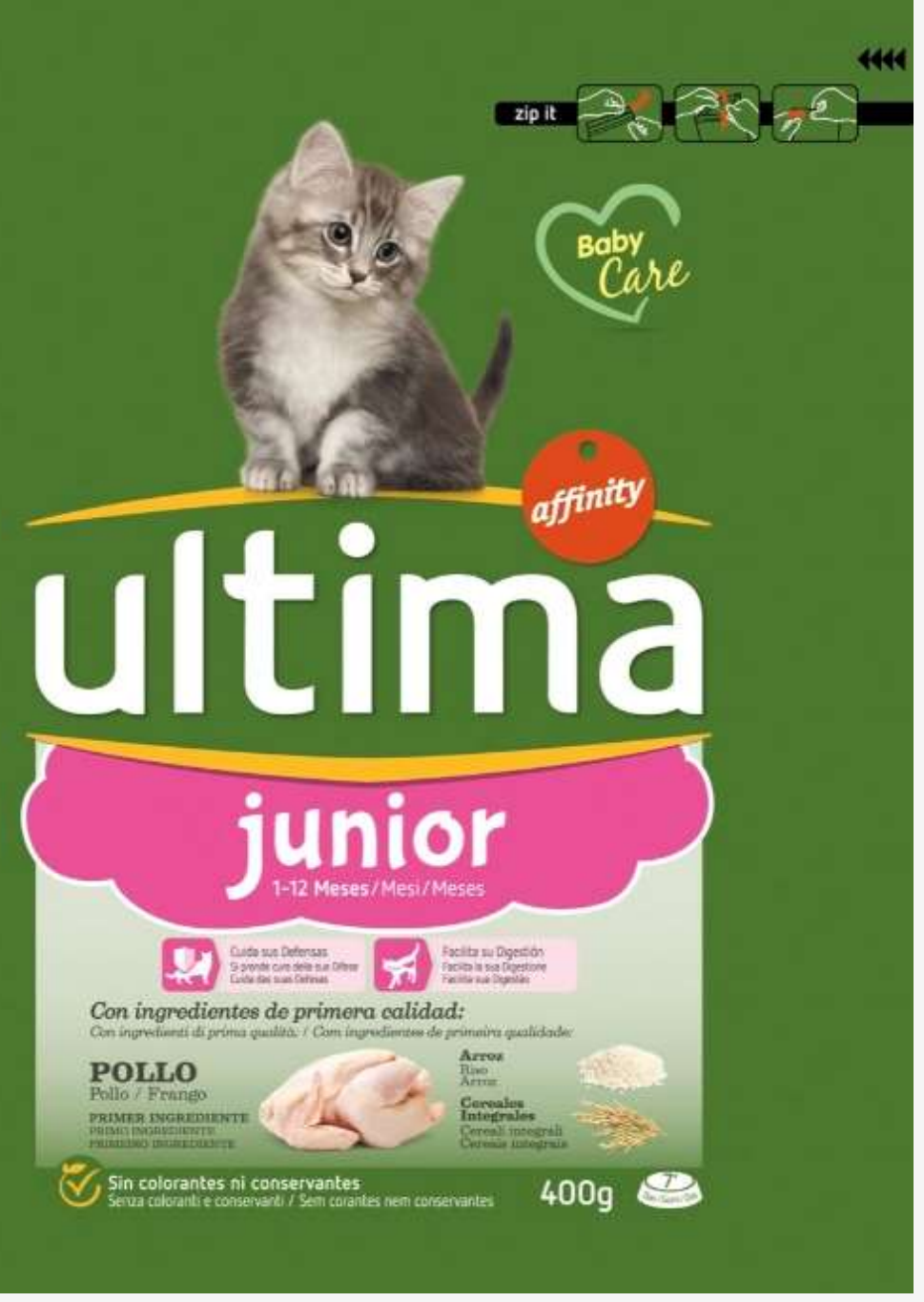


Ficha técnica:

Making Of del shooting para packaging de Ultima en Barcelona

https://www.youtube.com/watch?v=cdoOhodX $3{ }_{3} \mathrm{cc}$ 


\section{Animales}

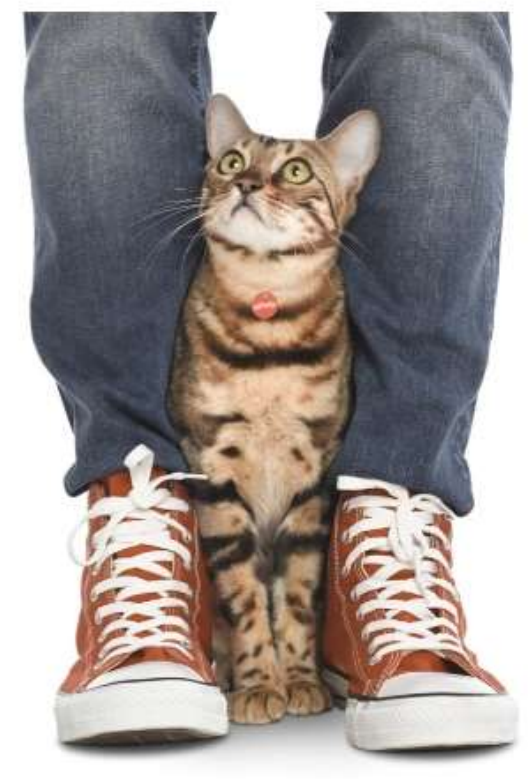

Fundación Affinity

Imágenes para web site https://www.fundacionaffinity.org/

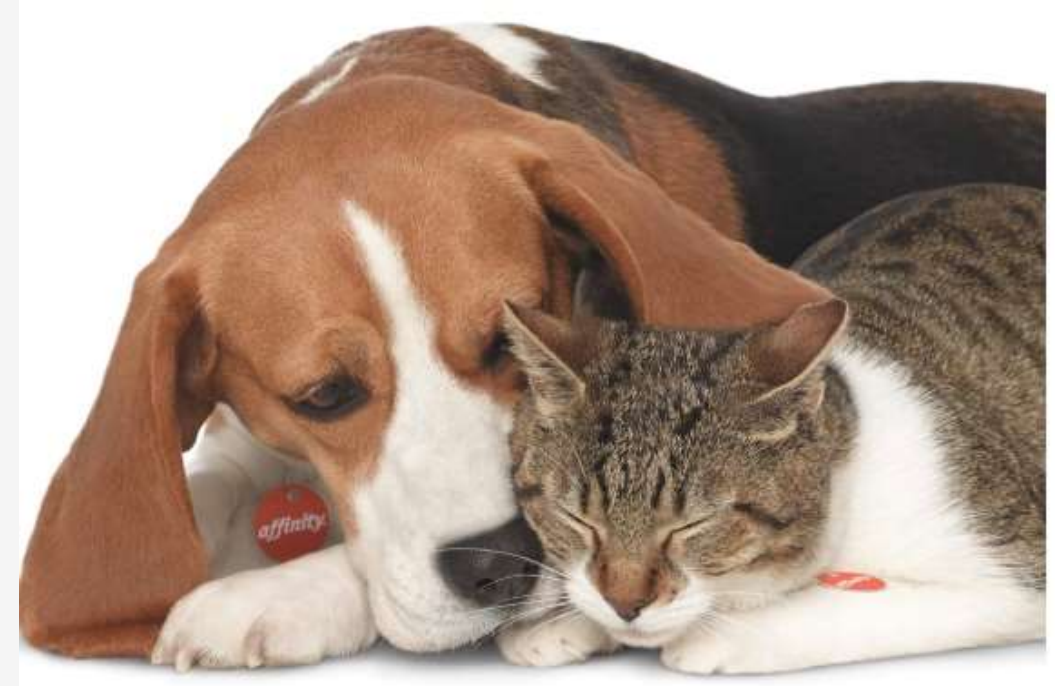




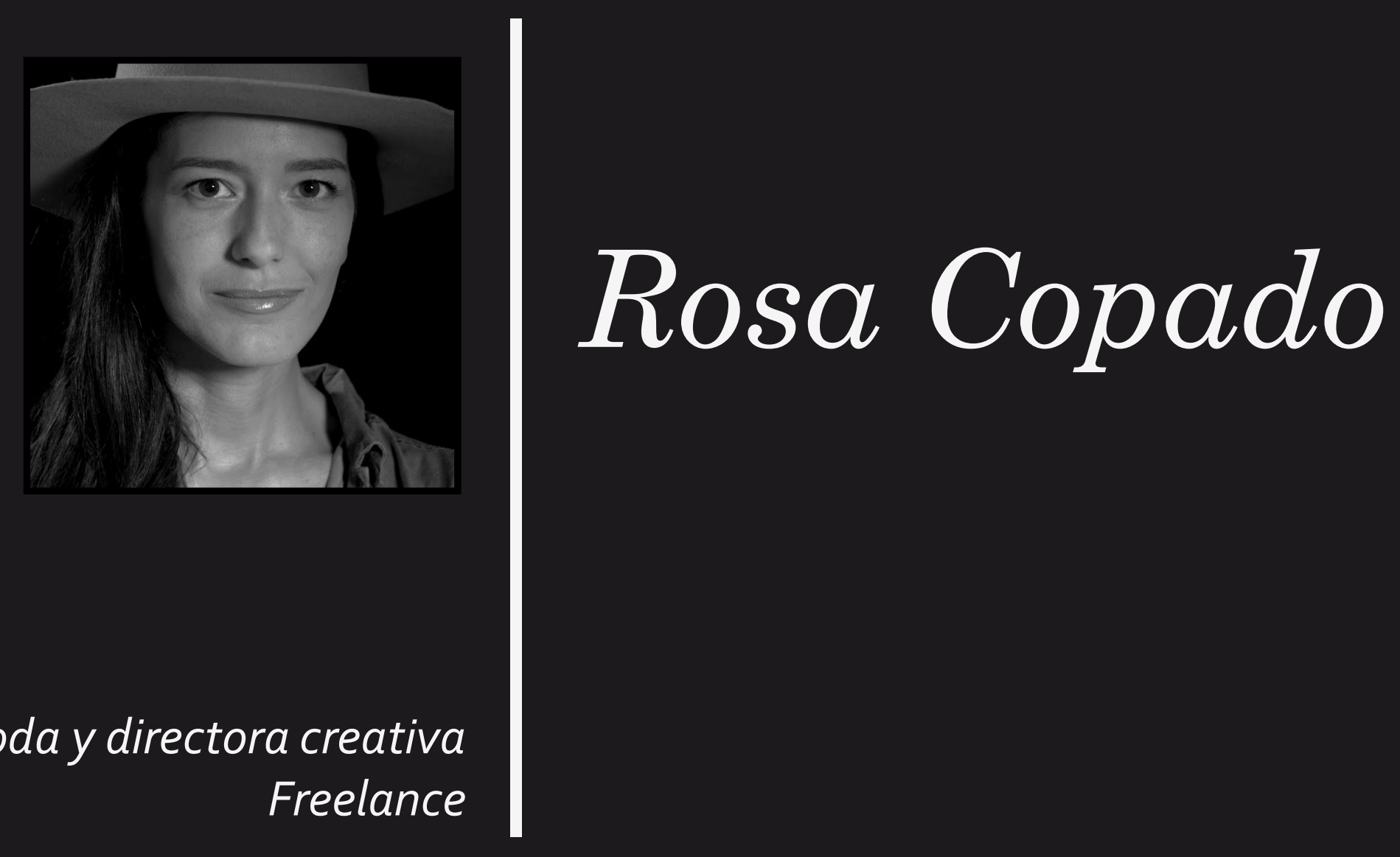

Fotógrafa de moda y directora creativa Freelance 


\section{Trabajo}

Empresas y revistas

destacadas

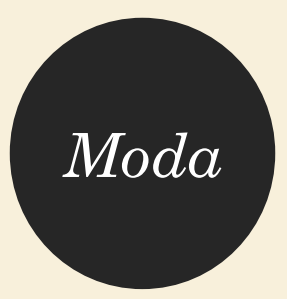

Lauder, Lancôme, Intropia, Sunad, Zara, Stradivarius, Pedro del Hierro, Malababa, Sunad, We are Knitters, Channel Beauty, El Ganso..

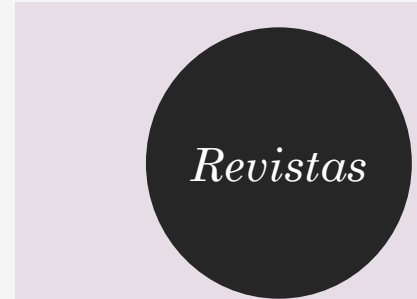

Telva, Marie Claire, L'Officiel, Vein, Sicky Magazine, Esquire, Hola Fashion, Harper's Bazaar, SModa El País... 


\section{Statement:}

"Ser mujer y fotógrafa a día de hoy no es fácil (...) Las mujeres que hay son muy luchadoras y tienen una personalidad muy fuerte para soportar las críticas (...). No he encontrado ese momento en que alguien te diga que tienes talento y por eso has llegado donde estás sino que si el físico te acompaña, que has tenido mucha suerte... Pero nadie regala nada a nadie, hay que demostrar que a parte de un físico hay un cerebro que funciona, en mi caso esto ha sido bastante complicado. Quiero que se me recuerde como una mujer soñadora que luchó por conseguir sus sueños... y libre, muy libre".

Fuentes: Serie documental Creadorxs, en formato entrevistas, creado y dirigido por David Velduque y Marco Laborda. https://elpais.com/elpais/2018/06/13/tentaciones/1528911770_742428.html https://www.youtube.com/watch?v=TM-NdKpAnm4\&t=15 


\section{Moda}

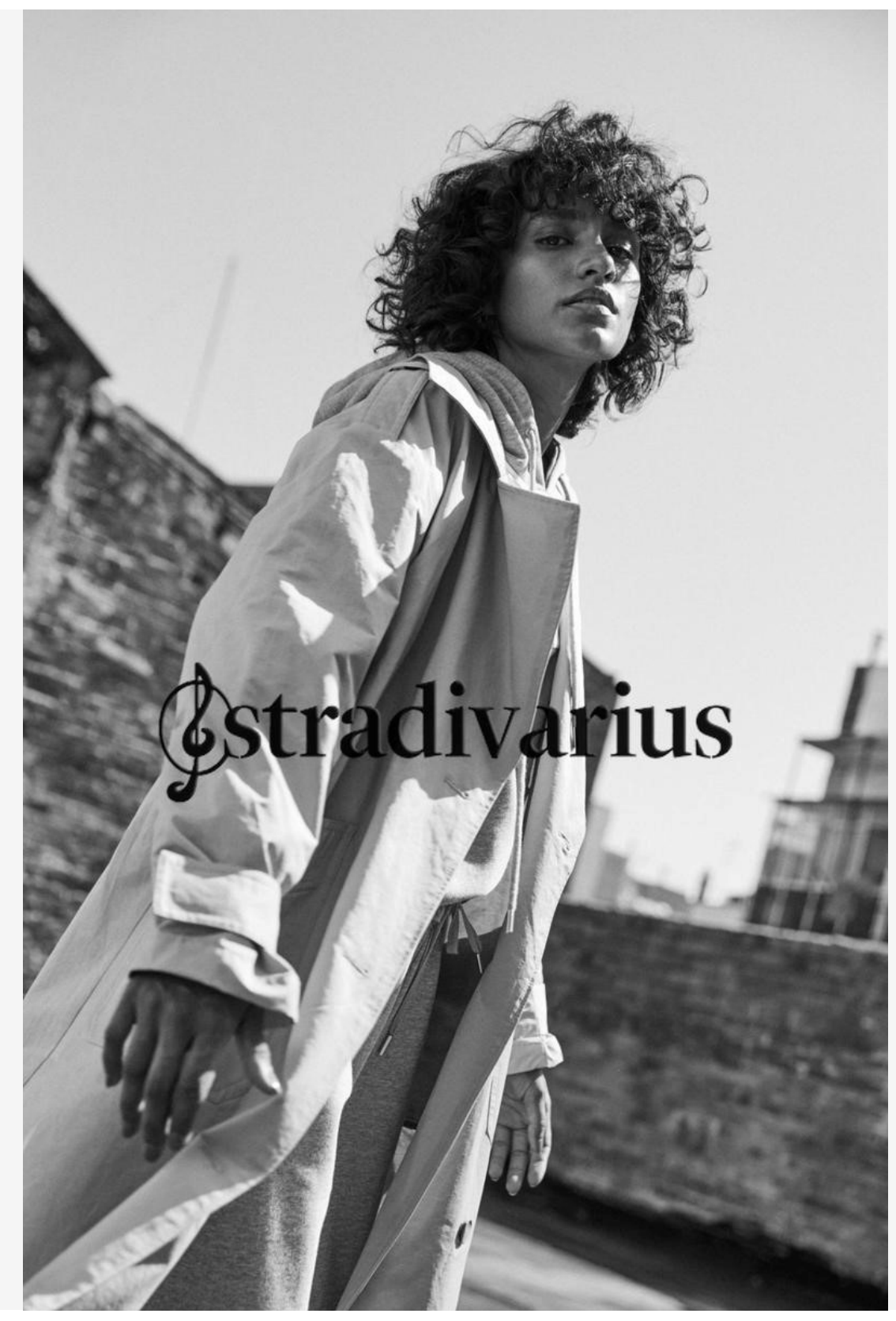


Ficha técnica:

\section{Fotografía: Rosa Copado}

Estilismo: Team Stradivarius STR

Fuente: https://rosacopado.cargo.site/Stradivarius-Fall-2020 


\section{Moda}

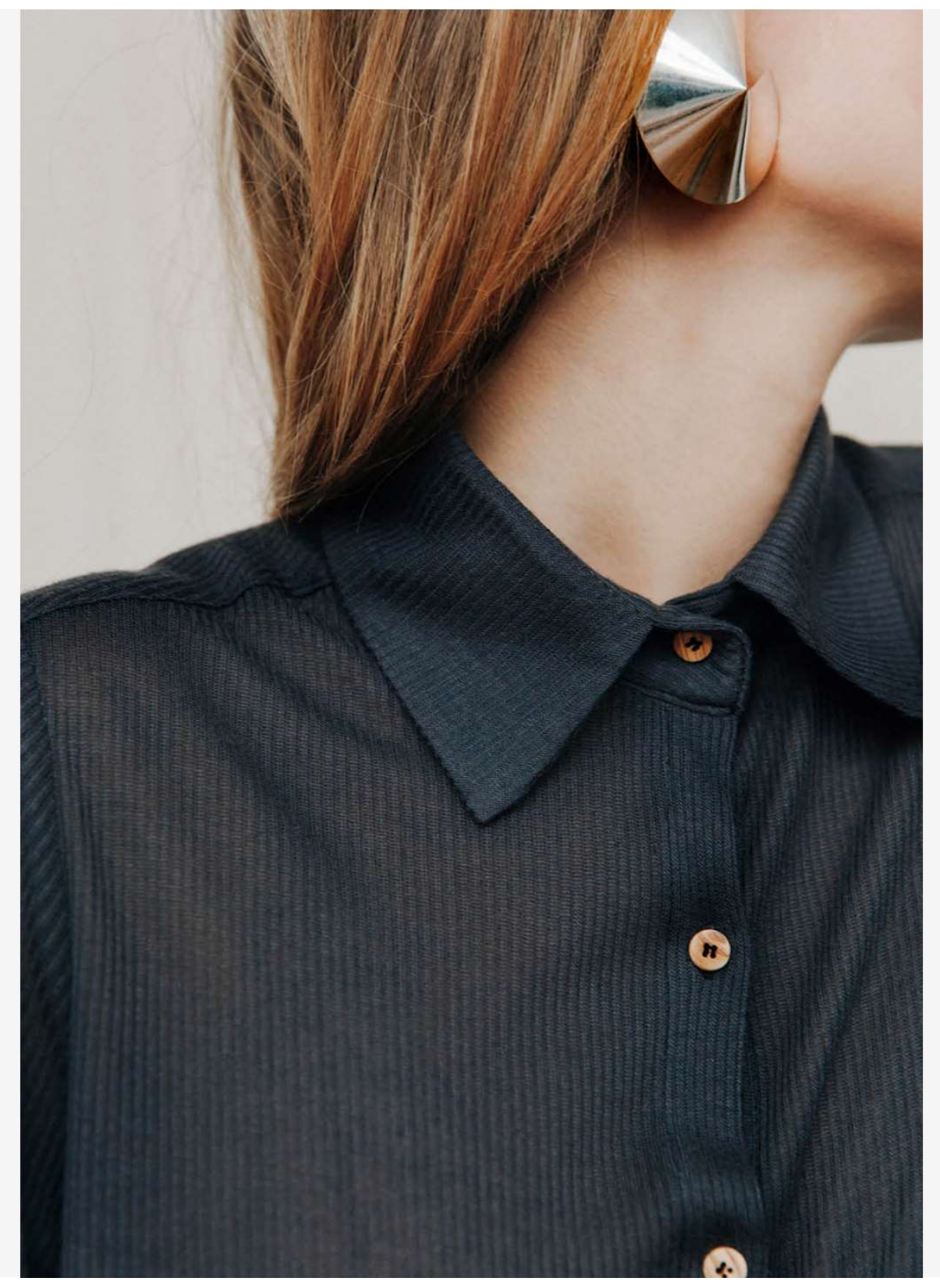


Ficha técnica:

\section{Fotografía: Rosa Copado}

Maquillaje y peluquería: Yohana

Rojas

Fuente: https://rosacopado.cargo.site/Sunad-AW-17 


\section{Moda}

La casualidad y la intrepidez fueron las responsables de reunir a estas dos talentosas mujeres para crear una relación artística todavía vigente y palpitante a día de hoy. Y prueba de ello son estas imágenes. La fotógrafa Rosa Copado captura la última colección de María Escoté, My Little Pony, título que hace referencia al popular juguete infantil.

María Escoté. My Little Pony 2016 


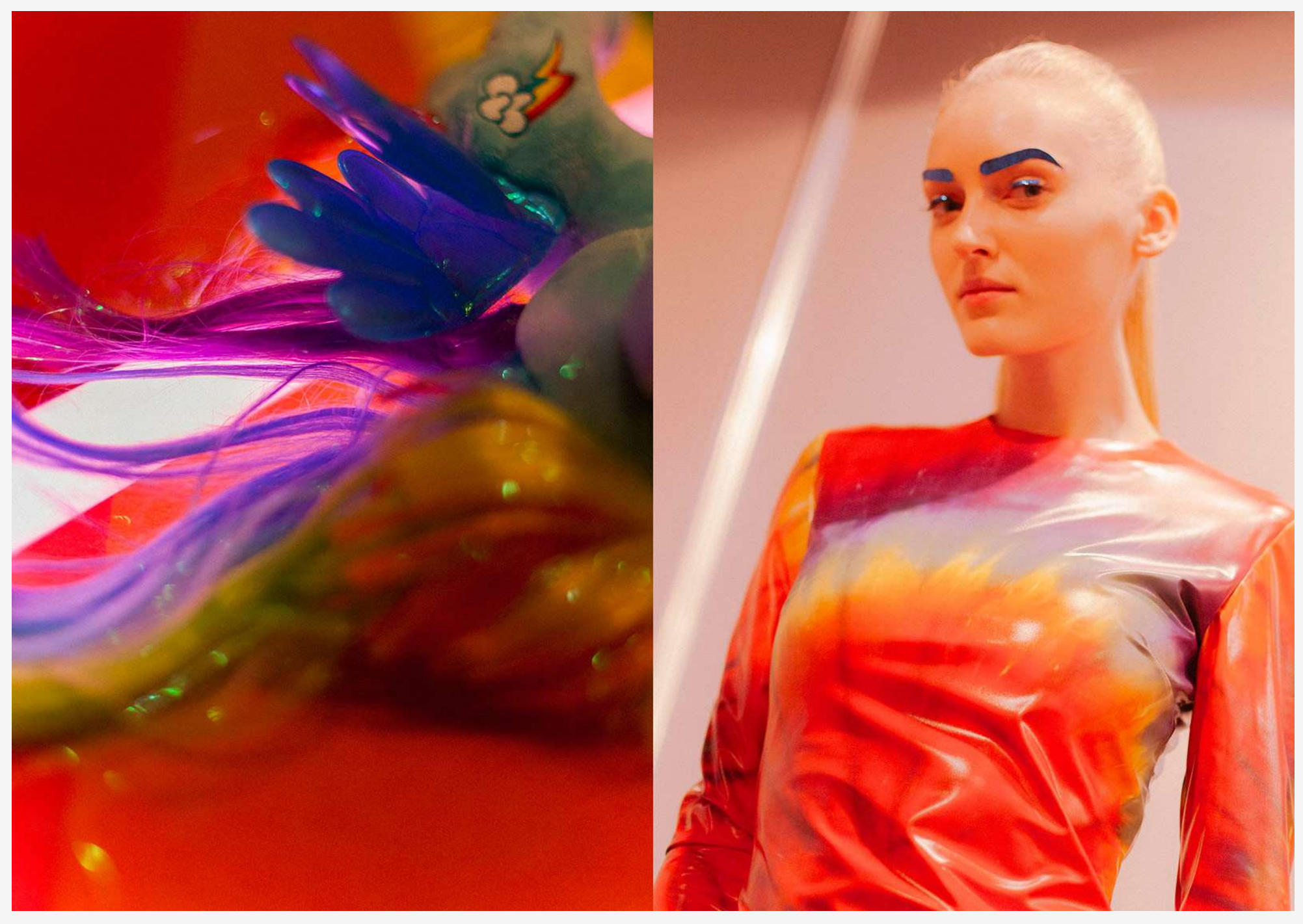




\section{Sobre el trabajo:}

"El díptico es un formato narrativo que recuerda a un libro abierto. Marca un ritmo y casi nos obliga a leer más que a mirar. Cada foto necesita de la de al lado para cobrar sentido. Todas esas modelos bellísimas, transformadas en ponis con un maquillaje de ensueño y vestidas como súper heroínas... Tenía los ingredientes y la necesidad de contar My Little Pony by María Escoté como si fuera un cómic o un cuento vivo dentro del mundo de la moda, lleno de personajes ficticios pero tangibles y con texturas reales" (Rosa Copado). 


\section{Moda}

Channel Beauty

Porfolio editorial Hola Fashion

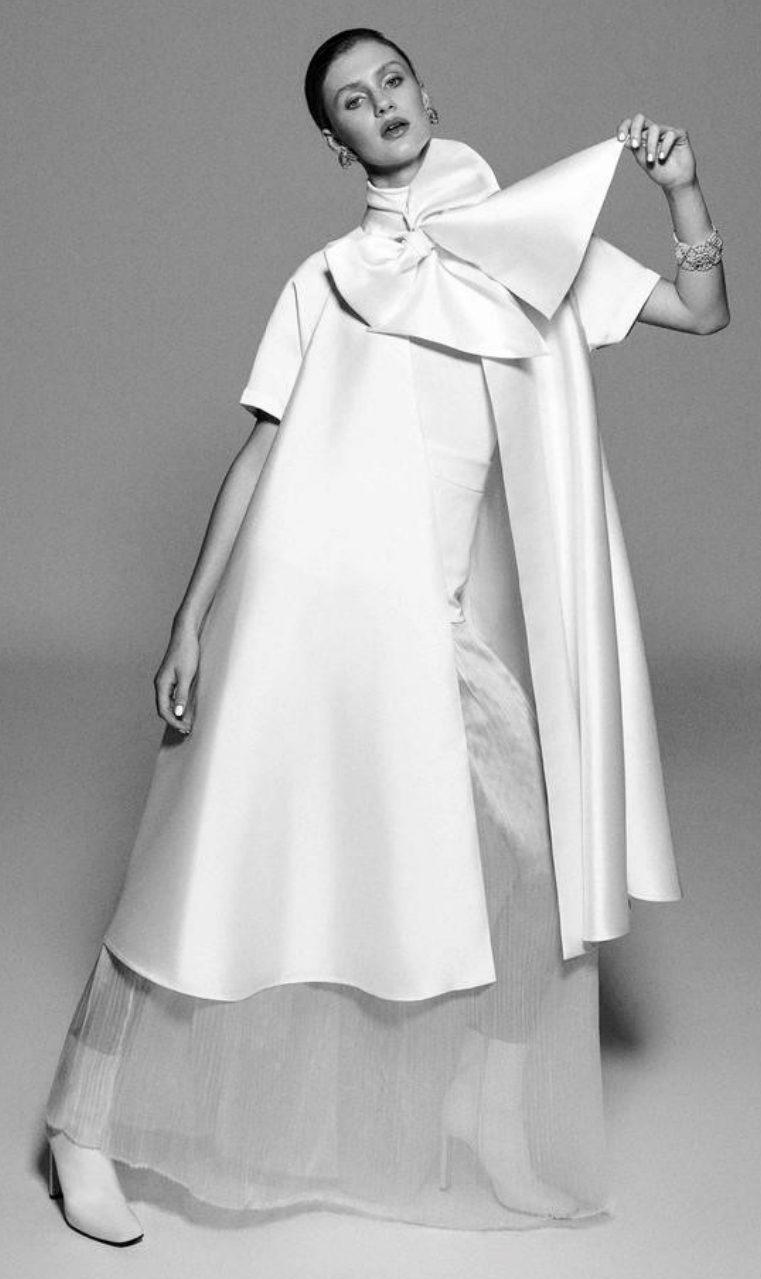


Ficha técnica:

\section{Fotografía: Rosa Copado}

Estilismo: Leonor Delkader

Maquillaje y peluquería: Noemí

Nohales 


\section{Retrato Celebrities}

Ana Duato

Harper's Bazaar Spain 
Ficha técnica:

\section{Fotografía: Rosa Copado}

Estilismo: Anais Ibañez

Dirección Artística: Cristina Ramos

Maquillaje: Pablo Iglesias

Fuente: https://rosacopado.cargo.site/Harper-s-Bazaar-Portrait-Ana-Duato 


\section{Retrato Celebrities}

Quim Gutiérrez

Fuera de Serie

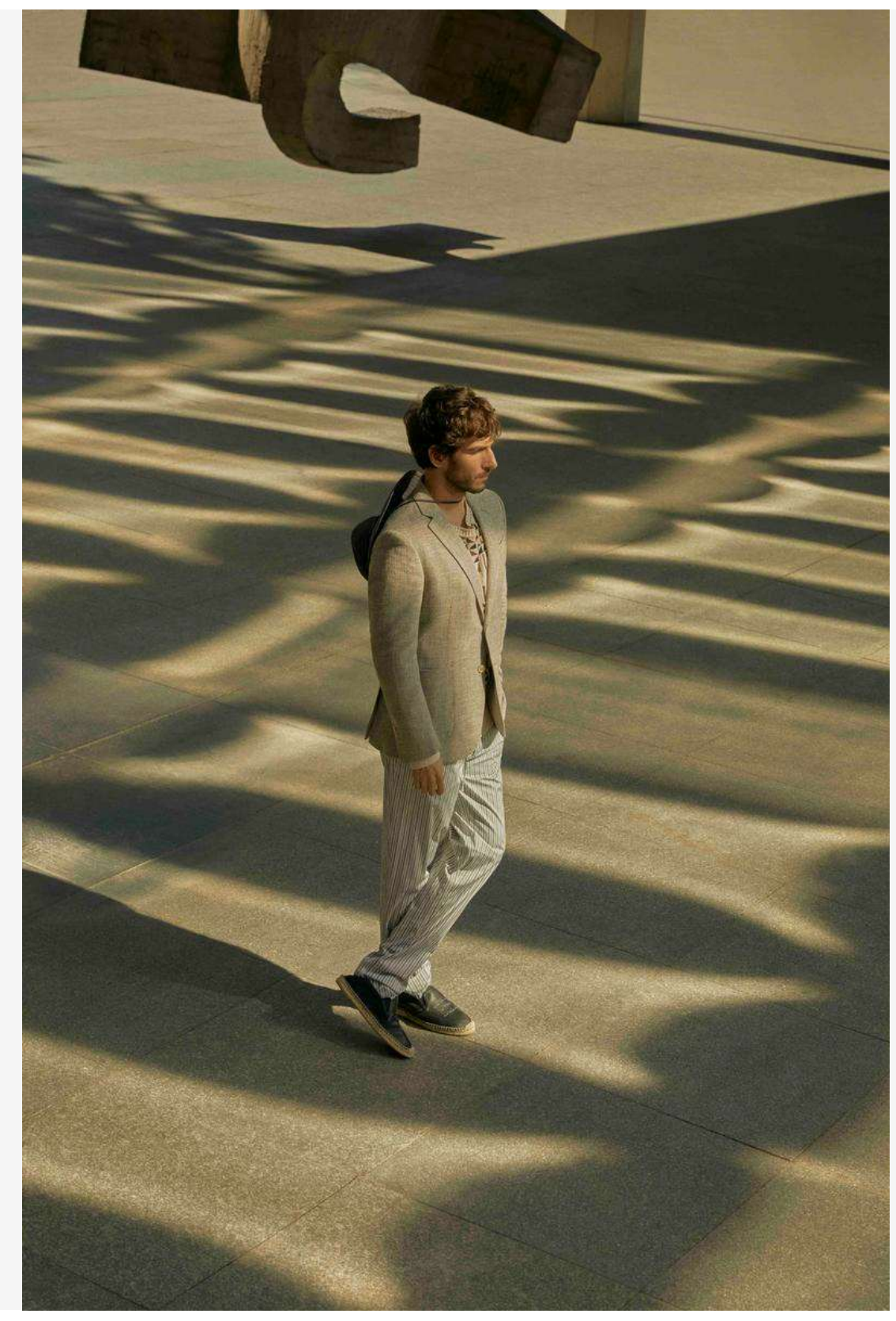


Ficha técnica:

\section{Fotografía: Rosa Copado}

Estilismo: Iria Ballesta

Maquillaje: Noemí Nohales

Photography - Rosa Copado

Stylist - Iria Ballesta

Make up Noemí Nohales

Fuente: https://rosacopado.cargo.site/Fuera-De-Serie-Cover-Story-Quim-Gutierrez 


\section{Portadas destacadas}

Esquire, octubre 2109

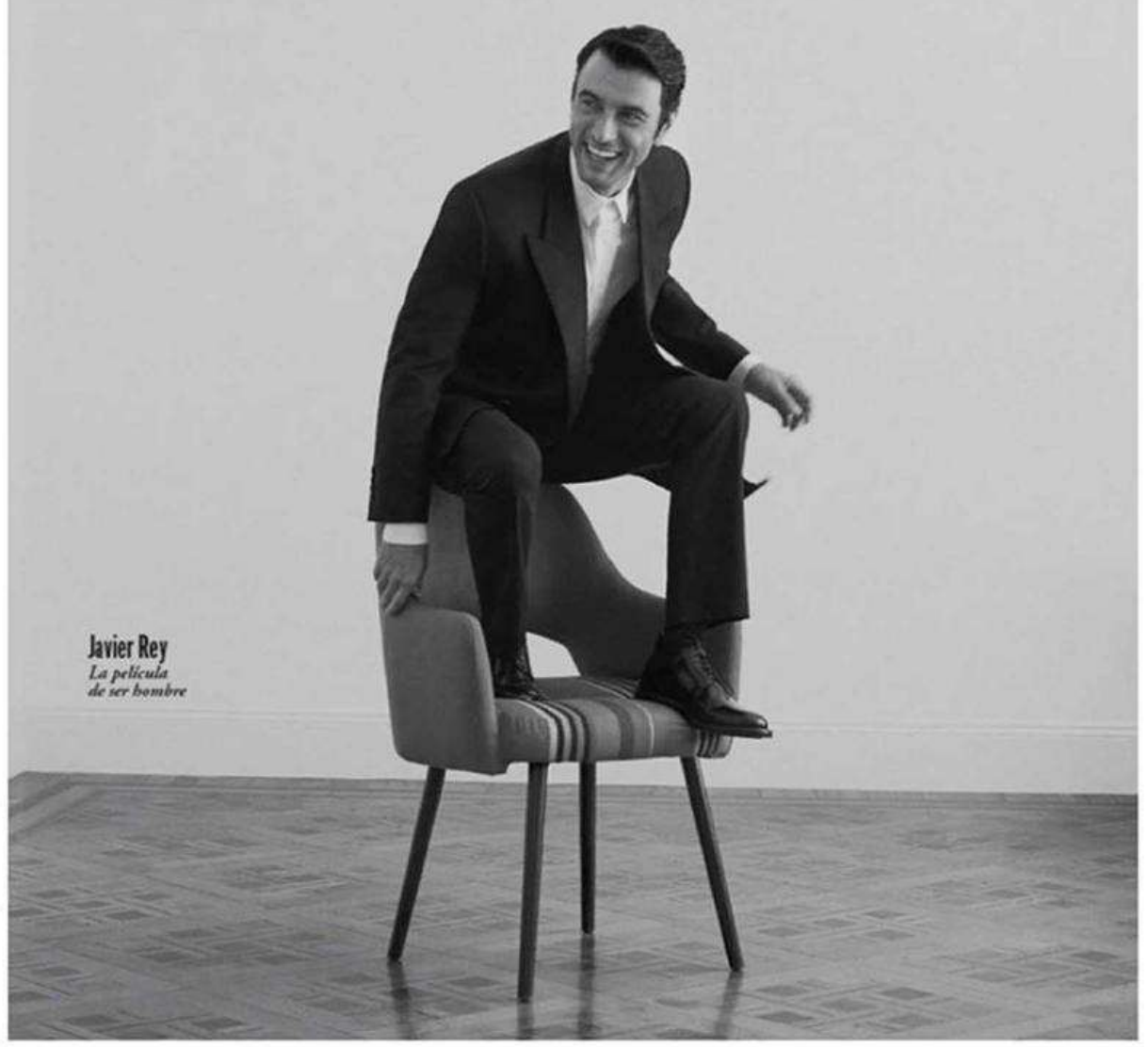


Ficha técnica:

\section{Fotografía: Rosa Copado}

Estilismo: Álvaro De Juan

Fuente: https://rosacopado.cargo.site/Esquire-Spain-Cover-Oct-19 


\section{Portadas destacadas}

L'Officiel, septiembre 2107

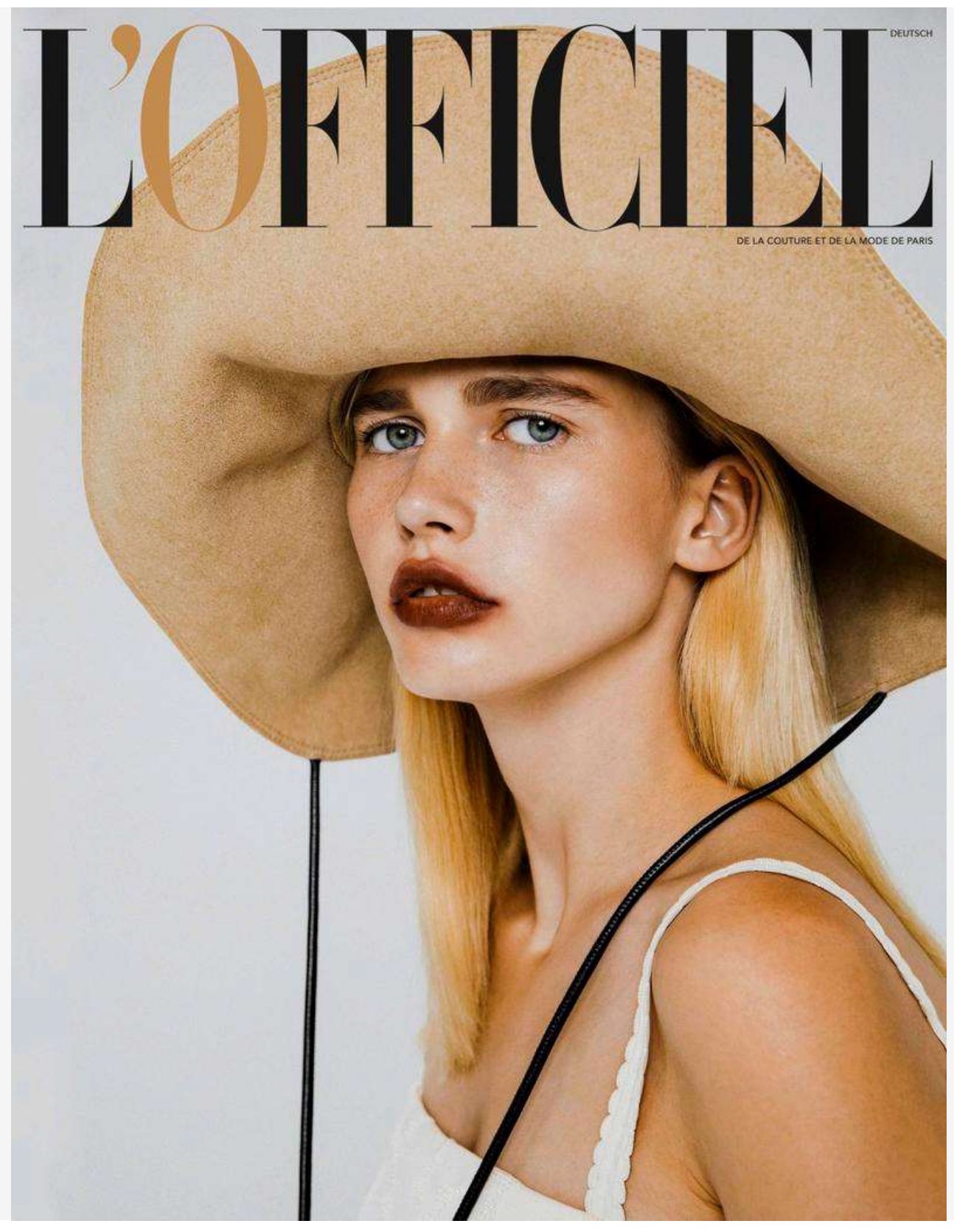


Ficha técnica:

\section{Fotografía: Rosa Copado}

Estilismo: Ana Rojas

Maquillaje y peluquería: Iván

Gómez

Asistente de fotografía: Daniel

Carretero 


\section{Apunte biográfico:}

Nacida en Jaén (1982) llegó a la fotografía de moda de forma autodidacta después de mucho pintar, dibujary esculpir en la Facultad de Bellas Artes de Universidad Complutense de Madrid. «Controlaba la composición, el volumen, la luz... Solo me quedaba aprender a manejar la cámara». De ahí le vienen a sus imágenes esa factura artística y la honestidad de su mirada. «He observado mucho el trabajo de Peter Lindbergh y Annie Leibovitz, con esos blancos y negros perfectos. Me harté de recortar fotografías de moda de los años go para dibujarlas». El acto de autorretratarse lo entiende como un ejercicio de autenticidad. «Yo fui mi primera modelo, me he dibujado mil veces. Es útil conocerte a ti misma para entender a los demás». Actualmente vive en Londres.

\section{Fuente: https://www.harpersbazaar.com/es/cultura/ocio/a2030748g/mujeres-poderosas-espanolas-dosis-de- autenticidad-uniqlo/ \\ https://uk.linkedin.com/in/rosa-copado-studio-71800483}




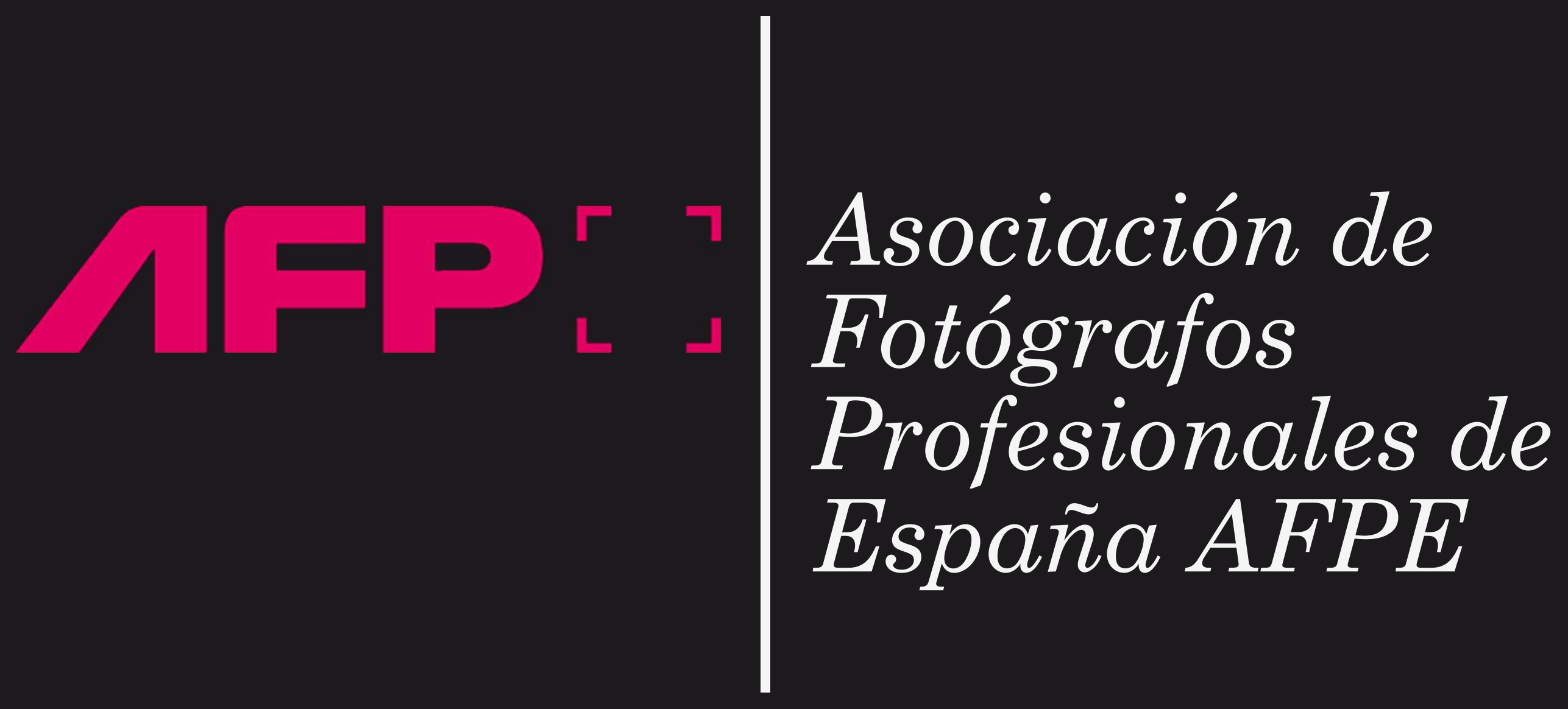


La Asociación de Fotógrafos Profesionales de España (AFPE) es una Asociación sin animo de lucro creada en 1984. En la actualidad la única asociación de ámbito estatal que asocia a los Fotógrafos Profesionales en defensa común de sus intereses.

La AFPE desarrolla una serie de actuaciones y ofrece unos servicios como entidad autónoma, al tiempo que es miembro y colabora con otros colectivos y entidades del sector a nivel nacional e internacional: Pyramide Europe, PLUS (Picture Licensing Universal System), UPDIG (Universal Phographic Digital Imaging Guidelines), Foro de la Comunicación Comercial, Consejo de Creadores Visuales, Ministerio de Educación y Ciencia, Ministerio de Cultura, Fundación Arte y Derecho, VEGAP (Visual Entidad de Gestión de Artistas Plásticos), Plataforma de la cultura para un Consejo de las Artes, etc. 


\section{ESTRUCTURA DE LA AFPE}

JUNTA DIRECTIVA (1 mujer, 4 hombres)

Presidenta: Eva Casado

Vicepresidente: José Ornia

Secretario: Jaume Lladòs

Tesorero: Germán Maymo

Vocal: General Massot

COMISIONES DE TRABAJO (1 hombre)

Comisión internacional: Ferrán Badía

EQUIPO TÉCNICO (2 mujeres, 1 hombre)

Responsable de comunicación: Andrea Torres

Responsable de producción y eventos: Mónica García

Responsable de dirección de arte: Alex Martín

Fuente: https://afpe.pro/asociacion-fotografos-profesionales/ 


\section{OBJETIVOS DE LA AFPE}

1. Promocionar en todos sus aspectos la Fotografía Profesional.

2. La representación, defensa y promoción de los intereses profesionales de sus miembros, defendiendo sus derechos y promocionando su buena imagen.

3. Facilitar la promoción, a través de la enseñanza oficial y privada, de nuevos fotógrafos, cuya actividad coincida con la de la Asociación.

4. Ofrecer servicios técnicos, materiales o de cualquier tipo que ayuden al Asociado en el ejercicio de su actividad profesional.

5. Participar y organizar muestras y manifestaciones relacionadas con la fotografía.

6. Representar a sus miembros ante cualquier ente público o privado, solicitando de los mismos el reconocimiento de sus derechos, así como ayuda y promoción.

7. Promover la defensa de los Derechos de Autor, morales y materiales, derivados de la obra de los Asociados, de acuerdo con la legalidad vigente y los tratados internacionales.

8. Sensibilizar a los organismos y entidades de la Administración y a la opinión pública sobre la importancia cultural y económica de la fotografía.

9. Elaborar normas orientadoras de honorarios profesionales y de cuantificación de percepciones por Derechos de Autor.

10. Establecer un Código Deontológico como marco de referencia para un correcto y leal ejercicio de la profesión.

11. Todas las actuaciones o actividades que acuerde la Asamblea General y estén permitidas por la legislación aplicable.

Fuente: https://afpe.pro/objetivos/ 
FOTÓGRAFOS/AS PROFESIONALES ASOCIADOS/AS A LA AFPE: ANÁLISIS DESDE LA PERSPECTIVA DE GÉNERO

\begin{tabular}{|l|c|c|c|c|c|}
\hline \multicolumn{1}{|c|}{ GÉNERO FOTOGRÁFICO } & HOMBRES & MUJERES & TOTAL & \%HOMBRES & \%MUJERES \\
\hline General & 47 & 15 & 62 & 75,81 & 24,19 \\
\hline Animales & 1 & 3 & 4 & 25,00 & 75,00 \\
\hline Arquitectura e interiorismo & 22 & 6 & 28 & 78,57 & 21,43 \\
\hline Automoción & 4 & 0 & 4 & 100,00 & 0,00 \\
\hline Bodegón y producto & 26 & 7 & 33 & 78,79 & 21,21 \\
\hline Retoque digital & 3 & 0 & 3 & 100,00 & 0,00 \\
\hline Científica & 2 & 0 & 2 & 100,00 & 0,00 \\
\hline Conceptual & 7 & 5 & 12 & 58,33 & 41,67 \\
\hline Corporativa & 12 & 4 & 16 & 75,00 & 25,00 \\
\hline Deportiva & 2 & 0 & 2 & 100,00 & 0,00 \\
\hline Eventos y espectáculos & 8 & 4 & 12 & 66,67 & 33,33 \\
\hline Foto fija & 5 & 1 & 6 & 83,33 & 16,67 \\
\hline Gastronomía y bebidas & 25 & 5 & 30 & 83,33 & 16,67 \\
\hline Gente y estilos de vida & 10 & 5 & 15 & 66,67 & 33,33 \\
\hline Industrial & 10 & 5 & 15 & 66,67 & 33,33 \\
\hline Infantil & 5 & 4 & 9 & 55,56 & 44,44 \\
\hline Moda y belleza & 8 & 2 & 10 & 80,00 & 20,00 \\
\hline Publicidad & 26 & 6 & 32 & 81,25 & 18,75 \\
\hline Reportaje documental & 9 & 6 & 15 & 60,00 & 40,00 \\
\hline Reportaje social & 9 & 5 & 14 & 64,29 & 35,71 \\
\hline Retrato & 15 & 13 & 28 & 53,57 & 46,43 \\
\hline Submarina & 1 & 0 & 1 & 100,00 & 0,00 \\
\hline Viajes y naturaleza & 11 & 2 & 13 & 84,62 & 15,38 \\
\hline & & & & & \\
\hline
\end{tabular}

Fuente: Elaboración propia 


\section{MUJERES PROFESIONALES ASOCIADAS A LA AFPE}

\begin{tabular}{|l|l|}
\hline NOMBRE & WEB SITE \\
\hline Ángela Domingo & https://angeladomingo.com/ \\
\hline Columna Villarroya & https://www.columnafoto.com/ \\
\hline Cris Concejero & http://www.gmgstudio.es/ \\
\hline Cristina Sabaté & https://www.flickr.com/photos/sallfotografia/ \\
\hline Elisabeth Serra & https://elisabethserrastudio.com/ \\
\hline Eva Casado* & https://evacasado.com/ \\
\hline Haizue Fotografía** & https://www.haizuefotografia.com/lang/es \\
\hline Irene Bel & https://irenebel.com/ \\
\hline Katherin Wermke & http://www.katherinwermke.com/ \\
\hline María Cano & http://www.mariacanophoto.com/ \\
\hline María Sánchez & \\
\hline M. Dolors G-Luumkab & https://luumkab.com/ \\
\hline Mentxu (Gran Angular)** & https://www.granangularfotografos.com/ \\
\hline Paloma Rincón & https://palomarincon.com/ \\
\hline Roig \& Portell** & http://roigportell.com/ \\
\hline $\begin{array}{l}* \text { Presidenta de la AFPE } \\
\text { **Equipo de profesionales formado por una mujer y un hombre }\end{array}$ \\
\hline
\end{tabular}

Fuente: Elaboración propia 


\section{Relaciones Públicas}


Advisory Director at Havas PR \& DIRCOM HAVAS GROUP Spain en Havas Group España «Mujer a seguir» en 2015 Jurado de Cannes PR 2015 


\section{Trabajo}
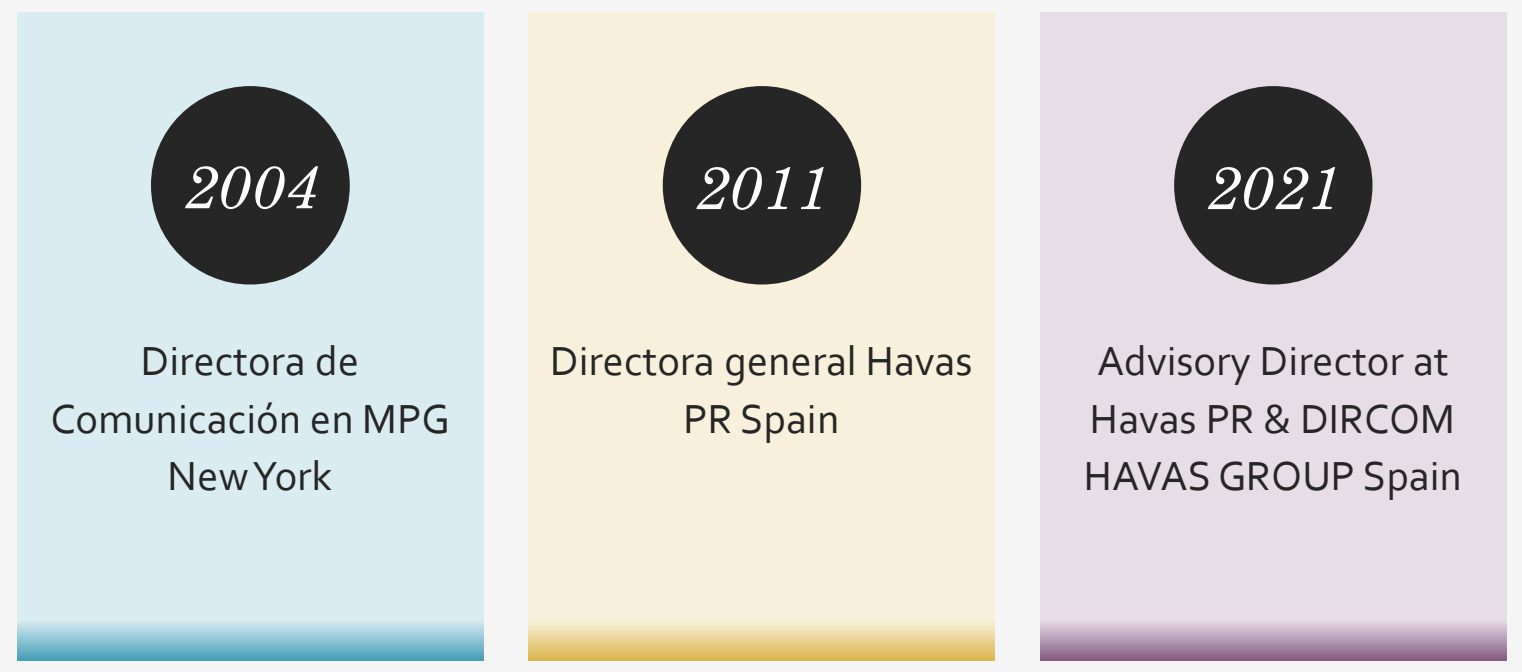

minanecastro10/ 


\section{Premios y campañas destacadas}
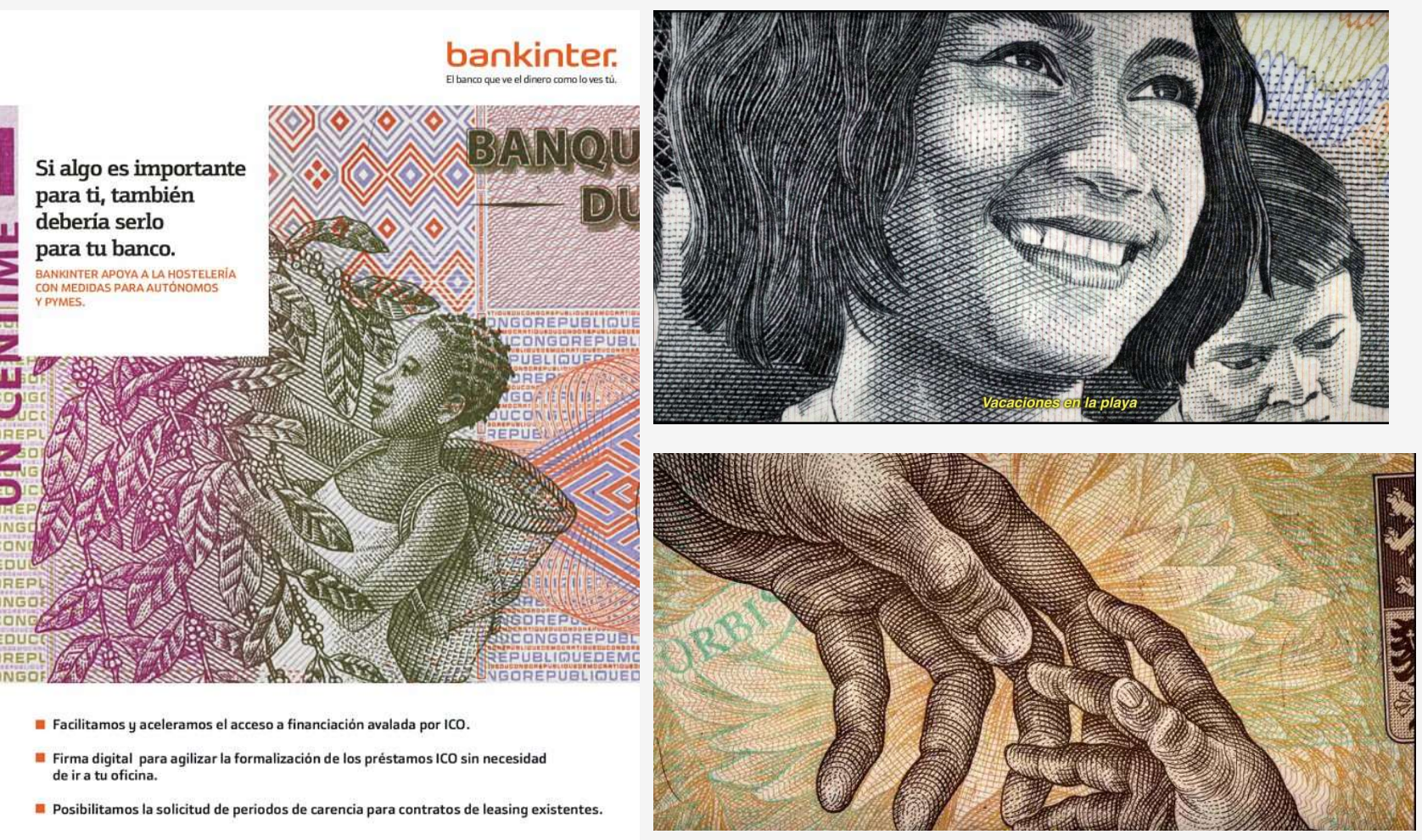

"Medidas concretas"

Bankinter

"Si algo es importante para ti, también debería serlo para tu banco" 


\section{Descripción:}

La primera fase de la campaña da comienzo con un spot de televisión de 120 segundos, lo que supone una duración algo más amplia que la habitual. A través de una historia narrada con un discurso emotivo, y sirviéndose de conceptos visualmente muy relacionados con la actividad financiera, como el dinero y los billetes del mundo, y una canción pegadiza creada especialmente para la ocasión, se van detallando en el spot las medidas diferenciales del plan de choque de Bankinter contra el impacto económico del COVID-19, así como las fortalezas del banco en el actual entorno.

Con este formato tan visual, Bankinter pretende empatizar con el público a través de una rima que evoca el momento que vivimos y un discurso emotivo que se apoya en la contundencia y verdad del plan de choque aplicado por el banco, retomando al mismo tiempo los valores más puramente financieros..

La campaña se convirtió, en apenas cuatro días, en el himno de esperanza de todo un país. 1,3 millones de espectadores únicos vieron el spot en YouTube y, a la tercera semana del lanzamiento, eran ya tres millones de visualizaciones y 2,5 millones de espectadores únicos procedentes de veintinueve países distintos.

La canción del anuncio fue la más buscada en Shazam y ocupó el segundo puesto en iTunes, precedida únicamente por Resistiré del Dúo Dinámico, de nuevo de actualidad debido al confinamiento derivado de la COVID-19.

Los principales medios de información y líderes de opinión del país convirtieron en noticia «el anuncio de Bankinter» y lo compartieron en sus perfiles sociales, lo que contribuyó a que la notoriedad de la entidad creciera un $996 \%$ durante la segunda semana de campaña y se convirtiera en el segundo banco más notorio por detrás del Santander.

Después de la campaña, todos los indicadores de marca crecieron por encima del 10\%, construyendo la imagen de un banco más cercano, comprometido y transparente. Además, y pese al impacto de la COVID-19, la captación online de clientes se incrementó un $21 \%$ y el objetivo anual de captación de pasivo fue sobrepasado con creces durante las primeras semanas de mayo.

Fuente: https://www.elpublicista.es/reportajes/gran-premio-oros-premios-eficacia-2020-explicacion-videos 


\section{PREMIOS}

Gran Premio Eficacia 2020

ORO Mejor Campaña Integrada Premios Eficacia 2020

Fuente: https://www.premioseficacia.com/palmares-eficacia-2020/ 


\section{LOEWE}

Premios y campañas destacadas

"Aromas"

Loewe perfumes
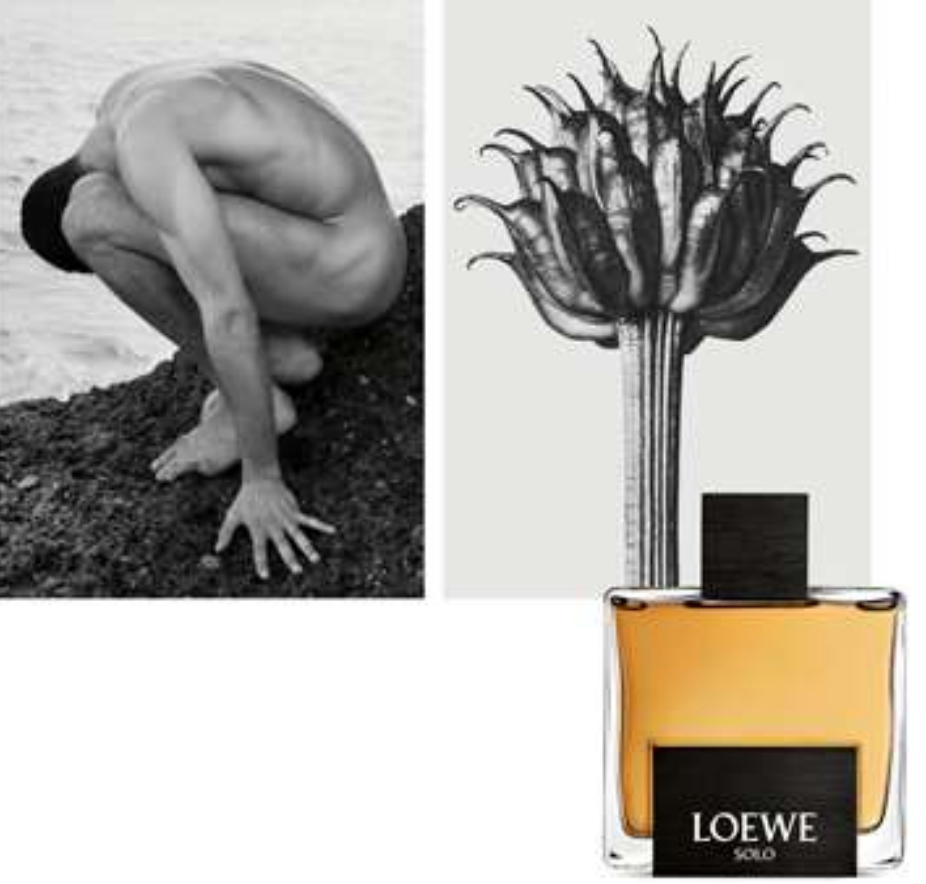

https://www.aromas.es/blog/loewe-nueva-imagen/ 


\section{Sobre la campaña:}

Perfumes Loewe creó una campaña para renovar su imagen, rejuvenecer su clientela e impulsar su web para aumentar las ventas vía e-commerce en el mercado español e internacional.

La nueva imagen de Loewe fue la gran apuesta de la casa por construir marca consistentemente, en lugar de comunicar sus productos de manera individual. Arte, naturaleza y piel serían los pilares que distinguirían a la "nueva Loewe", convirtiéndola en la marca española de referencia mundial del sector de la perfumería selectiva. Gracias a su nueva imagen, Loewe rompió con el lenguaje de opulencia y glamour de los perfumes, rejuveneció el target en todos los perfumes masculinos y femeninos, incrementó las ventas, desarrolló su canal de e-commerce e incrementó las ventas internacionales.

Utilizando fotografías de un botánico alemán llamado Karl Blossfeldt, la marca convirtió cada flor del artista en la imagen de cada uno de sus perfumes. Así, Perfumes Loewe logró un código de comunicación flexible.

La agencia llenó la capital, a través de acciones de ambient, de la nueva imagen de Loewe.

Fuente: https://www.reasonwhy.es/actualidad/mejor-campana-medios-ganados-premios-eficacia-2020 


\section{PREMIOS}

Premio Eficacia a la Internacionalidad 2020

Fuente: https://www.reasonwhy.es/actualidad/mejor-campana-medios-ganados-premios-eficacia-2020 


\section{Otros recursos}

$\equiv$ YouTube ${ }^{\text {Es }}$

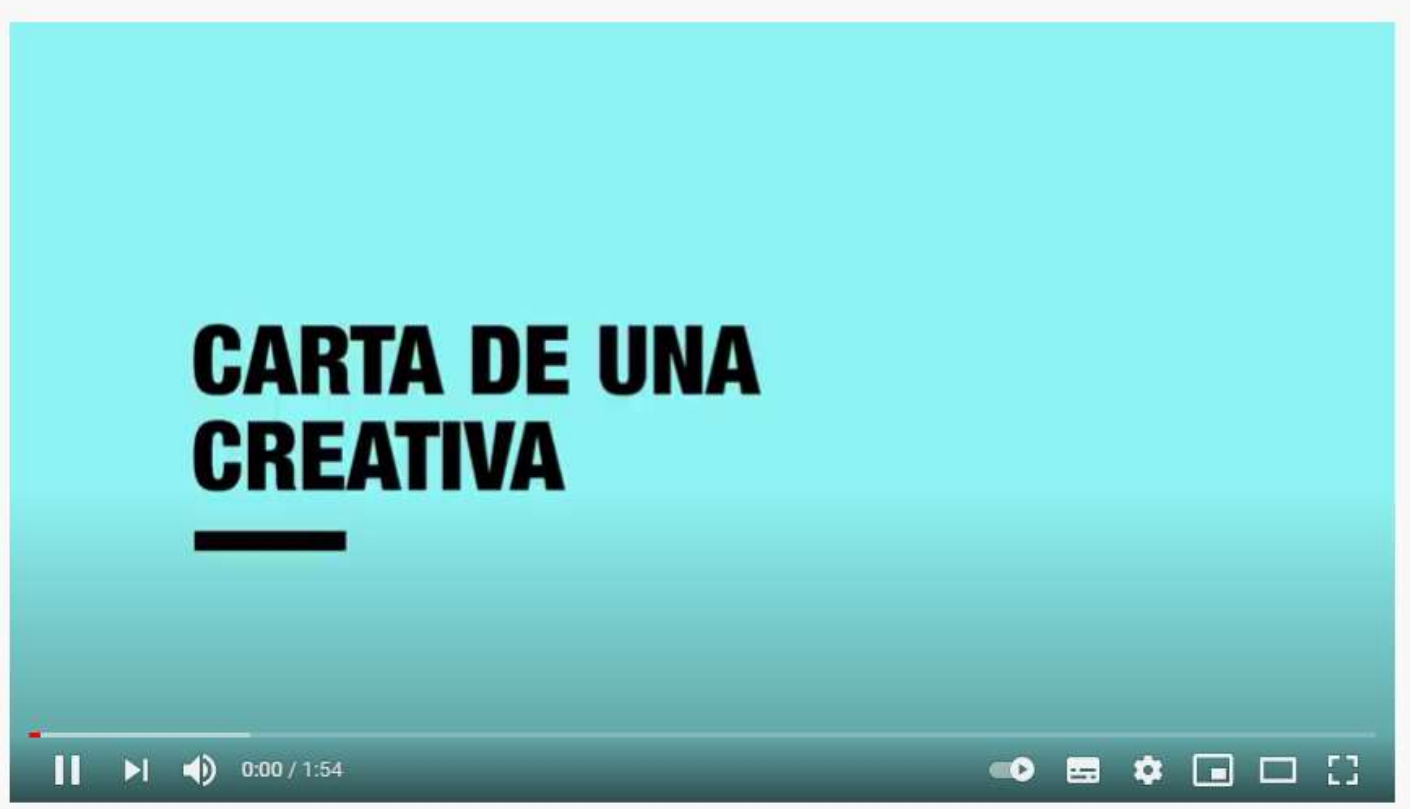

Campaña de \#MásMujeresCreativas y Shackleton para reivindicar la importancia de los referentes en la industria publicitaria.

Disponible en:

https://youtu.be/SKEqrafaqK 4 


\section{Otros recursos}

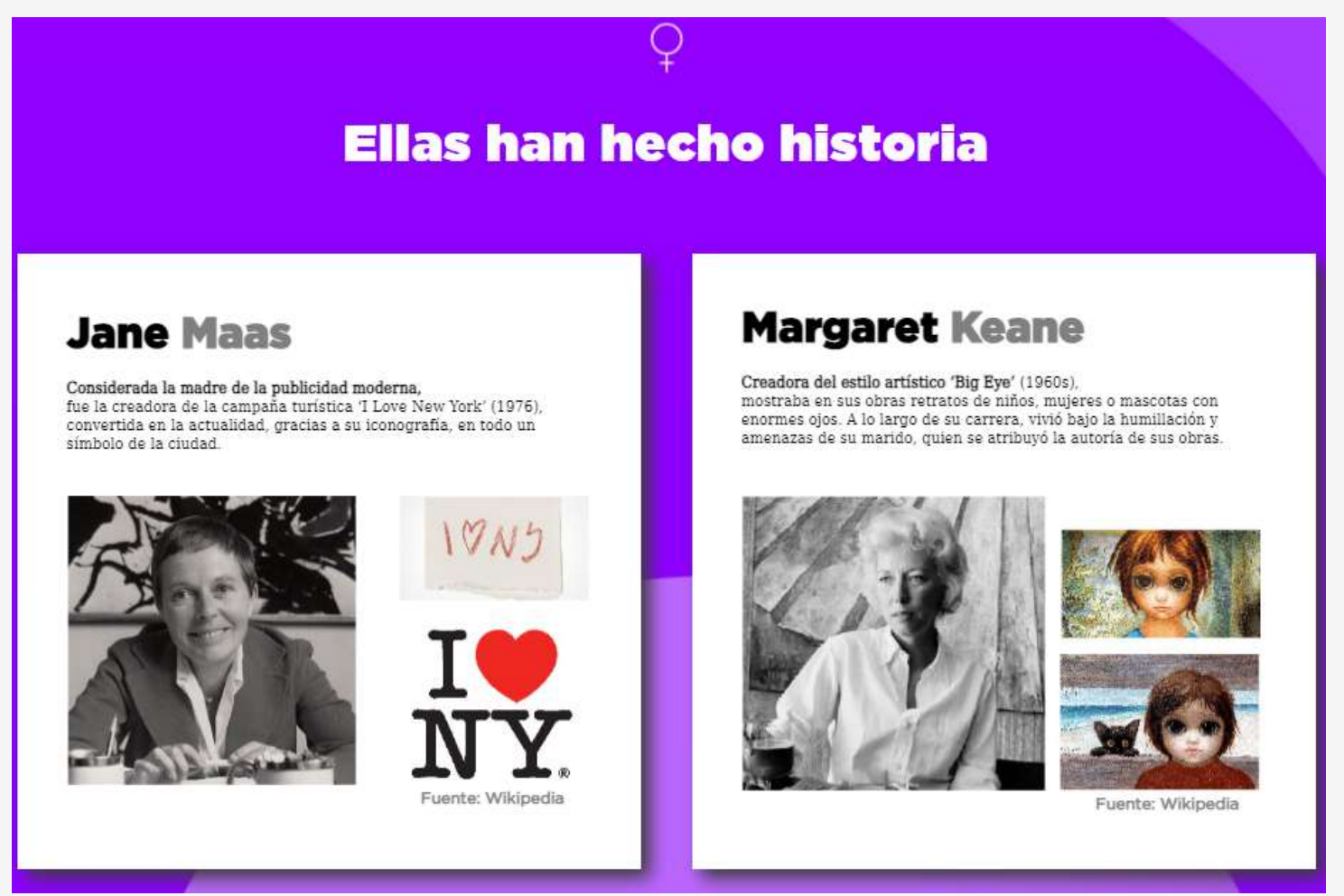

Campaña de la consultora de comunicación Grupoidex para visibilizar el talento femenino en el mundo de la publicidad, el diseño y la creatividad:

https://www.grupoidex.es/ochodetresmilmillones/ 


\section{Otros recursos}

\section{It's about time!}

Emma Pueyo

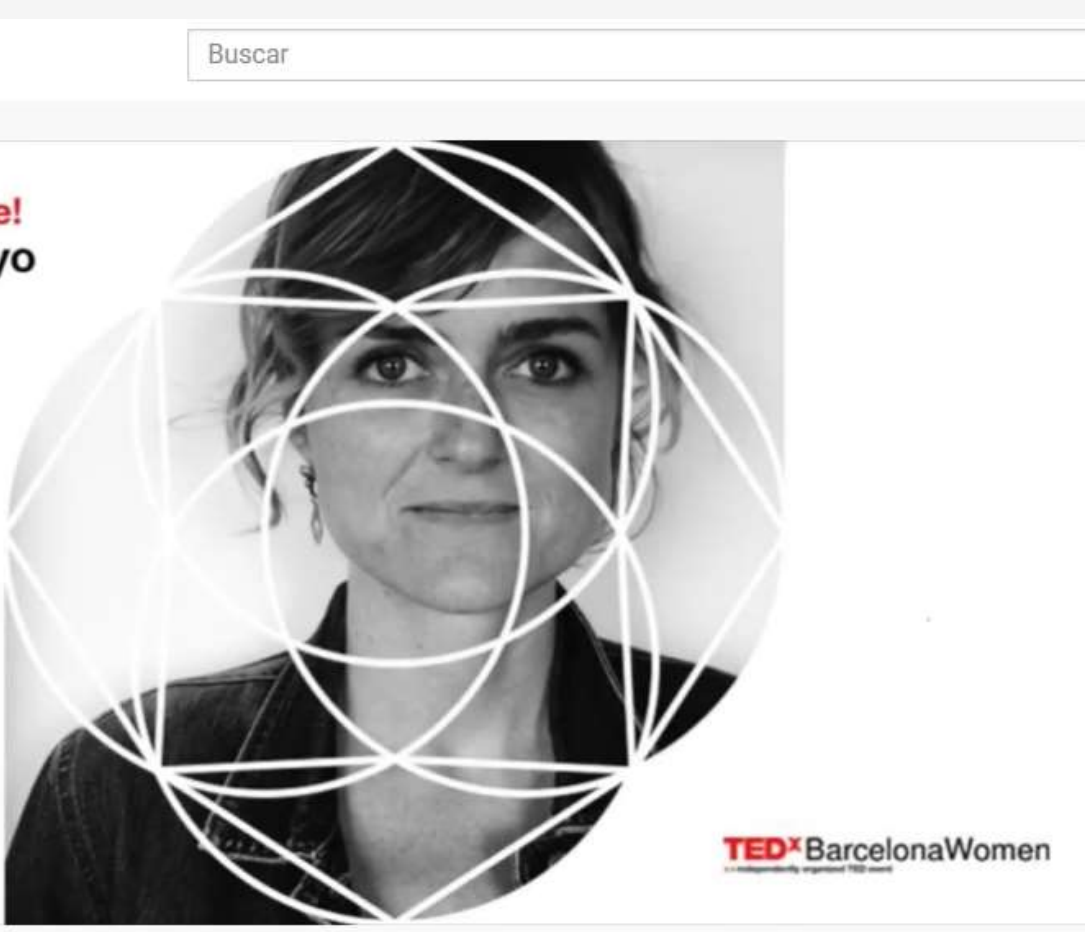

TEDxBarcelonaWomen | Pitch: Más Mujeres

Creativas | Emma Pueyo:

https://www.youtube.com/watch?v=ryBRXqsVtr

$$
\underline{1 \& \mathrm{t}=4 \mathrm{~S}}
$$

TEDxBarcelonaWomen | Pitch: Más Mujeres Creativas | Emma Pueyo 


\section{Otros recursos}

Mas

MUJERES A SEGUIR INFORMACION PARA MUJERES QUE SUMAN

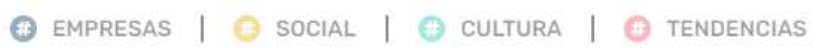

๑ INSPIRACIÓN TV

$f y$ in a

(1) REVISTA

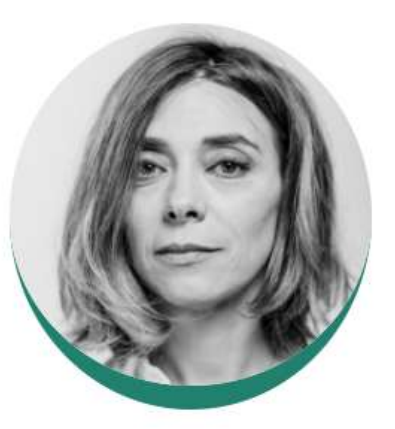

EL DICHOSO EMPODERAMIENTO

GEMA ARIAS

Artículo de Gema Arias "El dichoso empoderamiento"

http://bit.ly/3sKgsgs 